\title{
Structure-activity relationship-based optimization of small temporin-SHf analogs with potent antibacterial activity
}

Sonia André ${ }^{\dagger}$, Shannon K. Washington ${ }^{\S}$, Emily Darby ${ }^{\S}$, Marvin M. Vega ${ }^{\S}$, Ari D. Filip ${ }^{\S}$, Nathaniel S. Ash ${ }^{\S}$, Katy A. Muzikar ${ }^{\S}$, Christophe Piesse ${ }^{\&}$, Thierry Foulon ${ }^{\dagger} \star$, Daniel J.

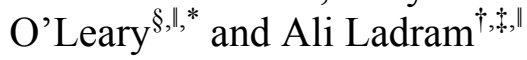

†Sorbonne Universités, UPMC Univ Paris 06, FR 3631, Institut de Biologie Paris Seine (IBPS), Biogenèse des Signaux Peptidiques (BIOSIPE), F-75005, Paris, France UPMC. ${ }^{\star}$ CNRS, FR 3631, IBPS, BIOSIPE, F-75005, Paris, France UPMC.

$\S$ Department of Chemistry, Pomona College, 645 North College Avenue, Claremont, CA 91711, California, USA.

${ }^{\&}$ Sorbonne Universités, UPMC Univ Paris 06, FR 3631, Institut de Biologie Paris Seine (IBPS), Plate-forme Ingénierie des Protéines et Synthèse Peptidique, F-75005 Paris, France.

\section{Supporting Information}

1. Methods

S2-S10

2. References.

S10-S11

3. LC traces of synthetic peptides.

4. $400 \mathrm{MHz}{ }^{1} \mathrm{H}$ NMR shift assignments

.S18-S29

5. $400 \mathrm{MHz}{ }^{1} \mathrm{H}$ 2D-TOCSY and 2D-ROESY data. S30-S53 


\section{METHODS}

Peptide synthesis. Temporin-SHf, $\left[\mathrm{S}^{2}\right] \mathrm{SHf},\left[\mathrm{R}^{5}\right] \mathrm{SHf}$ and $\left[\mathrm{R}^{5}\right] \mathrm{SHf}-\mathrm{CO}_{2} \mathrm{H}$ were synthesized using solid-phase standard FastMoc chemistry procedure on an Applied Biosystems 433A automated peptide synthesizer, as previously described ${ }^{42}$ (Peptide Synthesis Platform, FR 3631 UPMC-CNRS, IBPS, Paris, France). Peptides were purified by RP-HPLC using the same previously described procedure. ${ }^{1}$ D-SHf, Retro-SHf and RISHf were purchased from RS Synthesis (Louisville, KY, USA).

Temporin analogs $\left[\mathrm{HmS}^{5}\right] \mathrm{SHf}\left(\mathrm{Ser}^{5}\right.$ replaced with an achiral hydroxymethyl serine residue), $\left[\alpha \mathrm{MeF}^{3}\right] \mathrm{SHf},\left[p-{ }^{t} \mathrm{BuF}^{1}\right] \mathrm{SHf},\left[p-{ }^{t} \mathrm{BuF}^{2}\right] \mathrm{SHf},\left[p-{ }^{t} \mathrm{BuF}^{3}\right] \mathrm{SHf},\left[p-{ }^{t} \mathrm{BuF}^{1}, \mathrm{R}^{5}\right] \mathrm{SHf},[p-$ $\left.{ }^{t} \mathrm{BuF}^{2}, \mathrm{R}^{5}\right] \mathrm{SHf}$ and $\left[p-{ }^{t} \mathrm{BuF}^{3}, \mathrm{R}^{5}\right] \mathrm{SHf}$ were synthesized manually using Fmoc-based SPPS protocols on Knorr Resin. Fmoc- $\alpha-M e-L-P h e-O H$, Fmoc-L-4-tert-butyl-Phe-OH, and Fmoc-Arg-(Pbf)-OH were purchased from PepTech. Fmoc-L-Ile-OH, Fmoc-L-Leu-OH, Fmoc-L-Phe-OH, and Fmoc-O-tert-butyl-L-Ser-OH were purchased from Chemimpex. The $N$-Fmoc isopropylidene-protected variant of $\alpha$-hydroxymethylserine (FmocHmS(Ipr)-OH) was prepared according to literature procedures. ${ }^{2-5}$ Couplings involving C- $\mathrm{H}_{\square}$ amino acids used the appropriate Fmoc protected amino acid (6 equiv relative to resin) with HBTU as the activating agent (6 equiv) and DIEA (12 equiv) in DMF at room temperature. These couplings were monitored using the Kaiser test, and replicate couplings were employed until this test was negative. Couplings with or to resin-bound $\alpha$-Me-Phe or HmS(Ipr) residues used the appropriate Fmoc protected amino acid (3 equiv relative to resin) with PyAOP/HOAT as the activating agent (3 equiv) and DIEA (8 equiv) in DMF at room temperature (HmS(Ipr)) or $85{ }^{\circ} \mathrm{C}$ ( $\alpha$-Me-Phe). Couplings involving resin-bound $\alpha$-Me-Phe or HmS(Ipr) residues were monitored with the chloranil 
test, and replicate couplings were used until this test was negative. Fmoc deprotection was accomplished by resin treatment with piperidine in DMF (20\% v/v) for $30 \mathrm{~min}$.

Peptides [ $\left.\alpha \mathrm{MeF}^{3}\right] \mathrm{SHf},\left[p-{ }^{t} \mathrm{BuF}^{1}\right] \mathrm{SHf},\left[p-{ }^{t} \mathrm{BuF}^{2}\right] \mathrm{SHf},\left[p-{ }^{t} \mathrm{BuF}^{3}\right] \mathrm{SHf},\left[p-{ }^{t} \mathrm{BuF}^{1}, \mathrm{R}^{5}\right] \mathrm{SHf}$, $\left[p-{ }^{t} \mathrm{BuF}^{2}, \mathrm{R}^{5}\right] \mathrm{SHf}$ and $\left[p-{ }^{t} \mathrm{BuF}^{3}, \mathrm{R}^{5}\right] \mathrm{SHf}$ were cleaved from resin by treatment with a freshly prepared solution of TFA (95\%)/ $\mathrm{H}_{2} \mathrm{O}(2.5 \%) /$ triisopropyl silane (2.5\%) v/v/v mixture for 2-3 h with mechanical stirring. Filtration, followed by concentration in vacuo overnight, afforded the crude peptides as white solids or brown oils.

Peptide $\left[\mathrm{HmS}^{5}\right] \mathrm{SHf}$ was cleaved from resin using the same cleavage solution for $3 \mathrm{~h}$. The solvents were removed in vacuo and the residue was treated ${ }^{4}$ with acetonitrile (50\%)/0.1 M aqueous sodium bicarbonate (50\%) v/v mixture for $20 \mathrm{~min}$. The solvents were removed by lyophilization, and the crude peptide was recovered after dissolution in minimal TFA and precipitation in diethyl ether at $4^{\circ} \mathrm{C}$. The precipitate was recovered by centrifugation, washed 3 times with cold diethyl ether and dried under a stream of nitrogen. Trace solvents were removed in vacuo.

The crude peptides were purified by RP-HPLC on a Zorbax 300SB-C18 semipreparative column $(7 \mu \mathrm{m}, 250 \times 21.2 \mathrm{~mm})$ and eluted $(5 \mathrm{~mL} / \mathrm{min})$ with a $30-70 \%$ linear gradient of ACN (0.1\% TFA) in $0.1 \%$ TFA/water (1\% ACN/min), monitored with UV detection at $250 \mathrm{~nm}$.

Finally, the identity of $\left[\mathrm{S}^{2}\right] \mathrm{SHf}$ and $\left[\mathrm{R}^{5}\right] \mathrm{SHf}-\mathrm{CO}_{2} \mathrm{H}$ was assessed by matrix-assisted laser desorption/ionization-time of flight (MALDI-TOF) mass spectrometry (Voyager DE-PRO Applied Biosystems, Mass Spectrometry and Proteomics Platform, FR 3631 UPMC-CNRS, IBPS, Paris, France), and HRMS ESI data was obtained for D-SHf, RetroSHf, RI-SHf (Orbitrap XL, Mass Spectrometry and Proteomics Platform, FR 3631 
UPMC-CNRS, IBPS, Paris, France) and the remaining peptides (JEOL JMS-600H, California Institute of Technology, Pasadena, CA). The homogeneity of all synthetic peptides was assessed by analytical RP-HPLC using an Aeris PEPTIDE XB-C18 column (3.6 $\mu \mathrm{m}, 250 \times 4.6 \mathrm{~mm}$, Phenomenex) (peptide purity $\geq 95 \%$ ).

SHf: MS (ESI) $[\mathrm{M}+\mathrm{H}]^{+}$calc 1075.6087, found 1075.6104; [S²]SHf: MS (MALDITOF) calc 1015.670, found 1015.572; [R $\mathrm{R}^{5}$ SHf: MS (ESI) calc 1144.6778, found 1144.6776; [ $\mathrm{R}^{5}$ ]SHf-CO $\mathrm{CO}_{2} \mathrm{H}$ : MS (MALDI-TOF) calc 1145.662, found 1145.584; D-SHf: MS (ESI) calc 1075.6087, found 1075.6146; Retro-SHf: MS (ESI) calc 1075.6087, found 1075.6156; RI-SHf: MS (ESI) calc 1075.6087, found 1075.6142; [HmS $\left.{ }^{5}\right]$ SHf: MS (ESI) calc 1105.6193, found 1105.6219; [ $\left.\alpha \mathrm{MeF}^{3}\right]$ SHf: MS (ESI) calc 1089.6244, found 1089.6257; $\left[p-{ }^{t} \mathrm{BuF}^{3}\right] \mathrm{SHf}: \mathrm{MS}$ (ESI) calc 1131.6713, found 1131.6717; $\left[p-{ }^{t} \mathrm{BuF}^{2}\right] \mathrm{SHf}$ : MS (ESI) calc 1131.6713, found 1131.6754; [p- $\left.{ }^{t} \mathrm{BuF}^{1}\right] \mathrm{SHf}$ : MS (ESI) calc 1131.6713, found 1131.6747; [ $p^{-}{ }^{t} \mathrm{BuF}^{3}, \mathrm{R}^{5}$ ]SHf: MS (ESI) calc 1200.7404, found 1200.7397; [p${ }^{t} \mathrm{BuF}^{2}, \mathrm{R}^{5}$ ]SHf: MS (ESI) calc 1200.7404, found 1200.7404; [ - $^{\mathrm{t}} \mathrm{BuF}^{1}, \mathrm{R}^{5}$ ]SHf: MS (ESI) calc 1200.7404 , found 1200.7422 .

Bacterial strains. The following strains were used: Escherichia coli ATCC 25922, Pseudomonas aeruginosa ATCC 27853, Acinetobacter baumannii ATCC 19606, Klebsiella pneumoniae ATCC 13883 (Gram-negative bacteria), Staphylococcus aureus ATCC 25923, multi-drug resistant Staphylococcus aureus ATCC BAA-44, Streptococcus pyogenes ATCC 19615, Listeria ivanovii, Enterococcus faecalis ATCC 29212 (Grampositive bacteria), Candida albicans ATCC 90028, Candida parapsilosis ATCC 22019, Saccharomyces cerevisiae (yeasts). 
Antimicrobial assay. Antimicrobial activity was determined by a liquid growth inhibition assay as described previously, ${ }^{6}$ with the following modification. Using 96-well microtitration plates, $50 \mu \mathrm{L}$ of the microorganism suspension $\left(10^{6} \mathrm{cfu} / \mathrm{mL}\right)$ resuspended in MH broth (in LB broth for Enterococcus faecalis strain and in YPD medium for yeasts) was mixed with $50 \mu \mathrm{L}$ of 2 -fold serial dilutions of synthetic peptide in sterile Milli-Q $\mathrm{H}_{2} \mathrm{O}$ (100-1 $\mu \mathrm{M}$, final concentrations). After overnight incubation at $37^{\circ} \mathrm{C}$ (30 ${ }^{\circ} \mathrm{C}$ for yeasts), the minimal inhibitory concentration (MIC), i.e. the lowest concentration of peptide that totally inhibited bacterial growth, was obtained by measuring absorbance at $630 \mathrm{~nm}$. MIC values represent the average of three independent experiments, each performed in triplicate with negative (sterile Milli-Q $\mathrm{H}_{2} \mathrm{O}$ ) and positive $(0.7 \%$ formaldehyde) controls.

Antimicrobial activities in the presence of salt and serum. MIC values were determined against two reference bacterial strains, the Gram-positive S. aureus ATCC 25923 and the Gram-negative E. coli ATCC 25922, according to the liquid growth inhibition assay described above and using $\mathrm{MH}$ broth containing either $150 \mathrm{mM} \mathrm{NaCl}$ (final concentration) or fetal bovine serum (FBS) at various percentages (final percentages: 10, 20 and 30\%). MICs of D-SHf, RI-SHf, and retro-SHf (Table 1) were also determined against E. coli and S. aureus.

Cytotoxicity assay. Hemolytic experiments were performed using erythrocytes obtained from fresh blood samples of Wistar male rats (Charles River Laboratories, France) according to a previously described protocol. ${ }^{6}$ Briefly, synthetic peptides (500$6.25 \mu \mathrm{M}$, final concentrations) were incubated (100 $\mu \mathrm{L}$, final volume) with washed rat erythrocytes ( 2 x $10^{7}$ cells) in Dulbecco's phosphate-buffered saline (pH 7.4) for $1 \mathrm{~h}$ at 37 
${ }^{\circ} \mathrm{C}$. After centrifugation $(12,000 \mathrm{x} \mathrm{g}, 15 \mathrm{~s})$, the absorbance of the supernatant was measured at $450 \mathrm{~nm}$. The $\mathrm{LC}_{50}$ value, which is the average concentration of peptide producing 50\% hemolysis, was determined from three independent experiments carried out in triplicate with positive control (100\% hemolysis) corresponding to $0.1 \%$ triton (v/v). The cytotoxicity was also assessed on THP-1-derived macrophages, obtained from the differentiation of the human leukemia monocyte cell line THP-1 (kindly provided by Dr. B. Oury, IRD, Montpellier, France), and also on the human embryonic kidney cell line HEK-293 (kindly provided by Dr. O. Jean-Jean, IBPS, UPMC, Paris, France). THP-1 monocytes were cultured in RPMI 1640 (Life Technologies) supplemented with 10\% FBS, 25 mM HEPES, GlutaMax 1\%, 1 mM sodium pyruvate, penicillin (100 U/mL) and streptomycin $(100 \mu \mathrm{g} / \mathrm{mL})$. Cells were incubated at $37^{\circ} \mathrm{C}$ in a humidified atmosphere of 5\% CO2. HEK-293 cells were cultured in Dulbecco's modified Eagle's medium (DMEM, Life Technologies) supplemented with $10 \%$ FBS, penicillin $(100 \mathrm{U} / \mathrm{mL})$ and streptomycin $(100 \mu \mathrm{g} / \mathrm{mL})$, and incubated under the same conditions as THP-1 cells. THP-1 monocytes were differentiated into macrophages by adding $20 \mathrm{ng} / \mathrm{mL}$ PMA (phorbol 12-myristate 13-acetate) in the culture medium containing the cells (5 $\mathrm{x} 10^{5}$ cells $/ \mathrm{mL}$ ). Cells were then seeded in 96-well plates (100 $\mu \mathrm{L} /$ well) and incubated $48 \mathrm{~h}$ at $37^{\circ} \mathrm{C}$. After washing (2 times) with RPMI 1640, macrophages were incubated for $24 \mathrm{~h}$ at $37^{\circ} \mathrm{C}$ with $100 \mu \mathrm{L}$ of peptide (final concentrations: 12.5 to $200 \mu \mathrm{M}$ ) diluted in culture medium. HEK-293 cells were seeded in 96-well plates (100 $\mu \mathrm{L} /$ well) at a density of $5 \mathrm{x}$ $10^{5}$ cells $/ \mathrm{mL}$ and incubated overnight at $37^{\circ} \mathrm{C}$. The cells were washed with DMEM and then incubated for $24 \mathrm{~h}$ at $37^{\circ} \mathrm{C}$ with $100 \mu \mathrm{L}$ of peptide (final concentrations: 12.5 to 200 $\mu \mathrm{M})$ diluted in culture medium. Cell viability was quantified after peptide incubation 
using a MTT (Methylthiazolyldiphenyl-tetrazolium bromide)-based microassay. Briefly, $10 \mu \mathrm{L}$ of $5 \mathrm{mg} / \mathrm{mL}$ MTT were added to the 96 -well plate. After $4 \mathrm{~h}$ incubation at $37^{\circ} \mathrm{C}$, in the dark, formazan crystals were dissolved with $100 \mu \mathrm{L}$ of a solubilization solution (40\% dimethylformamide in $2 \%$ glacial acetic acid, $16 \%$ sodium dodecyl sulfate, $\mathrm{pH} 4.7$ ), followed by $1 \mathrm{~h}$ incubation at $37^{\circ} \mathrm{C}$ under shaking (150 rpm). Finally, absorbance of formazan was measured at $570 \mathrm{~nm}$ (Asys Hitech UVM 340) using a reference wavelength of $630 \mathrm{~nm}$. The $50 \%$ inhibitory concentration $\left(\mathrm{IC}_{50}\right)$ was determined with GraphPad Prism ${ }^{\circledR} 5.0$ software. Results were expressed as the mean of three independent experiments performed in triplicate.

SYTOX Green uptake assay. Peptide-induced permeabilization of the bacterial cytoplasmic plasma membrane (S. aureus ATCC 25923 and E. coli ATCC 25922) was determined by fluorometric measurement of SYTOX Green influx. ${ }^{7}$ SG is impermeant to live cells. However, when the cell membrane is damaged, this high-affinity nucleic acid dye penetrates into the cell and binds to intracellular DNA, leading to an intense green fluorescence light. For SG uptake assay, exponentially growing bacteria $\left(6 \times 10^{5} \mathrm{cfu} / \mathrm{mL}\right)$ were resuspended in PBS (1 M NaCl, $0.1 \mathrm{M} \mathrm{Na}_{2} \mathrm{HPO}_{4}, \mathrm{pH}$ 7.3) after centrifugation (1000 $\mathrm{x}$ g, $10 \mathrm{~min}, 4^{\circ} \mathrm{C}$ ) and washing steps. $792 \mu \mathrm{l}$ of the bacterial suspension was preincubated with $8 \mu \mathrm{L}$ of $100 \mu \mathrm{M}$ SG during $30 \mathrm{~min}$ at $37^{\circ} \mathrm{C}$ in the dark. After peptide addition (200 $\mu \mathrm{L}$, final concentration 2-fold above the MIC), the fluorescence was measured during $1 \mathrm{~h}$ at $37^{\circ} \mathrm{C}$ in a Varian Cary Eclipse fluorescence spectrophotometer, with excitation and emission wavelengths of 485 and $520 \mathrm{~nm}$, respectively. Three independent experiments were performed and results correspond to a representative experiment with negative (PBS) and positive (melittin) controls. 
Membrane Depolarization Assay. The peptide-induced depolarization of the bacterial cytoplasmic membrane (E. coli ATCC 25922 and S. aureus ATCC 25923) was analyzed using the membrane potential-sensitive cyanine dye $\operatorname{DiSC}_{3}(5)$ (3,3'dipropylthiadicarbocyanine iodide). This cationic and lipophilic dye accumulates into the cytoplasmic membrane according to the magnitude of the membrane potential gradient and then aggregates, causing self-quenching of the fluorescence. ${ }^{8}$ Membranepermeabilizing agents generate membrane potential dissipation that provokes the release of $\mathrm{DiSC}_{3}(5)$ into the medium, leading to an increase of fluorescence that can be monitored over time. For the experiment, exponentially growing bacteria were collected by centrifugation ( $\left.1000 \mathrm{x} \mathrm{g}, 10 \mathrm{~min}, 4{ }^{\circ} \mathrm{C}\right)$, washed with $\mathrm{PBS}$, and resuspended in the same buffer to an $\mathrm{OD}_{630}$ of 0.1 . $700 \mu \mathrm{L}$ of bacteria containing $1 \mu \mathrm{M} \mathrm{DiSC}_{3}(5)$ were preincubated in the dark during $10 \mathrm{~min}$ at $37{ }^{\circ} \mathrm{C}$ to allow maximal dye uptake and fluorescence quenching. $100 \mu \mathrm{L}$ of $1 \mathrm{mM} \mathrm{KCl}$ were then added to the mixture in order to equilibrate the cytoplasmic and external $\mathrm{K}^{+}$concentrations. Changes in fluorescence due to the collapse of the cytoplasmic membrane potential were recorded after addition of the peptide ( $200 \mu \mathrm{L}$, final concentration: 2 -fold above the MIC) at $37^{\circ} \mathrm{C}$ during 20 min at an excitation wavelength of $622 \mathrm{~nm}$ and an emission wavelength of $670 \mathrm{~nm}$ (Varian Cary Eclipse fluorescence spectrophotometer). Three independent experiments were performed and results correspond to a representative experiment with negative (PBS) and positive (melittin) controls.

Time-Killing Assay. Time-kill kinetics of temporins were studied against the Gramnegative strain E. coli ATCC 25922, as described previously. ${ }^{9}$ Briefly, peptides at 2-fold concentration above the MIC were incubated with bacterial suspension $\left(10^{6} \mathrm{cfu} / \mathrm{mL}\right)$ 
resuspended in PBS buffer (10 mM phosphate, $100 \mathrm{mM} \mathrm{NaCl}, \mathrm{pH}$ 7.3). Aliquots of 10 $\mu \mathrm{L}$ were withdrawn at different times and spread onto LB agar plates for cell counting after overnight incubation at $37{ }^{\circ} \mathrm{C}$. Controls were run without peptide. Three independent experiments were performed in triplicate. Results were expressed as the mean \pm S.E.M. of a representative experiment.

Circular Dichroism Spectroscopy. Circular dichroism (CD) spectra were recorded (Jobin-Yvon CD6 spectropolarimeter) at $25^{\circ} \mathrm{C}$ in a $0.1 \mathrm{~cm}$ quartz cell over a wavelength range of 190 to $260 \mathrm{~nm}$. Spectra were acquired with a spectral bandwidth of $2 \mathrm{~nm}$ and a step size of $0.5 \mathrm{~nm}$. Peptides (100 $\mu \mathrm{M})$ were solubilized either in $\mathrm{H}_{2} \mathrm{O}$ Milli-Q or $80 \mathrm{mM}$ sodium dodecyl sulfate (SDS). Each spectrum was the average of four successive scans and solvent spectra $\left(\mathrm{H}_{2} \mathrm{O}, 80 \mathrm{mM}\right.$ SDS) were subtracted, followed by baseline correction and smoothing. CD measurements were reported as the dichroic increment $(\Delta \varepsilon)$ per residue.

NMR Spectroscopy. Peptides (2 mg) were dissolved in $0.7 \mathrm{ml}$ of a 9:1 ratio of $\mathrm{H}_{2} \mathrm{O}$ to $\mathrm{D}_{2} \mathrm{O}$ containing sodium dodecyl- $d_{25}$ sulfate (17.5 mg, Cambridge Isotope Laboratories) and a trace amount of 4,4-dimethyl-4-silapentane-1-sulfonic acid (DSS) as a chemical shift calibration standard. Peptide concentrations, when adjusted for MW differences, ranged from 1.8 to $2.3 \mathrm{mM}$. For consistency with the CD spectroscopy experiments, the $\mathrm{pH}$ of the NMR samples was adjusted to 5.3-5.5 using a $\mathrm{pH}$ microelectrode (Thermo Scientific Orion 9826BN) and microliter additions of $0.1 \mathrm{M}$ aqueous $\mathrm{HCl}$ or $0.1 \mathrm{M}$ $\mathrm{NaOH}$.

$400 \mathrm{MHz}{ }^{1} \mathrm{H}$ NMR spectra were obtained on a $400 \mathrm{MHz}$ NMR spectrometer equipped with a $5 \mathrm{~mm}$ dual ${ }^{1} \mathrm{H} /{ }^{13} \mathrm{C}$ Z-gradient probe whose temperature was maintained 
at $40{ }^{\circ} \mathrm{C}$. $1 \mathrm{D}{ }^{1} \mathrm{H}$ spectra were acquired with a gradient-enhanced excitation sculpting water suppression sequence. ${ }^{10}$ The same water suppression method was used with 2D double quantum filtered COSY, ${ }^{11}$ TOCSY, ${ }^{12}$ and ROESY ${ }^{13}$ experiments. The TOCSY and ROESY spin lock periods were $60 \mathrm{~ms}$ and $100 \mathrm{~ms}$, respectively.

\section{ABBREVIATIONS}

ACN, acetonitrile; AMP, antimicrobial peptide; CD, circular dichroism; DiSC3(5), 3,3dipropylthiadicarbocyanine iodide; LB, Luria Bertani; MH, Mueller-Hinton; MIC, minimal inhibitory concentration; NMR, nuclear magnetic resonance; OD, optical density; PBS, phosphate buffered solution; RP-HPLC, reversed-phase high performance liquid chromatography; SDS, sodium dodecyl sulfate; SG, SYTOX green; TFA, trifluoroacetic acid; YPD, Yeast Peptone Dextrose.

\section{References}

1. Raja, Z., Andre, S., Piesse, C., Sereno, D., Nicolas, P., Foulon, T., Oury, B., and Ladram, A. (2013) Structure, antimicrobial activities and mode of interaction with membranes of novel phylloseptins from the painted-belly leaf frog, Phyllomedusa sauvagii. PLoS One 8, e70782.

2. Otani, T. T., and Winitz, M. (1960) Studies on hydroxyamino acids.1. Synthesis of some $\alpha$-alkylated serines. Arch. Biochem. Biophys. 90, 254-259.

3. Stasiak, M., Wolf, W. M., and Leplawy, M. T. (1998) $\alpha$-hydroxymethylserine as a peptide building block: synthetic and structural aspects. J. Pept. Sci. 4, 46-57.

4. Stasiak, M., and Leplawy, M. T. (1998) Peptides derived from $\alpha-$ hydroxymethylserine: aspects of solid-phase synthesis. Lett. Pept. Sci. 5, 449-453.

5. Stasiak, M., Slomczynska, U., Olma, A., and Leplawy, M. T. (2008) Chemistry of a-hydroxymethylserine: problems and solutions. J. Pept. Sci. 14, 1163-1172.

6. Abbassi, F., Oury, B., Blasco, T., Sereno, D., Bolbach, G., Nicolas, P., Hani, K., Amiche, M., and Ladram, A. (2008) Isolation, characterization and molecular 
cloning of new temporins from the skin of the North African ranid Pelophylax saharica. Peptides 29, 1526-1533.

7. Thevissen, K., Terras, F. R., and Broekaert, W. F. (1999) Permeabilization of fungal membranes by plant defensins inhibits fungal growth. Appl. Environ. Microbiol. 65, 5451-5458.

8. Sims, P. J., Waggoner, A. S., Wang, C.-H., and Hoffman, J. F. (1974) Mechanism by which cyanine dyes measure membrane potential in red blood cells and phosphatidylcholine vesicles. Biochemistry 13, 3315-3330.

9. $\quad$ Abbassi, F., Raja, Z., Oury, B., Gazanion, E., Piesse, C., Sereno, D., Nicolas, P., Foulon, T., and Ladram, A. (2013) Antibacterial and leishmanicidal activities of temporin-SHd, a 17-residue long membrane-damaging peptide. Biochimie 95, 388-399.

10. Hwang, T. L., and Shaka, A. J. (1995) Water suppression that works - excitation sculpting using arbitrary wave-forms and pulsed-field gradients. J. Magn. Reson. Ser. A 112, 275-279.

11. Derome, A. E., and Williamson, M. P. (1990) Rapid-pulsing artifacts in doublequantum-filtered COSY. J. Magn. Reson. 88, 177-185.

12. Bax, A., and Davis, D. G. (1985) MLEV-17-based two-dimensional homonuclear magnetization transfer spectroscopy. J. Magn. Reson. 65, 355-360.

13. Bax, A., and Davis, D. G. (1985) Practical aspects of two-dimensional transverse NOE spectroscopy. J. Magn. Reson. 63, 207-213. 
Waters Breeze HPLC system

Aeris PEPTIDE XB-C18 analytical column (3.6 $\mu \mathrm{m}, 250$ x $4.6 \mathrm{~mm})$

Linear gradient of acetonitrile (ACN): $20-80 \%$ (2\% ACN/min)

Flow rate: $1 \mathrm{~mL} / \mathrm{min}$

Absorbance monitored at 220 (dark) and $260 \mathrm{~nm}$ (blue)

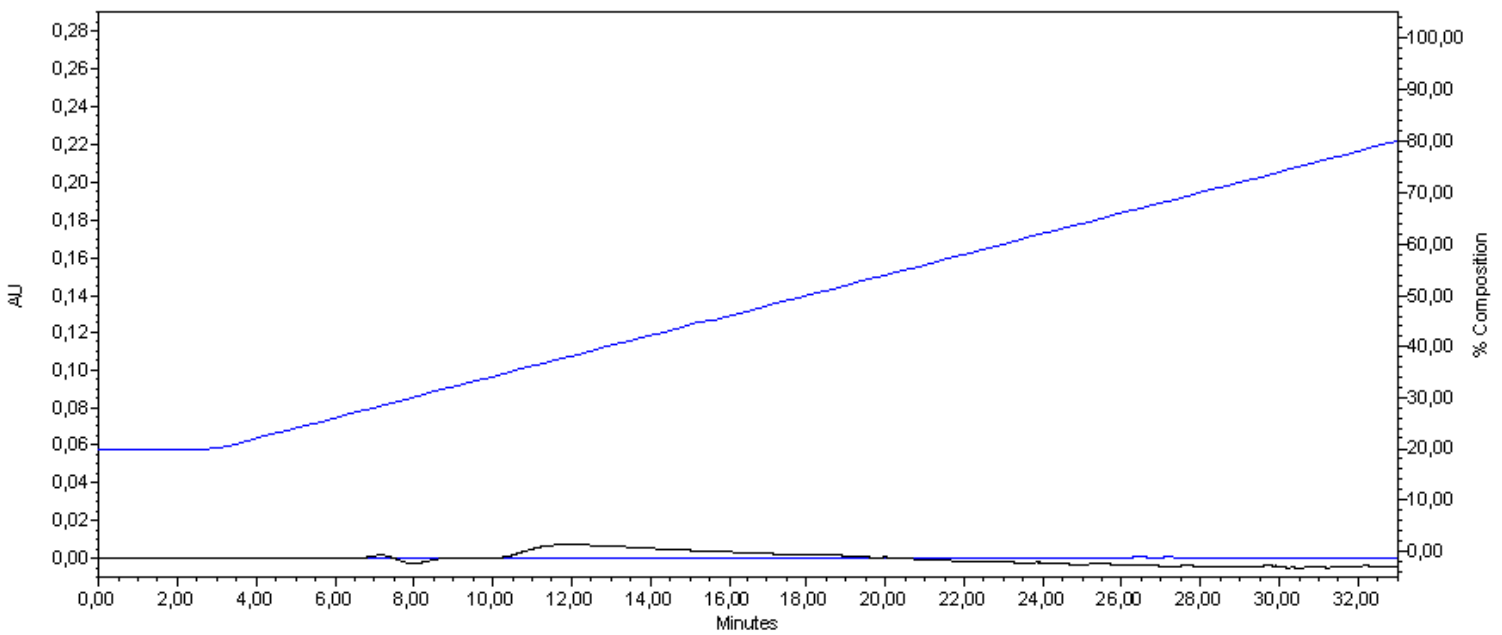

Figure S1. Background/blank injection.

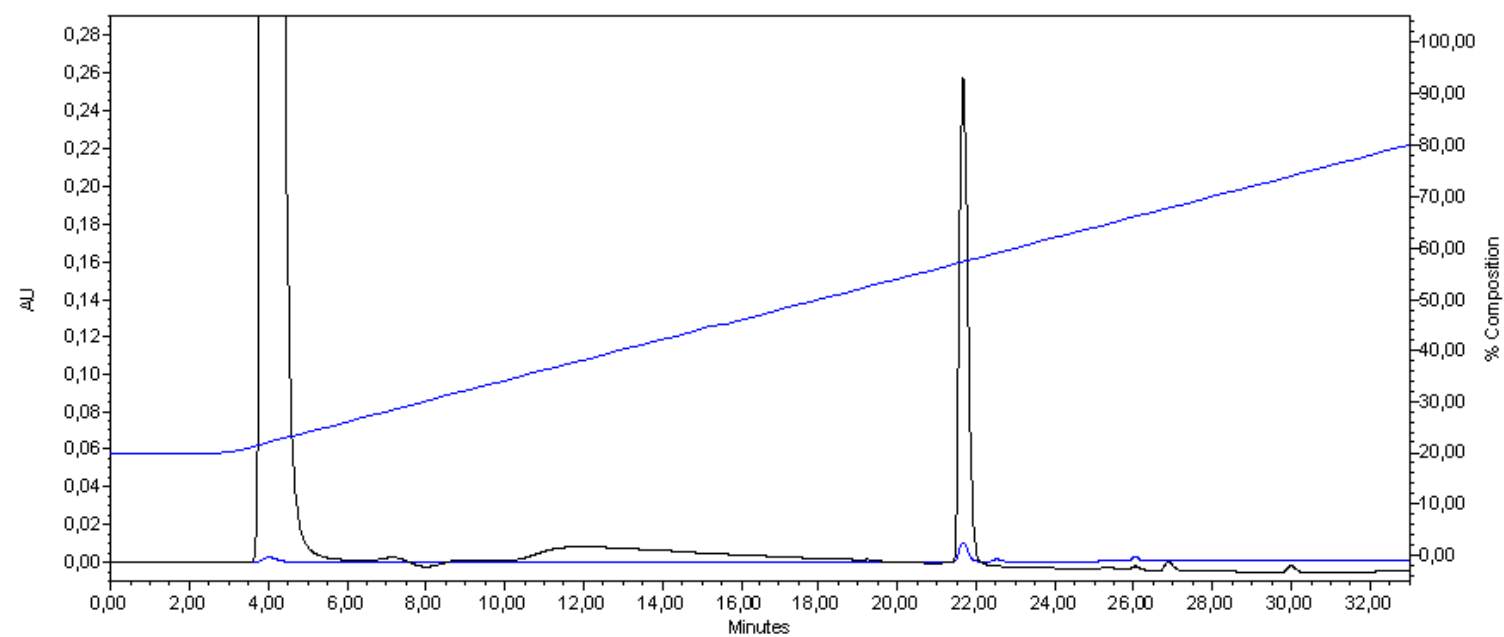

Figure S2. Temporin-SHf (3.2 $\mu \mathrm{g})$ LC trace. 


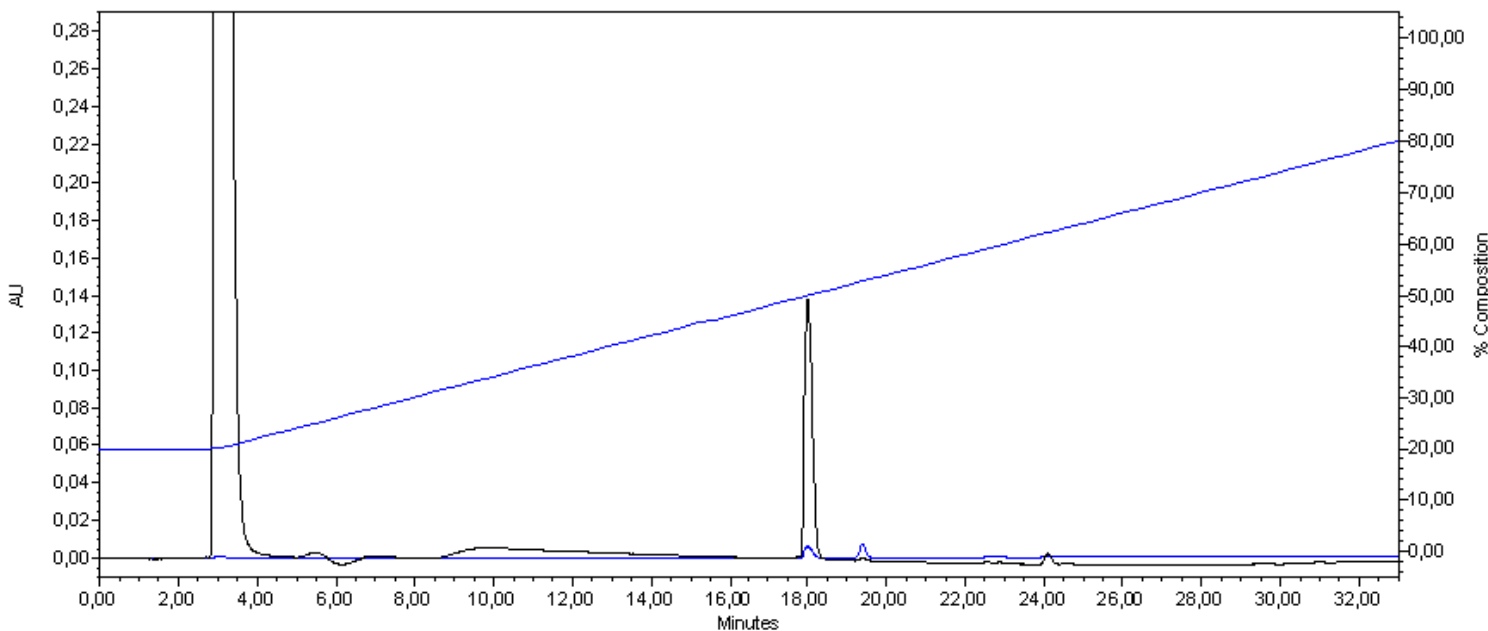

Figure S3. $\left[\mathrm{S}^{2}\right] \mathrm{SHf}(3.0 \mu \mathrm{g}) \mathrm{LC}$ trace.

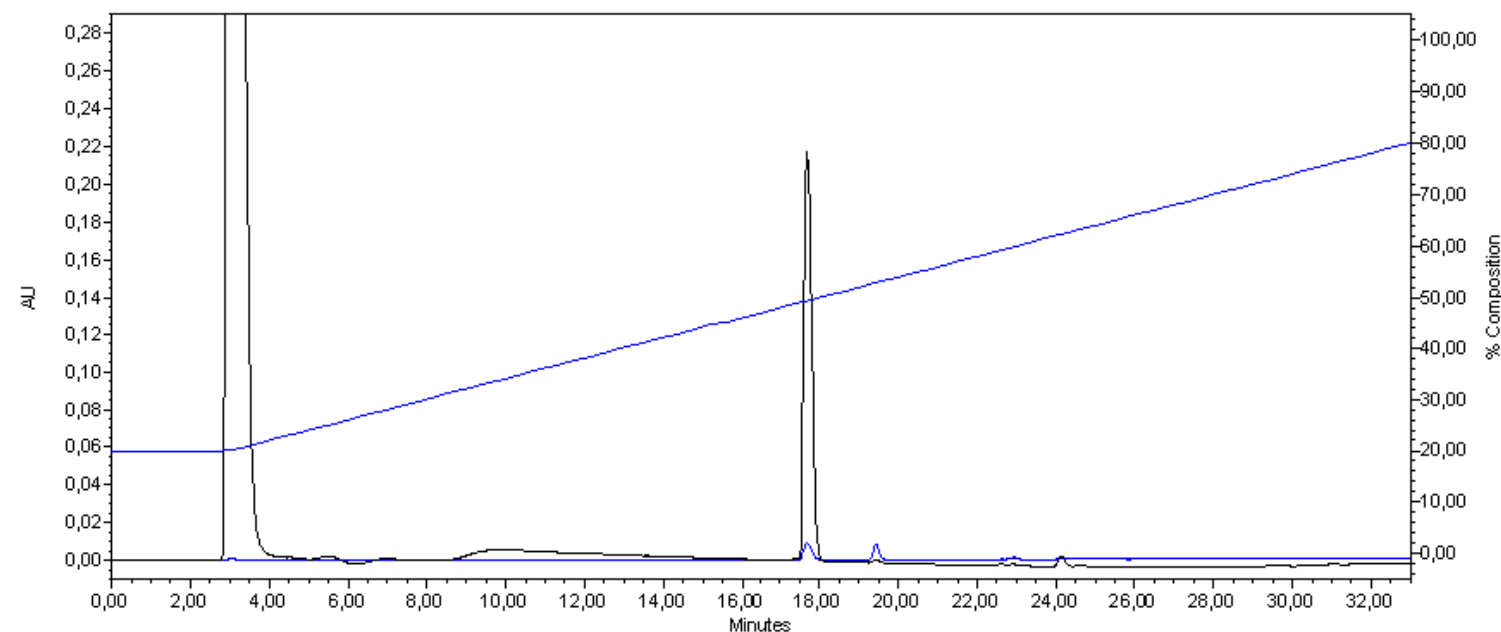

Figure S4. $\left[\mathrm{R}^{5}\right] \mathrm{SHf}(3.4 \mu \mathrm{g}) \mathrm{LC}$ trace.

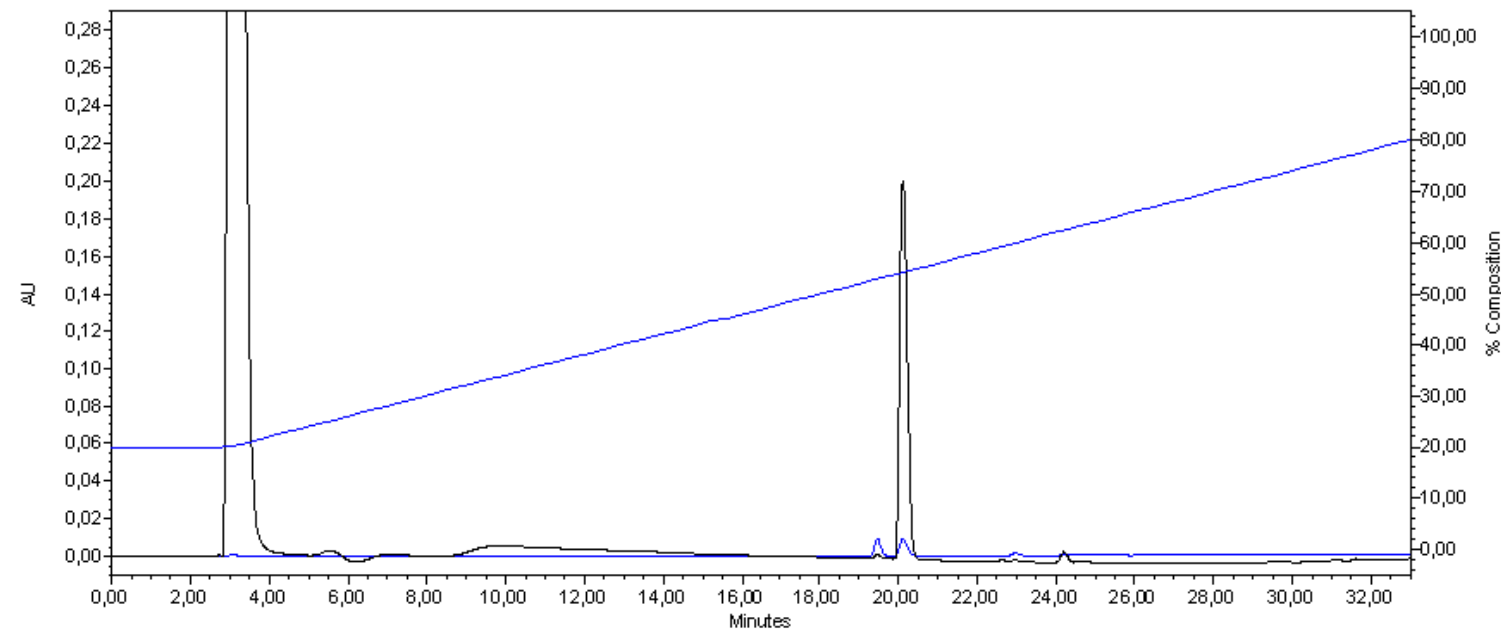

Figure S5. $\left[\mathrm{HmS}^{5}\right] \mathrm{SHf}(3.3 \mu \mathrm{g}) \mathrm{LC}$ trace. 


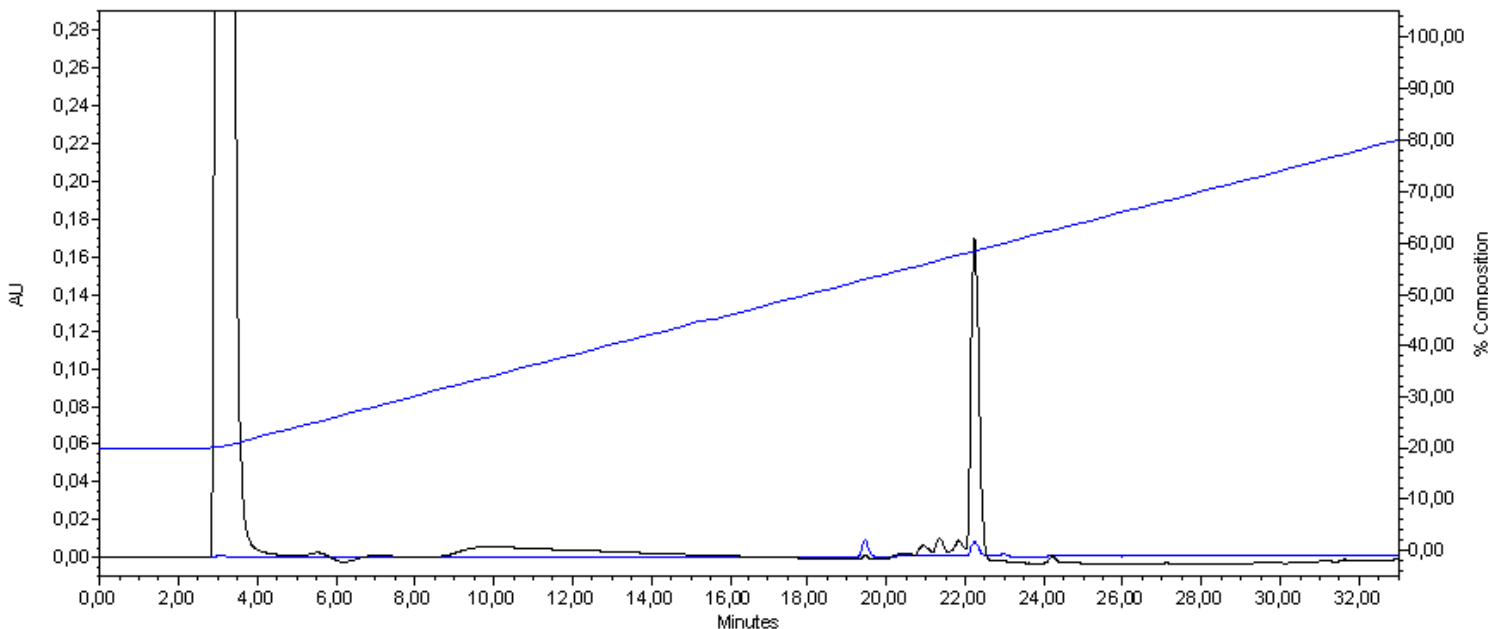

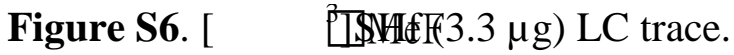

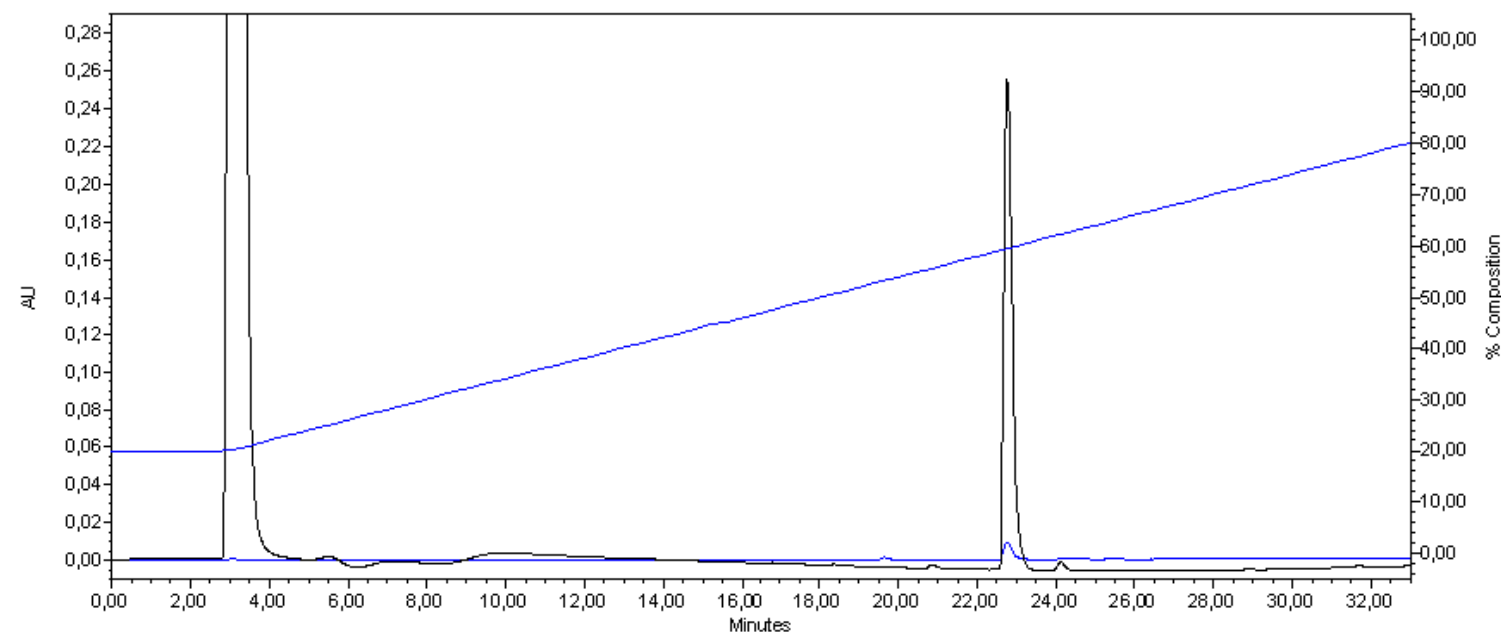

Figure S7. $\left[p-{ }^{t} \mathrm{BuF}^{3}\right] \mathrm{SHf}(3.4 \mu \mathrm{g}) \mathrm{LC}$ trace.

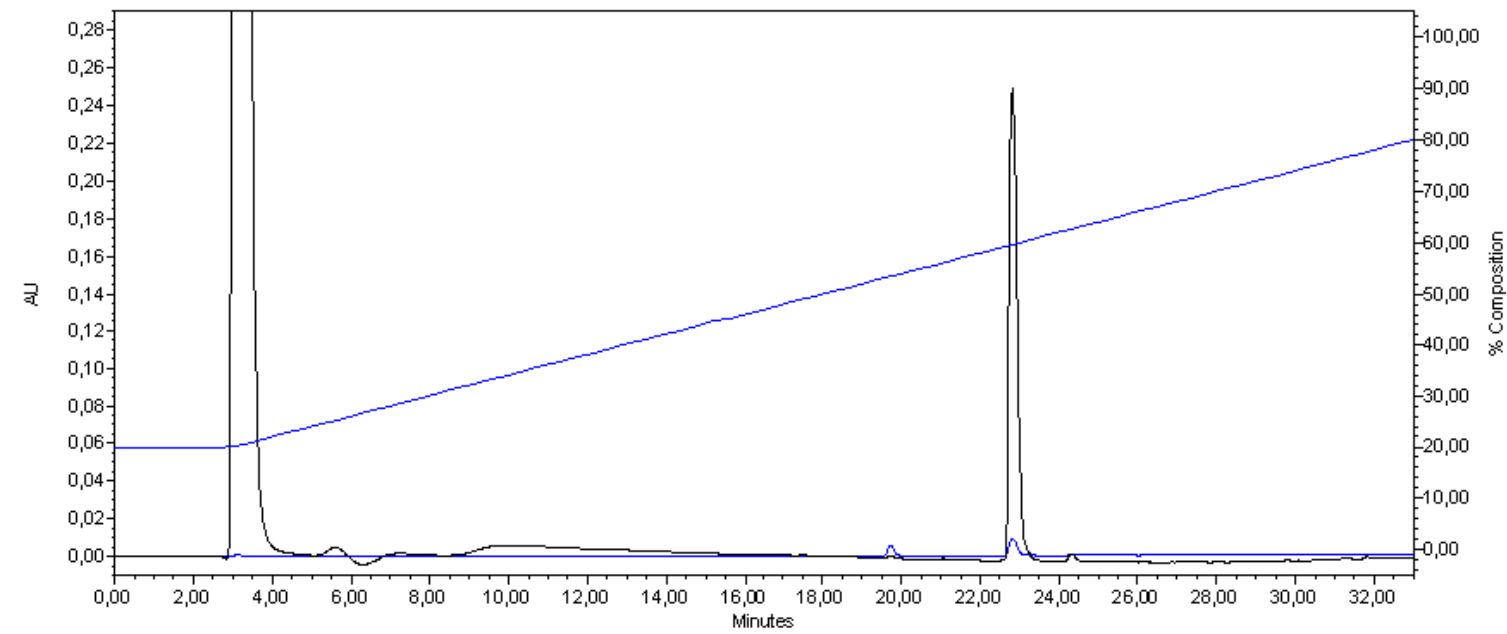

Figure S8. $\left[p-{ }^{t} \mathrm{BuF}^{2}\right] \mathrm{SHf}(3.4 \mu \mathrm{g}) \mathrm{LC}$ trace. 


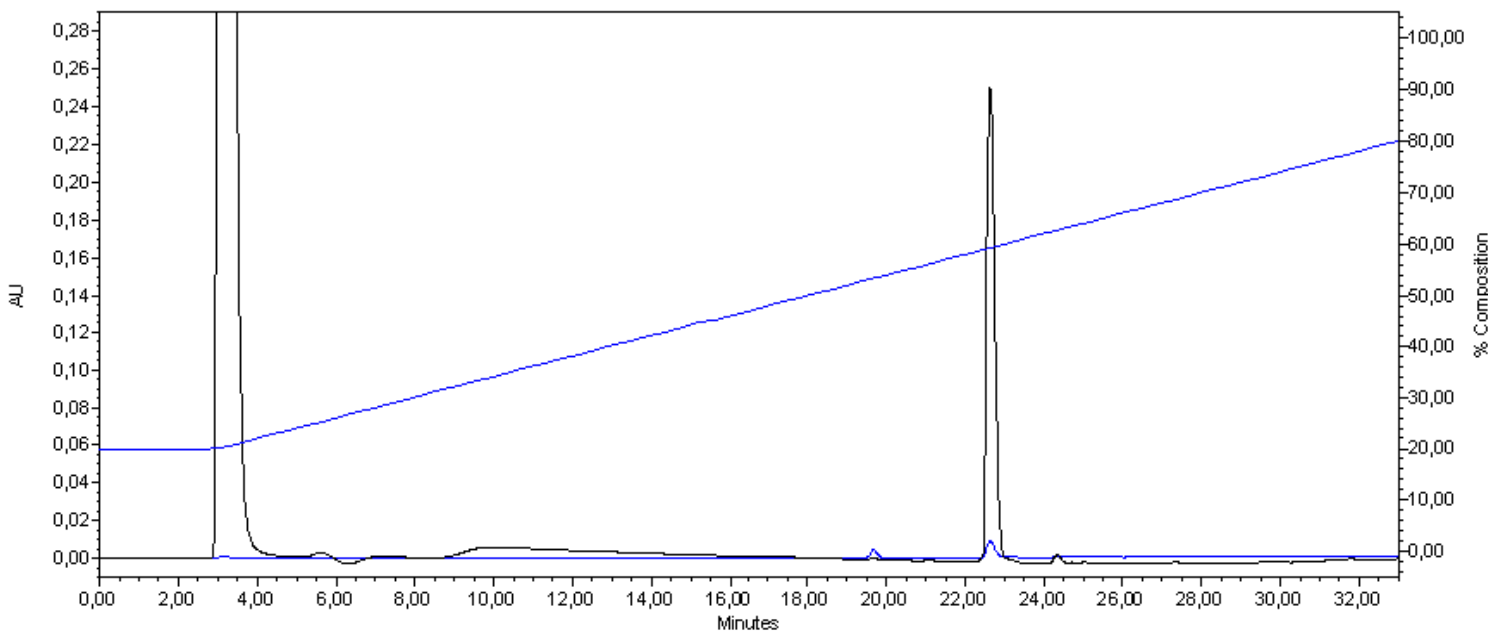

Figure S9. $\left[p-{ }^{t} \mathrm{BuF}^{1}\right] \mathrm{SHf}(3.4 \mu \mathrm{g}) \mathrm{LC}$ trace.

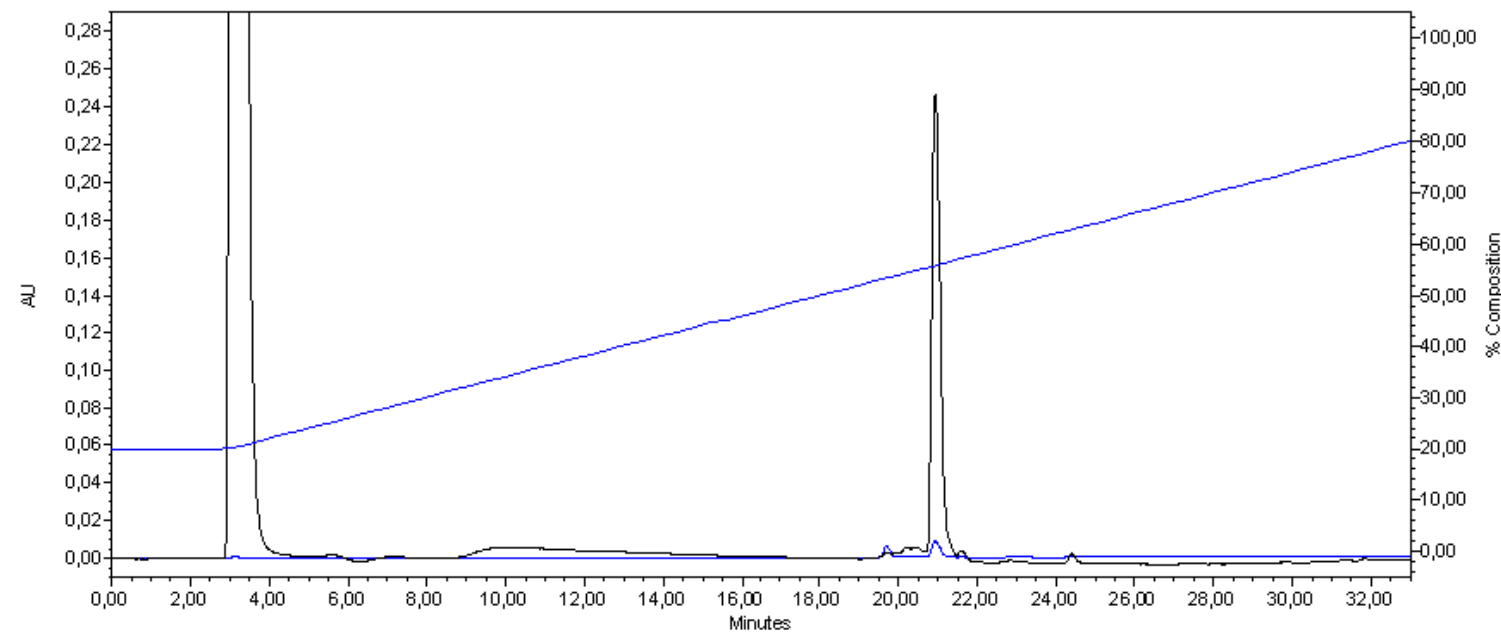

Figure S10. $\left[p-{ }^{t} \mathrm{BuF}^{3}, \mathrm{R}^{5}\right] \mathrm{SHf}(3.6 \mu \mathrm{g}) \mathrm{LC}$ trace.

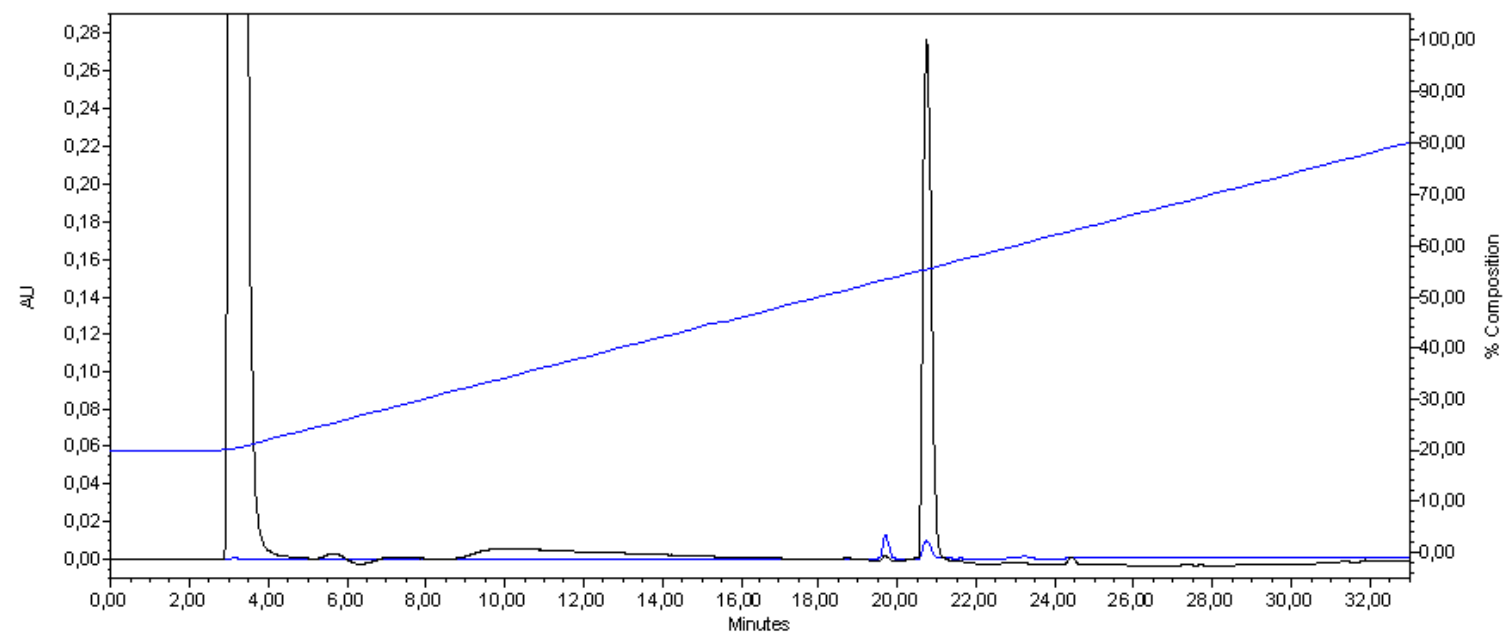

Figure S11. $\left[p-{ }^{t} \mathrm{BuF}^{2}, \mathrm{R}^{5}\right] \mathrm{SHf}(3.6 \mu \mathrm{g}) \mathrm{LC}$ trace. 


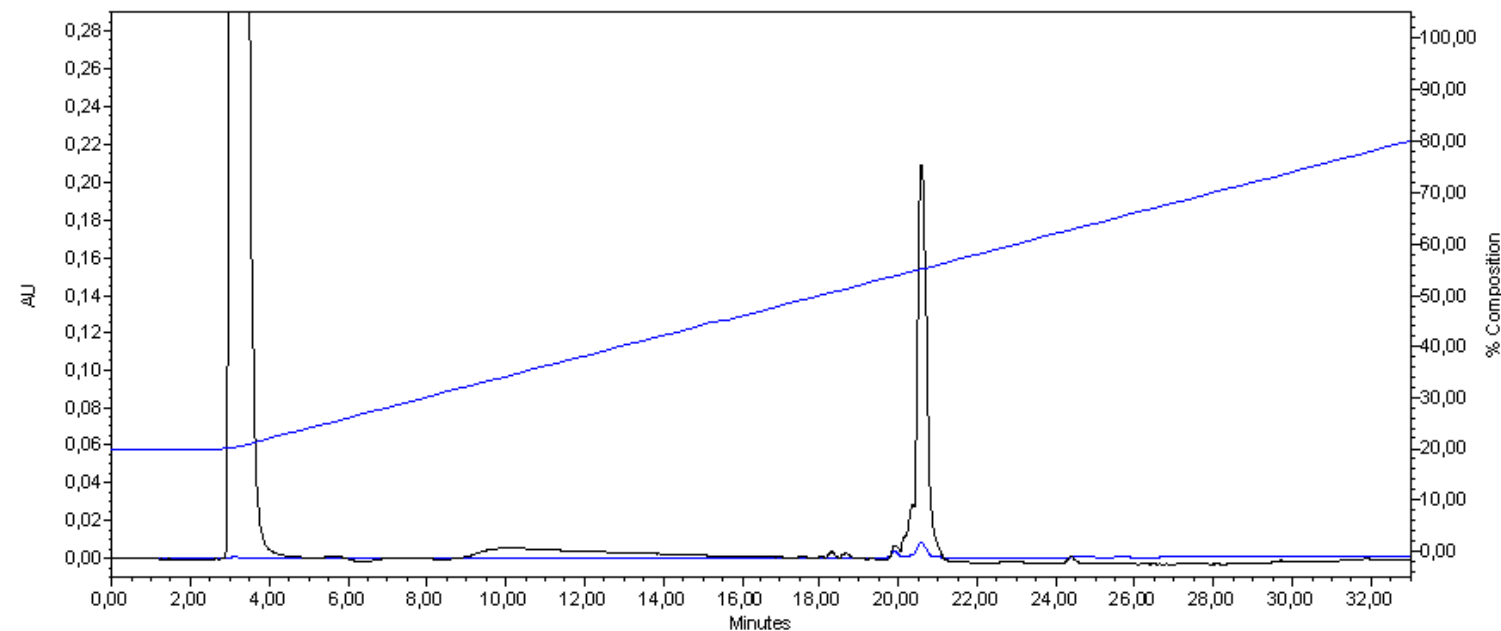

Figure S12. $\left[p-{ }^{t} \mathrm{BuF}^{1}, \mathrm{R}^{5}\right] \mathrm{SHf}(3.6 \mu \mathrm{g}) \mathrm{LC}$ trace.

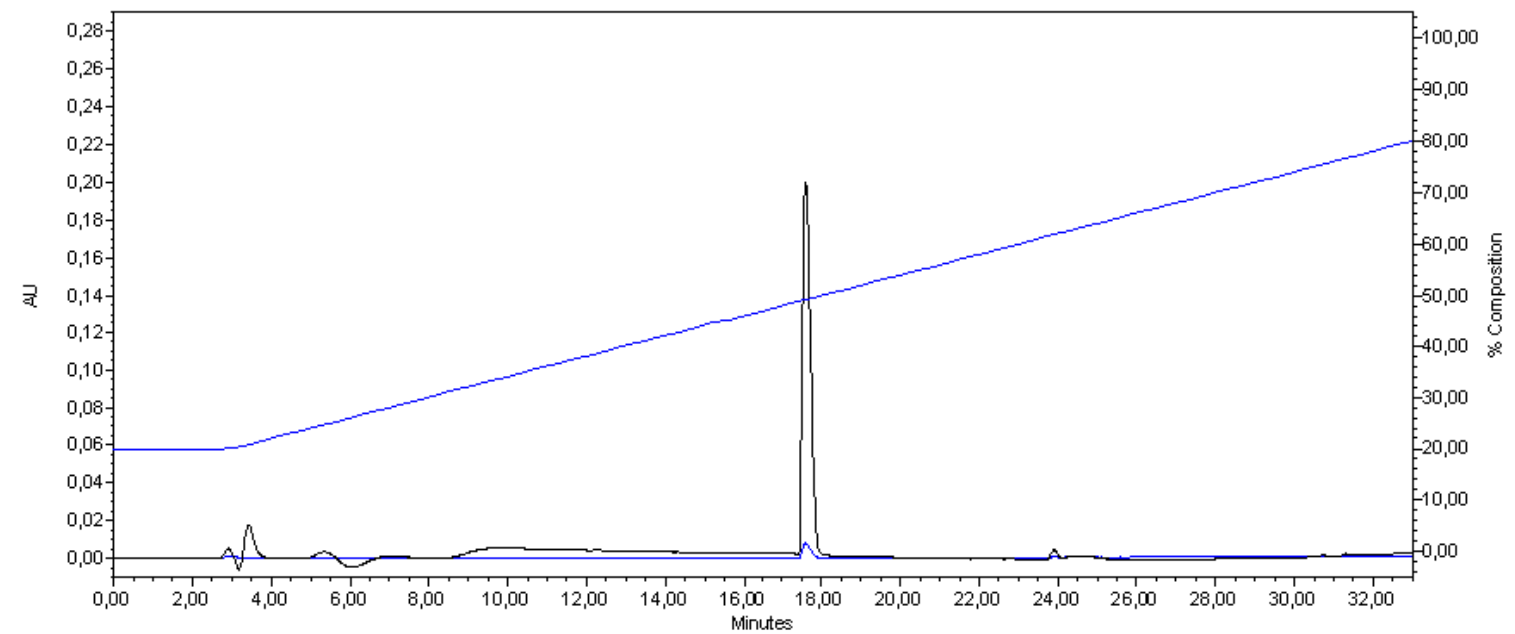

Figure S13. $\left[\mathrm{R}^{5}\right] \mathrm{SHf}-\mathrm{CO}_{2} \mathrm{H}(3.4 \mu \mathrm{g}) \mathrm{LC}$ trace.

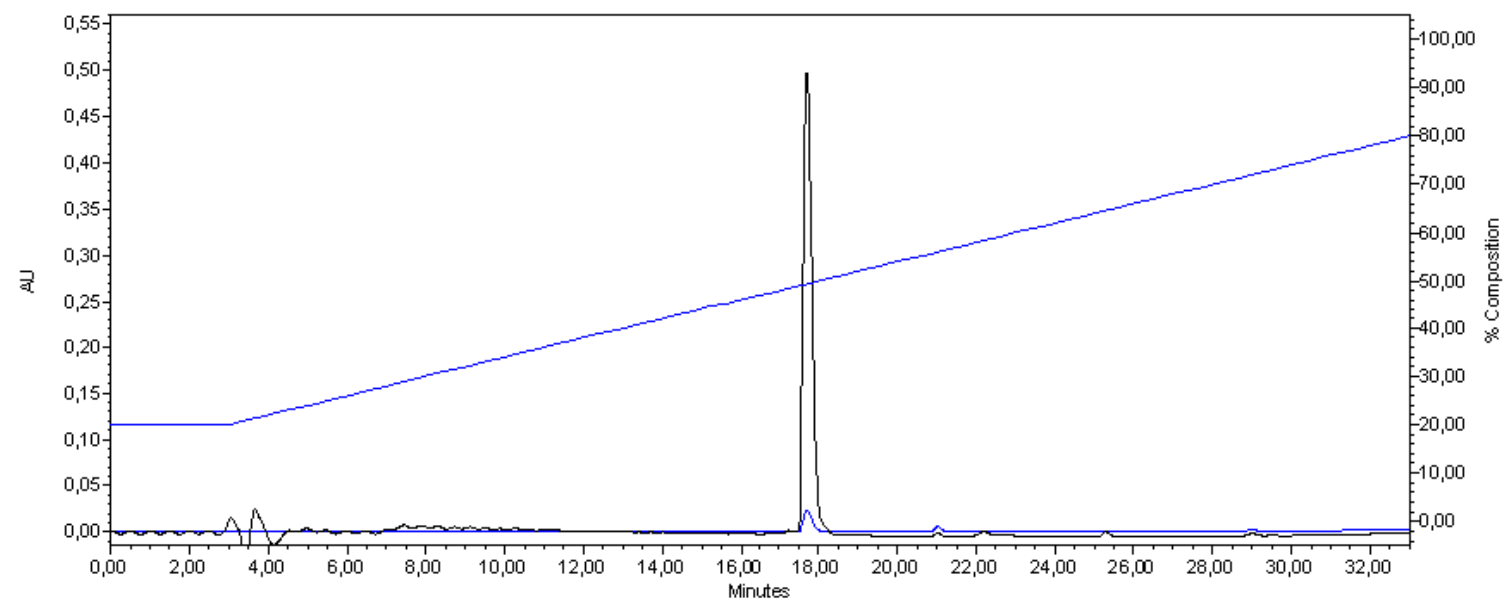

Figure S14. D-SHf $(10.7 \mu \mathrm{g}) \mathrm{LC}$ trace. 


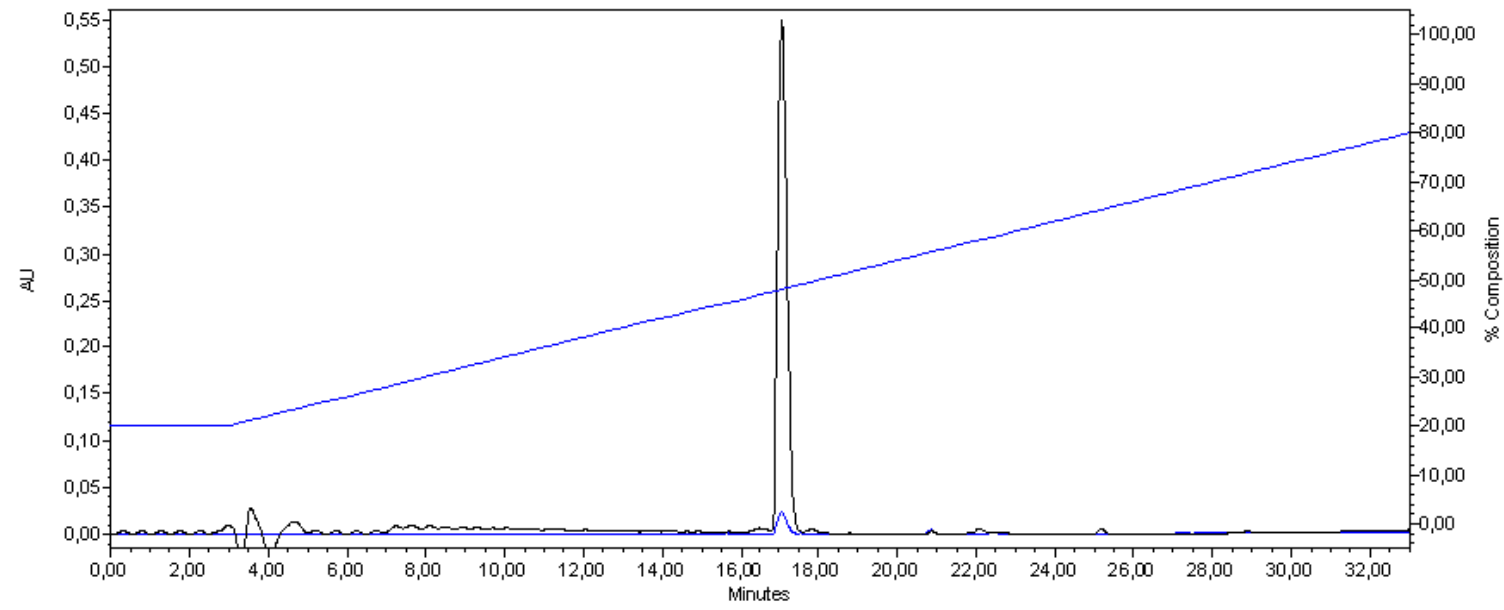

Figure S15. RI-SHf $(10.7 \mu \mathrm{g})$ LC trace

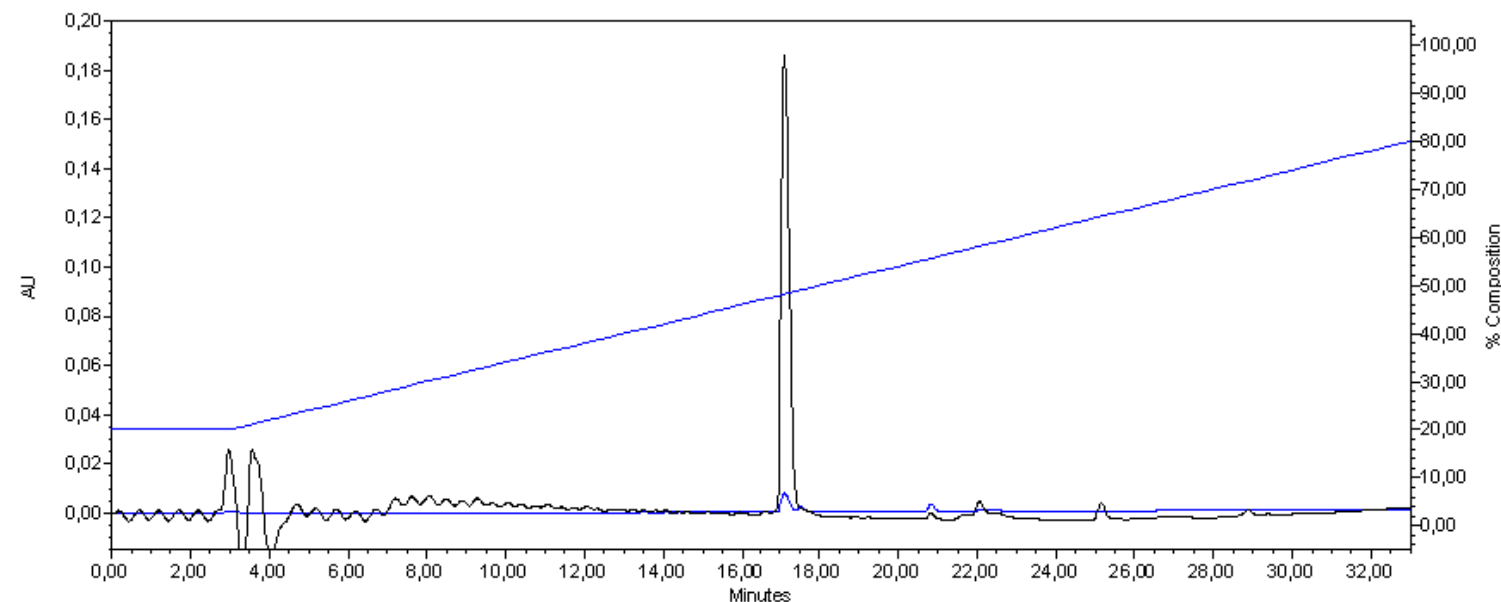

Figure S16. Retro-SHf $(10.7 \mu \mathrm{g})$ LC trace 
Table S1. $400 \mathrm{MHz}{ }^{1} \mathrm{H}$ Proton Chemical Shifts of SHf in $80 \mathrm{mM}$ SDS- $d_{25}$ (9:1 $\left.\mathrm{H}_{2} \mathrm{O} / \mathrm{D}_{2} \mathrm{O}\right), 40{ }^{\circ} \mathrm{C}$.

\begin{tabular}{|c|c|c|c|}
\hline Hydrogen & $\begin{array}{c}\text { Chemical Shift } \\
\text { (ppm) }\end{array}$ & Hydrogen & $\begin{array}{c}\text { Chemical Shift } \\
\text { (ppm) }\end{array}$ \\
\hline Phe1 - H $\alpha$ & & Ser5 - NH & 7.90 \\
\hline Phe1 - H $\beta 1$ & & Ser $5-\mathrm{H} \alpha$ & 4.25 \\
\hline Phe1 - H $\beta 1$ & & Ser5 - H $\beta 1$ & 3.94 \\
\hline Phe2 - NH & & Ser5 - H $\beta 2$ & 3.94 \\
\hline Phe 2 - H $\alpha$ & & Arg6 - NH & 7.72 \\
\hline Phe2 - H $\beta 1$ & & Arg6 - H $\alpha$ & 4.17 \\
\hline Phe 2 - H $\beta 2$ & & Arg6 - H $\beta 1$ & 1.84 \\
\hline Phe3 - NH & 7.96 & Arg6 - H $\beta 2$ & 1.84 \\
\hline Phe $3-\mathrm{H} \alpha$ & 4.33 & 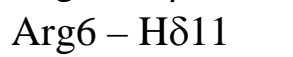 & 3.13 \\
\hline Phe 3 - H $\beta 1$ & 3.10 & Arg6 - H $\delta 12$ & 3.13 \\
\hline Phe 3 - H $\beta 2$ & 3.10 & Ile7 - NH & 7.43 \\
\hline Leu4 - NH & 7.98 & Ile7 - H $\alpha$ & 3.90 \\
\hline Leu4 - H $\alpha$ & 4.08 & Ile7 - H $\beta$ & 1.54 \\
\hline Leu4 - H $\beta 1$ & 1.82 & Ile7 - H $\gamma 11$ & 1.28 \\
\hline Leu4 - Hß2 & 1.66 & Ile7 - H $\gamma 12$ & 1.00 \\
\hline Leu4 - Hס11 & 0.96 & Ile7 - H $\gamma 21$ & 0.37 \\
\hline Leu4 - Hס12 & 0.96 & Ile7 - H $\gamma 22$ & 0.37 \\
\hline Leu4 - H $\delta 13$ & 0.96 & Ile7 - H $\gamma 23$ & 0.37 \\
\hline Leu4 - H821 & 0.91 & Ile7 - Hס1 & 0.70 \\
\hline 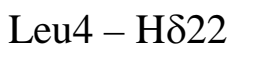 & 0.91 & Ile7 - H $\delta 2$ & 0.70 \\
\hline Leu4 - H $\delta 23$ & 0.91 & Ile7 - H83 & 0.70 \\
\hline \multirow[t]{4}{*}{ Leu4 - H $\gamma$} & 1.66 & Phe8 - NH & 7.72 \\
\hline & & Phe8 - H $\alpha$ & 4.62 \\
\hline & & Phe8 - H $\beta 1$ & 3.30 \\
\hline & & Phe8 - H $\beta 2$ & 2.84 \\
\hline
\end{tabular}


Table S2. $400 \mathrm{MHz}{ }^{1} \mathrm{H}$ Proton Chemical Shifts of $\left[\mathrm{S}^{2}\right] \mathrm{SHf}$ in $80 \mathrm{mM}$ SDS- $d_{25}$ (9:1 $\left.\mathrm{H}_{2} \mathrm{O} / \mathrm{D}_{2} \mathrm{O}\right), 40^{\circ} \mathrm{C}$.

\begin{tabular}{|c|c|c|c|}
\hline Hydrogen & $\begin{array}{c}\text { Chemical Shift } \\
\text { (ppm) }\end{array}$ & Hydrogen & $\begin{array}{l}\text { Chemical Shift } \\
\text { (ppm) }\end{array}$ \\
\hline Phe1 - H $\alpha$ & & Ser5-NH & 7.95 \\
\hline Phe1 - Hß1 & & Ser5 - H $\alpha$ & 4.26 \\
\hline Phe1 - H $\beta 1$ & & Ser5 - H $\beta 1$ & 3.96 \\
\hline Ser 2 - NH & & Ser5 - H $\beta 2$ & 3.96 \\
\hline Ser $2-\mathrm{H} \alpha$ & & Arg6 - NH & 7.77 \\
\hline Ser $2-\mathrm{H} \beta 1$ & & Arg6 - H $\alpha$ & 4.19 \\
\hline Ser $2-\mathrm{H} \beta 2$ & & Arg6 - H $\beta 1$ & 1.88 \\
\hline Phe3 - NH & 7.96 & Arg6 - Hß2 & 1.88 \\
\hline Phe3 - H $\alpha$ & 4.40 & Arg6 - H $\delta 11$ & 3.18 \\
\hline Phe3 - Hß1 & 3.18 & Arg6 - H $\delta 12$ & 3.18 \\
\hline Phe3 - H $\beta 2$ & 3.08 & Ile7 - NH & 7.43 \\
\hline Leu4 - NH & 7.96 & Ile7 - H $\alpha$ & 3.89 \\
\hline Leu 4 - H $\alpha$ & 4.05 & Ile7 - H $\beta$ & 1.52 \\
\hline Leu4 - Hß1 & 1.90 & Ile7 - Hy11 & 1.26 \\
\hline Leu4 - Hß2 & 1.61 & Ile7 - H $\gamma 12$ & 0.98 \\
\hline Leu4 - H 111 & 0.98 & Ile7 - Hү21 & 0.35 \\
\hline Leu4 - H $\delta 12$ & 0.98 & Ile7 - Hү22 & 0.35 \\
\hline Leu4 - H $\delta 13$ & 0.98 & Ile7 - Hy23 & 0.35 \\
\hline Leu4 - H $\delta 21$ & 0.90 & Ile7 - H $\delta 1$ & 0.68 \\
\hline Leu4 - H $\delta 22$ & 0.90 & Ile7 - H $\delta 2$ & 0.68 \\
\hline Leu4 - H $\delta 23$ & 0.90 & Ile7 - Hס3 & 0.68 \\
\hline \multirow[t]{4}{*}{ Leu $4-\mathrm{H} \gamma$} & 1.61 & Phe8 - NH & 7.75 \\
\hline & & Phe8 - H $\alpha$ & 4.64 \\
\hline & & Phe8 - Hß1 & 3.32 \\
\hline & & Phe8 - Hß2 & 2.86 \\
\hline
\end{tabular}


Table S3. $400 \mathrm{MHz}{ }^{1} \mathrm{H}$ Proton Chemical Shifts of [ $\left.{ }^{5}\right]$ SHf in $80 \mathrm{mM}$ SDS- $d_{25}(9: 1$ $\left.\mathrm{H}_{2} \mathrm{O} / \mathrm{D}_{2} \mathrm{O}\right), 40^{\circ} \mathrm{C}$.

\begin{tabular}{|c|c|c|c|}
\hline Hydrogen & $\begin{array}{c}\text { Chemical Shift } \\
\text { (ppm) }\end{array}$ & Hydrogen & $\begin{array}{c}\text { Chemical Shift } \\
\text { (ppm) }\end{array}$ \\
\hline Phe $1-\mathrm{H} \alpha$ & & Arg5-NH & 7.78 \\
\hline Phe1 - H $\beta 1$ & & Arg5 - H $\alpha$ & 4.10 \\
\hline Phe1 - H $\beta 1$ & & Arg5 - H $\beta 1$ & 1.84 \\
\hline Phe2 - NH & & Arg5 - H $\beta 2$ & 1.84 \\
\hline Phe2 - H $\alpha$ & & Arg5 - H $\delta 11$ & \\
\hline Phe2 - H $\beta 1$ & & Arg5 - H $\delta 12$ & \\
\hline Phe 2 - H $\beta 2$ & & Arg6 - NH & 7.72 \\
\hline Phe3 - NH & 7.77 & Arg6 - H $\alpha$ & 4.14 \\
\hline Phe 3 - H $\alpha$ & 4.43 & Arg6 - H $\beta 1$ & 1.81 \\
\hline Phe3 - H $\beta 1$ & 3.09 & Arg6 - H $\beta 2$ & 1.81 \\
\hline Phe3 - H $\beta 2$ & 3.09 & Arg6 - H $\delta 11$ & 3.17 \\
\hline Leu4 - NH & 7.88 & Arg6 - H $\delta 12$ & 3.17 \\
\hline Leu4 - H $\alpha$ & 4.06 & Ile7 - NH & 7.53 \\
\hline Leu4 - Hß1 & 1.81 & Ile7 - H $\alpha$ & 3.85 \\
\hline Leu4 - H $\beta 2$ & 1.59 & Ile7 - H $\beta$ & 1.55 \\
\hline Leu4 - Hס11 & 0.98 & Ile7 - H $\gamma 11$ & 1.26 \\
\hline Leu4 - H $\delta 12$ & 0.98 & Ile7 - Hy12 & 1.01 \\
\hline Leu4 - H $\delta 13$ & 0.98 & Ile7 - Hy21 & 0.37 \\
\hline Leu4 - H $\delta 21$ & 0.91 & Ile7 - Hy22 & 0.37 \\
\hline Leu4 - H $\delta 22$ & 0.91 & Ile7 - Hy23 & 0.37 \\
\hline Leu4 - H $\delta 23$ & 0.91 & Ile7 - H $\delta 1$ & 0.68 \\
\hline \multirow[t]{6}{*}{ Leu $4-\mathrm{H} \gamma$} & 1.69 & Ile7 - H $\delta 2$ & 0.68 \\
\hline & & Ile7 - H $\delta 3$ & 0.68 \\
\hline & & Phe8 - NH & 7.69 \\
\hline & & Phe 8 - H $\alpha$ & 4.60 \\
\hline & & Phe8 - H $\beta 1$ & 3.29 \\
\hline & & Phe 8 - H $\beta 2$ & 2.84 \\
\hline
\end{tabular}


Table S4. $400 \mathrm{MHz}{ }^{1} \mathrm{H}$ Proton Chemical Shifts of $\left[\mathrm{R}^{5}\right] \mathrm{SHf}-\mathrm{CO}_{2} \mathrm{H}$ in $80 \mathrm{mM}$ SDS- $d_{25}$ (9:1 $\left.\mathrm{H}_{2} \mathrm{O} / \mathrm{D}_{2} \mathrm{O}\right), 40^{\circ} \mathrm{C}$.

\begin{tabular}{|c|c|c|c|}
\hline Hydrogen & $\begin{array}{l}\text { Chemical Shift } \\
\text { (ppm) }\end{array}$ & Hydrogen & $\begin{array}{l}\text { Chemical Shift } \\
\text { (ppm) }\end{array}$ \\
\hline Phe1 - H $\alpha$ & & Arg5-NH & 7.72 \\
\hline Phe1 - H $\beta 1$ & & Arg5 - H $\alpha$ & 4.23 \\
\hline Phe1 - H $\beta 1$ & & Arg5 - H $\beta 1$ & 1.74 \\
\hline Phe2 - NH & & Arg5 - H $\beta 2$ & 1.74 \\
\hline Phe $2-\mathrm{H} \alpha$ & & Arg5 - H $\delta 11$ & 3.17 \\
\hline Phe2 - Hß1 & & Arg5 - H $\delta 12$ & 3.17 \\
\hline Phe 2 - H $\beta 2$ & & Arg6 - NH & 7.79 \\
\hline Phe3 - NH & 7.55 & Arg6 - H $\alpha$ & 4.28 \\
\hline Phe3 - H $\alpha$ & 4.52 & Arg6 - H $\beta 1$ & 1.79 \\
\hline Phe3 - H $\beta 1$ & 3.07 & Arg6 - Hß2 & 1.79 \\
\hline Phe3 - H $\beta 2$ & 3.07 & Arg6 - H $\delta 11$ & 3.17 \\
\hline Leu4 - NH & 7.70 & Arg6 - H $\delta 12$ & 3.17 \\
\hline Leu $4-\mathrm{H} \alpha$ & 4.14 & Ile7 - NH & 7.59 \\
\hline Leu4 - H $\beta 1$ & 1.71 & Ile7 - H $\alpha$ & 4.03 \\
\hline Leu4 - Hß2 & 1.60 & Ile7 - H $\beta$ & 1.70 \\
\hline Leu4 - H $\delta 11$ & 0.96 & Ile7 - Hү11 & \\
\hline Leu4 - H $\delta 12$ & 0.96 & Ile7 - Hy12 & 1.04 \\
\hline Leu4 - H $\delta 13$ & 0.96 & Ile7 - Hy21 & 0.58 \\
\hline Leu4 - Hס21 & 0.89 & Ile7 - Hy22 & 0.58 \\
\hline Leu4 - H $\delta 22$ & 0.89 & Ile7 - Hy23 & 0.58 \\
\hline Leu4 - H $\delta 23$ & 0.89 & Ile7 - Hס1 & 0.73 \\
\hline \multirow[t]{6}{*}{ Leu $4-\mathrm{H} \gamma$} & 1.60 & Ile7 - H $\delta 2$ & 0.73 \\
\hline & & Ile7 - Hס3 & 0.73 \\
\hline & & Phe8 - NH & 7.54 \\
\hline & & Phe8 - H $\alpha$ & 4.54 \\
\hline & & Phe8 - Hß1 & 3.23 \\
\hline & & Phe 8 - H $\beta 2$ & 2.89 \\
\hline
\end{tabular}


Table S5. $400 \mathrm{MHz}{ }^{1} \mathrm{H}$ Proton Chemical Shifts of $\left[\mathrm{HmS}^{5}\right] \mathrm{SHf}$ in $80 \mathrm{mM}$ SDS- $d_{25}$ (9:1 $\left.\mathrm{H}_{2} \mathrm{O} / \mathrm{D}_{2} \mathrm{O}\right), 40^{\circ} \mathrm{C}$.

\begin{tabular}{|c|c|c|c|}
\hline Hydrogen & $\begin{array}{c}\text { Chemical Shift } \\
\text { (ppm) }\end{array}$ & Hydrogen & $\begin{array}{c}\text { Chemical Shift } \\
\text { (ppm) }\end{array}$ \\
\hline Phe $1-\mathrm{H} \alpha$ & & Ser5 - NH & \\
\hline \multicolumn{4}{|l|}{ Phe1 - H $\beta 1$} \\
\hline Phe1 - H $\beta 1$ & & Ser5 - H $\beta 1 / H \beta 2$ & \\
\hline Phe2 - NH & & Ser5 - H $\beta 1^{\prime} / H \beta 2^{\prime}$ & \\
\hline Phe2 - H $\alpha$ & & Arg6 - NH & 7.81 \\
\hline Phe 2 - H $\beta 1$ & & Arg6 - H $\alpha$ & 4.11 \\
\hline Phe 2 - H $\beta 2$ & & Arg6 - H $\beta 1$ & 1.85 \\
\hline Phe3 - NH & 7.68 & Arg6 - H $\beta 2$ & 1.85 \\
\hline Phe3 - H $\alpha$ & 4.34 & Arg6 - H $\delta 11$ & 3.15 \\
\hline Phe3 - H $\beta 1$ & 3.08 & Arg6 - Hס12 & 3.15 \\
\hline Phe 3 - H $\beta 2$ & 3.08 & Ile7 - NH & 7.56 \\
\hline Leu4 - NH & 8.00 & Ile7 - H $\alpha$ & 3.89 \\
\hline Leu4 - H $\alpha$ & 4.05 & Ile7 - H $\beta$ & 1.54 \\
\hline Leu4 - H $\beta 1$ & 1.88 & Ile7 - Hү11 & 1.29 \\
\hline Leu4 - H $\beta 2$ & 1.65 & Ile7 - H $\gamma 12$ & 1.01 \\
\hline Leu4 - H反11 & 0.97 & Ile7 - H $\gamma 21$ & 0.36 \\
\hline Leu4 - Hס12 & 0.97 & Ile7 - H $\gamma 22$ & 0.36 \\
\hline Leu4 - H813 & 0.97 & Ile7 - H $\gamma 23$ & 0.36 \\
\hline 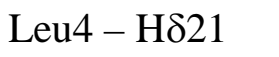 & 0.90 & Ile7 - H $\delta 1$ & 0.70 \\
\hline 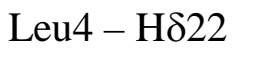 & 0.90 & Ile7 - H $\delta 2$ & 0.70 \\
\hline Leu4 - H823 & 0.90 & Ile7 - Hס3 & 0.70 \\
\hline \multirow[t]{4}{*}{ Leu4 - H $\gamma$} & 1.65 & Phe8 - NH & 7.60 \\
\hline & & Phe8 - H $\alpha$ & 4.65 \\
\hline & & Phe8 - H $\beta 1$ & 3.36 \\
\hline & & Phe8 - H $\beta 2$ & 2.76 \\
\hline
\end{tabular}


Table S6. $400 \mathrm{MHz}{ }^{1} \mathrm{H}$ Proton Chemical Shifts of $\left[\alpha \mathrm{MeF}^{3}\right] \mathrm{SHf}$ in $80 \mathrm{mM}$ SDS- $d_{25}(9: 1$ $\left.\mathrm{H}_{2} \mathrm{O} / \mathrm{D}_{2} \mathrm{O}\right), 40^{\circ} \mathrm{C}$.

\begin{tabular}{|c|c|c|c|}
\hline Hydrogen & $\begin{array}{c}\text { Chemical Shift } \\
\text { (ppm) }\end{array}$ & Hydrogen & $\begin{array}{c}\text { Chemical Shift } \\
\text { (ppm) }\end{array}$ \\
\hline Phe $1-\mathrm{H} \alpha$ & & Ser5 - NH & 8.00 \\
\hline Phe1 - H $\beta 1$ & & Ser5 - H $\alpha$ & 4.26 \\
\hline Phe1 - H $\beta 1$ & & Ser5 - H $\beta 1$ & 3.96 \\
\hline Phe2 - NH & & Ser5 - H $\beta 2$ & 3.96 \\
\hline Phe $2-\mathrm{H} \alpha$ & & Arg6 - NH & 7.61 \\
\hline Phe 2 - H $\beta 1$ & & Arg6 - H $\alpha$ & 4.17 \\
\hline Phe 2 - H $\beta 2$ & & Arg6 - H $\beta 1$ & 1.75 \\
\hline Phe3 - NH & & Arg6 - H $\beta 2$ & 1.75 \\
\hline Phe3 - Me $\alpha$ & 1.21 & 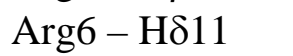 & 3.12 \\
\hline Phe 3 - H $\beta 1$ & 2.93 & Arg6 - Hס12 & 3.12 \\
\hline Phe 3 - H $\beta 2$ & 3.79 & Ile7 - NH & 7.30 \\
\hline Leu4 - NH & 7.94 & Ile7 - H $\alpha$ & 3.83 \\
\hline Leu4 - H $\alpha$ & 3.97 & Ile7 - H $\beta$ & 1.49 \\
\hline Leu4 - H $\beta 1$ & 1.79 & Ile7 - H $\gamma 11$ & 1.21 \\
\hline Leu4 - H $\beta 2$ & 1.66 & Ile7 - H $\gamma 12$ & 0.94 \\
\hline 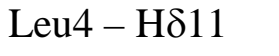 & 1.03 & Ile7 - H $\gamma 21$ & 0.30 \\
\hline Leu4 - H812 & 1.03 & Ile7 - H $\gamma 22$ & 0.30 \\
\hline Leu4 - H $\delta 13$ & 1.03 & Ile7 - Hy23 & 0.30 \\
\hline Leu4 - H821 & 1.01 & Ile7 - H $\delta 1$ & 0.59 \\
\hline Leu4 - H822 & 1.01 & Ile7 - Hס2 & 0.59 \\
\hline Leu4 - H823 & 1.01 & Ile7 - Hס3 & 0.59 \\
\hline \multirow[t]{4}{*}{ Leu4 - H $\gamma$} & 1.66 & Phe8 - NH & 7.75 \\
\hline & & Phe8 - H $\alpha$ & 4.63 \\
\hline & & Phe8 - H $\beta 1$ & 3.32 \\
\hline & & Phe8 - H $\beta 2$ & 2.86 \\
\hline
\end{tabular}


Table S7. $400 \mathrm{MHz}{ }^{1} \mathrm{H}$ Proton Chemical Shifts of $\left[p-{ }^{t} \mathrm{BuF}^{3}\right] \mathrm{SHf}$ in $80 \mathrm{mM}$ SDS- $d_{25}$ (9:1 $\left.\mathrm{H}_{2} \mathrm{O} / \mathrm{D}_{2} \mathrm{O}\right), 40^{\circ} \mathrm{C}$.

\begin{tabular}{|c|c|c|c|}
\hline Hydrogen & $\begin{array}{c}\text { Chemical Shift } \\
\text { (ppm) }\end{array}$ & Hydrogen & $\begin{array}{c}\text { Chemical Shift } \\
\text { (ppm) }\end{array}$ \\
\hline Phe1-H $\alpha$ & & Ser5 - NH & 7.88 \\
\hline Phe1 - H $\beta 1$ & & Ser5 - H $\alpha$ & 4.27 \\
\hline Phe1 - H $\beta 1$ & & Ser5 - H $\beta 1$ & 3.94 \\
\hline Phe2 - NH & & Ser5 - H $\beta 2$ & 3.94 \\
\hline Phe 2 - H $\alpha$ & & Arg6 - NH & 7.72 \\
\hline Phe 2 - H $\beta 1$ & & Arg6 - H $\alpha$ & 4.18 \\
\hline Phe 2 - H $\beta 2$ & & Arg6 - H $\beta 1$ & 1.85 \\
\hline Phe3 - NH & 7.77 & Arg6 - H $\beta 2$ & 1.85 \\
\hline Phe3 - H $\alpha$ & 4.31 & Arg6 - H $\delta 11$ & 3.15 \\
\hline Phe3 - H $\beta 1$ & 3.08 & Arg6 - H $\delta 12$ & 3.15 \\
\hline Phe3 - H $\beta 2$ & 3.08 & Ile7 - NH & 7.44 \\
\hline Phe $3-p-{ }^{t} \mathrm{Bu}$ & 1.18 & Ile7 - H $\alpha$ & 3.90 \\
\hline Leu4 - NH & 7.67 & Ile7 - H $\beta$ & 1.55 \\
\hline Leu4 - H $\alpha$ & 4.07 & Ile7 - Hy11 & 1.34 \\
\hline Leu4 - H $\beta 1$ & 1.79 & Ile7 - Hy12 & 1.03 \\
\hline Leu4 - H $\beta 2$ & 1.56 & Ile7 - Hy21 & 0.37 \\
\hline Leu4 - H $\delta 11$ & 0.95 & Ile7 - Hy22 & 0.37 \\
\hline Leu4 - H $\delta 12$ & 0.95 & Ile7 - Hy23 & 0.37 \\
\hline Leu4 - Hס13 & 0.95 & Ile7 - H $\delta 1$ & 0.73 \\
\hline Leu4 - H821 & 0.90 & Ile7 - H82 & 0.73 \\
\hline 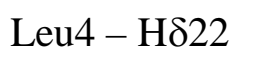 & 0.90 & Ile7 - H $\delta 3$ & 0.73 \\
\hline Leu4 - H823 & 0.90 & Phe8 - NH & 7.74 \\
\hline \multirow[t]{3}{*}{ Leu4 - H $\gamma$} & 1.56 & Phe8 - H $\alpha$ & 4.64 \\
\hline & & Phe8 - H $\beta 1$ & 3.32 \\
\hline & & Phe8 - H $\beta 2$ & 2.86 \\
\hline
\end{tabular}


Table S8. $400 \mathrm{MHz}{ }^{1} \mathrm{H}$ Proton Chemical Shifts of $\left[p-{ }^{t} \mathrm{BuF}^{2}\right] \mathrm{SHf}$ in $80 \mathrm{mM}$ SDS- $d_{25}$ (9:1 $\left.\mathrm{H}_{2} \mathrm{O} / \mathrm{D}_{2} \mathrm{O}\right), 40^{\circ} \mathrm{C}$.

\begin{tabular}{|c|c|c|c|}
\hline Hydrogen & $\begin{array}{c}\text { Chemical Shift } \\
\text { (ppm) }\end{array}$ & Hydrogen & $\begin{array}{c}\text { Chemical Shift } \\
\text { (ppm) }\end{array}$ \\
\hline Phe $1-\mathrm{H} \alpha$ & & Ser5 - NH & 7.94 \\
\hline Phe1 - H $\beta 1$ & & Ser5 - H $\alpha$ & 4.28 \\
\hline Phe1 - H $\beta 1$ & & Ser5 - H $\beta 1$ & 3.94 \\
\hline Phe2 - NH & & Ser5 - H $\beta 2$ & 3.94 \\
\hline Phe 2 - H $\alpha$ & & Arg6 - NH & 7.76 \\
\hline Phe 2 - H $\beta 1$ & & Arg6 - H $\alpha$ & 4.22 \\
\hline Phe2 - H $\beta 2$ & & Arg6 - H $\beta 1$ & 1.85 \\
\hline Phe $2-p-{ }^{t} \mathrm{Bu}$ & 1.28 & Arg6 - H $\beta 2$ & 1.85 \\
\hline Phe3 - NH & & 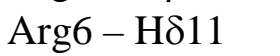 & 3.15 \\
\hline Phe3 - H $\alpha$ & & Arg6 - H $\delta 12$ & 3.15 \\
\hline Phe3 - H $\beta 1$ & & Ile7 - NH & 7.47 \\
\hline Phe 3 - H $\beta 2$ & & Ile7 - H $\alpha$ & 3.92 \\
\hline Leu4 - NH & 7.87 & Ile7 - H $\beta$ & 1.56 \\
\hline Leu4 - H $\alpha$ & 4.14 & Ile7 - H $\gamma 11$ & 1.27 \\
\hline Leu4 - H $\beta 1$ & 1.83 & Ile7 - Hү12 & 1.02 \\
\hline Leu4 - H $\beta 2$ & 1.66 & Ile7 - Hү21 & 0.40 \\
\hline Leu4 - Hס11 & 0.98 & Ile7 - H $\gamma 22$ & 0.40 \\
\hline Leu4 - Hס12 & 0.98 & Ile7 - H $\gamma 23$ & 0.40 \\
\hline Leu4 - Hס13 & 0.98 & Ile7 - H $\delta 1$ & 0.71 \\
\hline 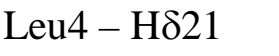 & 0.92 & Ile7 - H反2 & 0.71 \\
\hline Leu4 - H822 & 0.92 & Ile7 - Hס3 & 0.71 \\
\hline Leu4 - H $\delta 23$ & 0.92 & Phe8 - NH & 7.71 \\
\hline \multirow[t]{3}{*}{ Leu $4-\mathrm{H} \gamma$} & 1.66 & Phe8 - H $\alpha$ & 4.65 \\
\hline & & Phe8 - H $\beta 1$ & 3.30 \\
\hline & & Phe 8 - H $\beta 2$ & 2.86 \\
\hline
\end{tabular}


Table S9. $400 \mathrm{MHz}{ }^{1} \mathrm{H}$ Proton Chemical Shifts of $\left[p-{ }^{t} \mathrm{BuF}^{1}\right] \mathrm{SHf}$ in $80 \mathrm{mM}$ SDS- $d_{25}$ (9:1 $\left.\mathrm{H}_{2} \mathrm{O} / \mathrm{D}_{2} \mathrm{O}\right), 40^{\circ} \mathrm{C}$.

\begin{tabular}{|c|c|c|c|}
\hline Hydrogen & $\begin{array}{c}\text { Chemical Shift } \\
\text { (ppm) }\end{array}$ & Hydrogen & $\begin{array}{c}\text { Chemical Shift } \\
\text { (ppm) }\end{array}$ \\
\hline Phe $1-\mathrm{H} \alpha$ & & Ser5 - NH & 7.91 \\
\hline Phe1 - H $\beta 1$ & & Ser5 - H $\alpha$ & 4.28 \\
\hline Phe1 - H $\beta 1$ & & Ser5 - H $\beta 1$ & 3.95 \\
\hline Phe $1-p-{ }^{t} \mathrm{Bu}$ & 1.30 & Ser5 - H $\beta 2$ & 3.95 \\
\hline Phe2 - NH & & Arg6 - NH & 7.73 \\
\hline Phe2 - H $\alpha$ & & Arg6 - H $\alpha$ & 4.18 \\
\hline Phe 2 - H $\beta 1$ & & Arg6 - H $\beta 1$ & 1.85 \\
\hline Phe 2 - H $\beta 2$ & & Arg6 - H $\beta 2$ & 1.85 \\
\hline Phe3 - NH & & 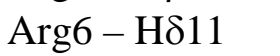 & 3.13 \\
\hline Phe3 - H $\alpha$ & 4.33 & Arg6 - H $\delta 12$ & 3.13 \\
\hline Phe3 - H $\beta 1$ & 3.08 & Ile7 - NH & 7.44 \\
\hline Phe 3 - H $\beta 2$ & 3.08 & Ile7 - H $\alpha$ & 3.91 \\
\hline Leu4 - H & 7.98 & Ile7 - H $\beta$ & 1.55 \\
\hline Leu4 - H $\alpha$ & 4.10 & Ile7 - H $\gamma 11$ & 1.29 \\
\hline Leu4 - H $\beta 1$ & 1.84 & Ile7 - Hү12 & 1.00 \\
\hline Leu4 - H $\beta 2$ & 1.67 & Ile7 - Hү21 & 0.38 \\
\hline Leu4 - H $\delta 11$ & 0.98 & Ile7 - H $\gamma 22$ & 0.38 \\
\hline Leu4 - Hס12 & 0.98 & Ile7 - H $\gamma 23$ & 0.38 \\
\hline Leu4 - Hס13 & 0.98 & Ile7 - H $\delta 1$ & 0.70 \\
\hline Leu4 - H821 & 0.92 & Ile7 - H反2 & 0.70 \\
\hline Leu4 - H822 & 0.92 & Ile7 - Hס3 & 0.70 \\
\hline Leu4 - H $\delta 23$ & 0.92 & Phe8 - NH & 7.73 \\
\hline \multirow[t]{3}{*}{ Leu $4-\mathrm{H} \gamma$} & 1.67 & Phe8 - H $\alpha$ & 4.64 \\
\hline & & Phe8 - H $\beta 1$ & 3.30 \\
\hline & & Phe 8 - H $\beta 2$ & 2.85 \\
\hline
\end{tabular}


Table S10. $400 \mathrm{MHz}{ }^{1} \mathrm{H}$ Proton Chemical Shifts of $\left[p-{ }^{t} \mathrm{BuF}^{3}, \mathrm{R}^{5}\right] \mathrm{SHf}$ in $80 \mathrm{mM}$ SDS- $d_{25}$ (9:1 $\left.\mathrm{H}_{2} \mathrm{O} / \mathrm{D}_{2} \mathrm{O}\right), 40^{\circ} \mathrm{C}$.

\begin{tabular}{|c|c|c|c|}
\hline Hydrogen & $\begin{array}{c}\text { Chemical Shift } \\
\text { (ppm) }\end{array}$ & Hydrogen & $\begin{array}{c}\text { Chemical Shift } \\
\text { (ppm) }\end{array}$ \\
\hline Phe1 - H $\alpha$ & & Arg5 - NH & 7.78 \\
\hline Phe1 - H $\beta 1$ & & $\operatorname{Arg} 5-\mathrm{H} \alpha$ & 4.11 \\
\hline Phe1 - H $\beta 1$ & & Arg5 - H $\beta 1$ & 1.77 \\
\hline Phe2 - H & & $\operatorname{Arg} 5-H \beta 2$ & 1.77 \\
\hline Phe $2-\mathrm{H} \alpha$ & & Arg5 - H $\delta 11$ & \\
\hline Phe2 - H $\beta 1$ & & Arg5 - H $\delta 12$ & \\
\hline Phe 2 - H $\beta 2$ & & Arg6 - NH & 7.73 \\
\hline Phe3 - NH & 7.68 & Arg6 - H $\alpha$ & 4.15 \\
\hline Phe 3 - H $\alpha$ & 4.42 & Arg6 - H $\beta 1$ & 1.81 \\
\hline Phe 3 - H $\beta 1$ & 3.07 & Arg6 - H $\beta 2$ & 1.81 \\
\hline Phe3 - H $\beta 2$ & 3.07 & Arg6 - H $\delta 11$ & \\
\hline Phe $3-p-{ }^{t} \mathrm{Bu}$ & 1.22 & Arg6 - Hס12 & \\
\hline Leu4 - NH & 7.74 & Ile7 - NH & 7.52 \\
\hline Leu4 - H $\alpha$ & 4.05 & Ile7 - H $\alpha$ & 3.85 \\
\hline Leu4 - H $\beta 1$ & 1.73 & Ile $7-H \beta$ & 1.55 \\
\hline Leu4 - H $\beta 2$ & 1.53 & Ile7 - H $\gamma 11$ & 1.31 \\
\hline Leu4 - Hס11 & 0.94 & Ile7 - H $\gamma 12$ & 1.02 \\
\hline Leu4 - Hס12 & 0.94 & Ile7 - Hү21 & 0.36 \\
\hline Leu4 - Hס13 & 0.94 & Ile7 - H $\gamma 22$ & 0.36 \\
\hline Leu4 - H821 & 0.88 & Ile7 - H $\gamma 23$ & 0.36 \\
\hline Leu4 - H822 & 0.88 & Ile7 - Hס1 & 0.71 \\
\hline Leu4 - H823 & 0.88 & Ile7 - Hס2 & 0.71 \\
\hline \multirow[t]{5}{*}{ Leu4 - H $\gamma$} & 1.53 & Ile7 - Hס3 & 0.71 \\
\hline & & Phe8 - NH & 7.71 \\
\hline & & Phe8 - H $\alpha$ & 4.60 \\
\hline & & Phe8 - H $\beta 1$ & 3.28 \\
\hline & & Phe8 - H $\beta 2$ & 2.84 \\
\hline
\end{tabular}


Table S11. $400 \mathrm{MHz}{ }^{1} \mathrm{H}$ Proton Chemical Shifts of $\left[p-{ }^{t} \mathrm{BuF}^{2}, \mathrm{R}^{5}\right] \mathrm{SHf}$ in $80 \mathrm{mM}$ SDS- $d_{25}$ (9:1 $\left.\mathrm{H}_{2} \mathrm{O} / \mathrm{D}_{2} \mathrm{O}\right), 40^{\circ} \mathrm{C}$.

\begin{tabular}{|c|c|c|c|}
\hline Hydrogen & $\begin{array}{l}\text { Chemical Shift } \\
\text { (ppm) }\end{array}$ & Hydrogen & $\begin{array}{c}\text { Chemical Shift } \\
\text { (ppm) }\end{array}$ \\
\hline Phe1 - H $\alpha$ & & Arg5-NH & 7.80 \\
\hline Phe1 - H $\beta 1$ & & Arg5 - H $\alpha$ & 4.14 \\
\hline Phe1 - H $\beta 1$ & & Arg5 - H $\beta 1$ & 1.85 \\
\hline Phe2 - NH & & Arg5 - H $\beta 2$ & 1.85 \\
\hline Phe $2-\mathrm{H} \alpha$ & & Arg5 - H $\delta 11$ & 3.17 \\
\hline Phe 2 - H $\beta 1$ & & Arg5 - H $\delta 12$ & 3.17 \\
\hline Phe2 - H $\beta 2$ & & Arg6 - NH & 7.78 \\
\hline Phe $2-p-{ }^{t} \mathrm{Bu}$ & 1.29 & Arg6 $-\mathrm{H} \alpha$ & 4.21 \\
\hline Phe3 - NH & & Arg6 - H $\beta 1$ & 1.85 \\
\hline Phe $3-\mathrm{H} \alpha$ & & Arg6 - H $\beta 2$ & 1.85 \\
\hline Phe3 - H $\beta 1$ & & Arg6 - H $\delta 11$ & 3.19 \\
\hline Phe3 - H $\beta 2$ & & Arg6 - H $\delta 12$ & 3.17 \\
\hline Leu4 - NH & 7.66 & Ile7 - NH & 7.59 \\
\hline Leu $4-\mathrm{H} \alpha$ & 4.13 & Ile7 - H $\alpha$ & 3.89 \\
\hline Leu4 - Hß1 & 1.71 & Ile7 - H $\beta$ & 1.60 \\
\hline Leu4 - Hß2 & 1.63 & Ile7 - Hy11 & 1.27 \\
\hline Leu4 - H $\delta 11$ & 0.98 & Ile7 - Hy12 & 1.04 \\
\hline Leu4 - H $\delta 12$ & 0.98 & Ile7 - Hy21 & 0.42 \\
\hline Leu4 - H $\delta 13$ & 0.98 & Ile7 - Hy22 & 0.42 \\
\hline Leu4 - H $\delta 21$ & 0.91 & Ile7 - Hy23 & 0.42 \\
\hline Leu4 - H $\delta 22$ & 0.91 & Ile7 - H $\delta 1$ & 0.72 \\
\hline Leu4 - H $\delta 23$ & 0.91 & Ile7 - H $\delta 2$ & 0.72 \\
\hline \multirow{5}{*}{ Leu $4-\mathrm{H} \gamma$} & 1.63 & Ile7 - H $\delta 3$ & 0.72 \\
\hline & & Phe8 - NH & 7.69 \\
\hline & & Phe8 - H $\alpha$ & 4.62 \\
\hline & & Phe8 - H $\beta 1$ & 3.29 \\
\hline & & Phe 8 - H $\beta 2$ & 2.88 \\
\hline
\end{tabular}


Table S12. $400 \mathrm{MHz}{ }^{1} \mathrm{H}$ Proton Chemical Shifts of $\left[{ }^{t}-{ }^{t} \mathrm{BuF}^{1}, \mathrm{R}^{5}\right] \mathrm{SHf}$ in $80 \mathrm{mM}$ SDS- $d_{25}$ (9:1 $\left.\mathrm{H}_{2} \mathrm{O} / \mathrm{D}_{2} \mathrm{O}\right), 40^{\circ} \mathrm{C}$.

\begin{tabular}{|c|c|c|c|}
\hline Hydrogen & $\begin{array}{l}\text { Chemical Shift } \\
\text { (ppm) }\end{array}$ & Hydrogen & $\begin{array}{c}\text { Chemical Shift } \\
\text { (ppm) }\end{array}$ \\
\hline Phe1 - H $\alpha$ & & Arg5-NH & 7.73 \\
\hline Phe1 - H $\beta 1$ & & Arg5 - H $\alpha$ & 4.25 \\
\hline Phe1 - H $\beta 1$ & & Arg5 - H $\beta 1$ & 1.83 \\
\hline Phe $1-p-{ }^{t} \mathrm{Bu}$ & 1.30 & Arg5 - H $\beta 2$ & 1.83 \\
\hline Phe2 - NH & & Arg5 - H $\delta 11$ & 3.18 \\
\hline Phe 2 - H $\alpha$ & & Arg5 - H $\delta 12$ & 3.18 \\
\hline Phe 2 - H $\beta 1$ & & Arg6 - NH & 7.71 \\
\hline Phe 2 - H $\beta 2$ & & Arg6 $6-\mathrm{H} \alpha$ & 4.16 \\
\hline Phe3 - NH & 7.82 & Arg6 - H $\beta 1$ & 1.83 \\
\hline Phe $3-\mathrm{H} \alpha$ & 4.28 & Arg6 - H $\beta 2$ & 1.83 \\
\hline Phe3 - H $\beta 1$ & & Arg6 - H $\delta 11$ & 3.18 \\
\hline Phe3 - H $\beta 2$ & & Arg6 - H $\delta 12$ & 3.18 \\
\hline Leu4 - NH & 7.61 & Ile7 - NH & 7.54 \\
\hline Leu $4-\mathrm{H} \alpha$ & 4.07 & Ile7 - H $\alpha$ & 3.86 \\
\hline Leu4 - Hß1 & 1.86 & Ile7 - H $\beta$ & 1.56 \\
\hline Leu4 - Hß2 & 1.61 & Ile7 - Hy11 & 1.25 \\
\hline Leu4 - H $\delta 11$ & 0.99 & Ile7 - Hy12 & 1.01 \\
\hline Leu4 - H $\delta 12$ & 0.99 & Ile7 - Hy21 & 0.38 \\
\hline Leu4 - H $\delta 13$ & 0.99 & Ile7 - Hy22 & 0.38 \\
\hline Leu4 - H $\delta 21$ & 0.92 & Ile7 - Hy23 & 0.38 \\
\hline Leu4 - H $\delta 22$ & 0.92 & Ile7 - H $\delta 1$ & 0.68 \\
\hline Leu4 - H $\delta 23$ & 0.92 & Ile7 - H $\delta 2$ & 0.68 \\
\hline \multirow{5}{*}{ Leu $4-\mathrm{H} \gamma$} & 1.73 & Ile7 - H $\delta 3$ & 0.68 \\
\hline & & Phe8 - NH & 7.71 \\
\hline & & Phe8 - H $\alpha$ & 4.61 \\
\hline & & Phe8 - H $\beta 1$ & 3.28 \\
\hline & & Phe 8 - H $\beta 2$ & 2.84 \\
\hline
\end{tabular}


file djo_253 2

$2 \mathrm{mg} \mathrm{SHf}$ in $80 \mathrm{mM} \mathrm{SDS}-d_{25}\left(9: 1 \mathrm{H}_{2} \mathrm{O} / \mathrm{D}_{2} \mathrm{O}\right), 40^{\circ} \mathrm{C}, 400 \mathrm{MHz}$ TOCSY.

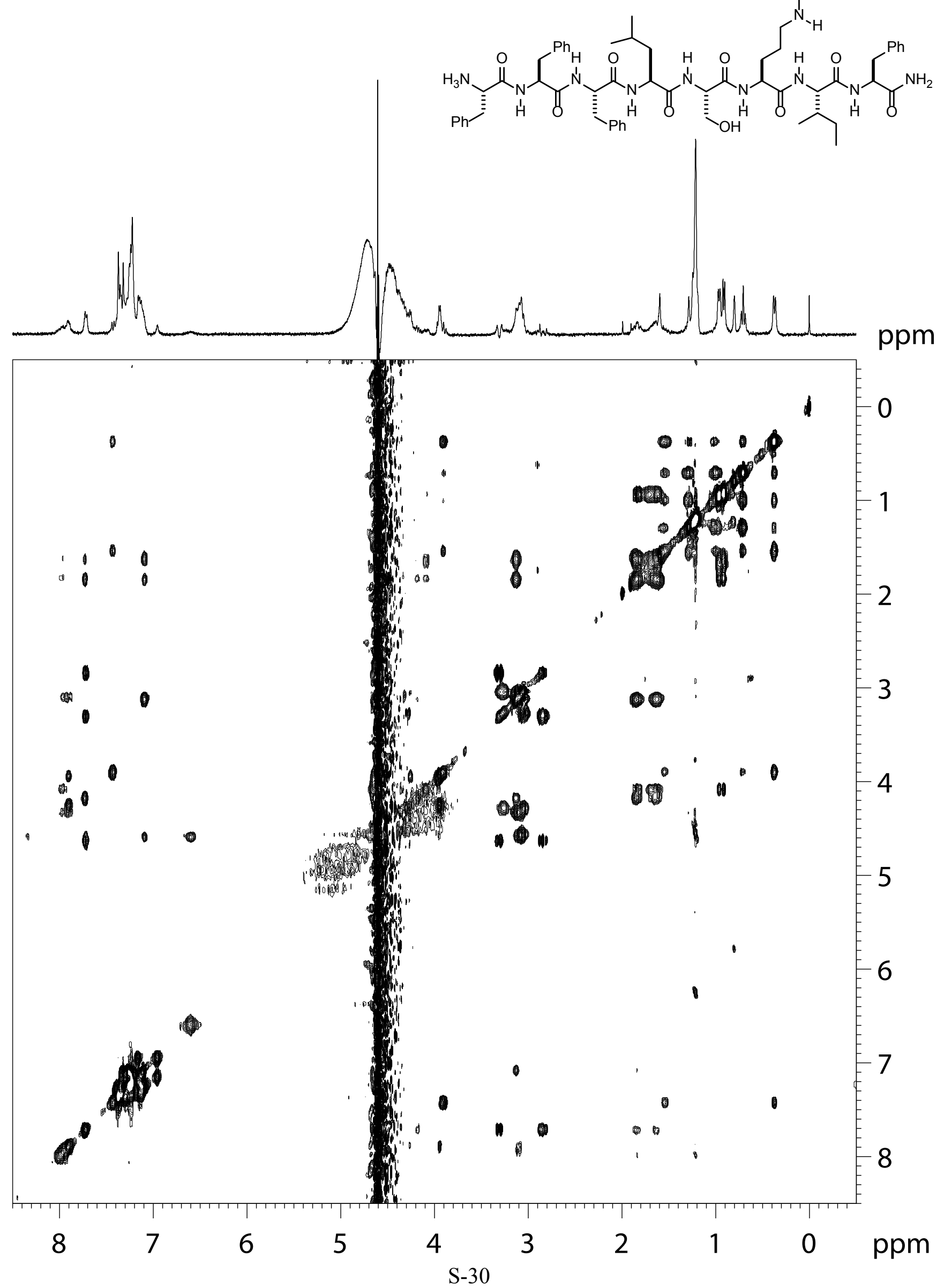


file djo_253a 2

$2 \mathrm{mg} \mathrm{SHf}$ in $80 \mathrm{mM} \mathrm{SDS}-d_{25}\left(9: 1 \mathrm{H}_{2} \mathrm{O} / \mathrm{D}_{2} \mathrm{O}\right), 40{ }^{\circ} \mathrm{C}, 400 \mathrm{MHz}$ ROESY.

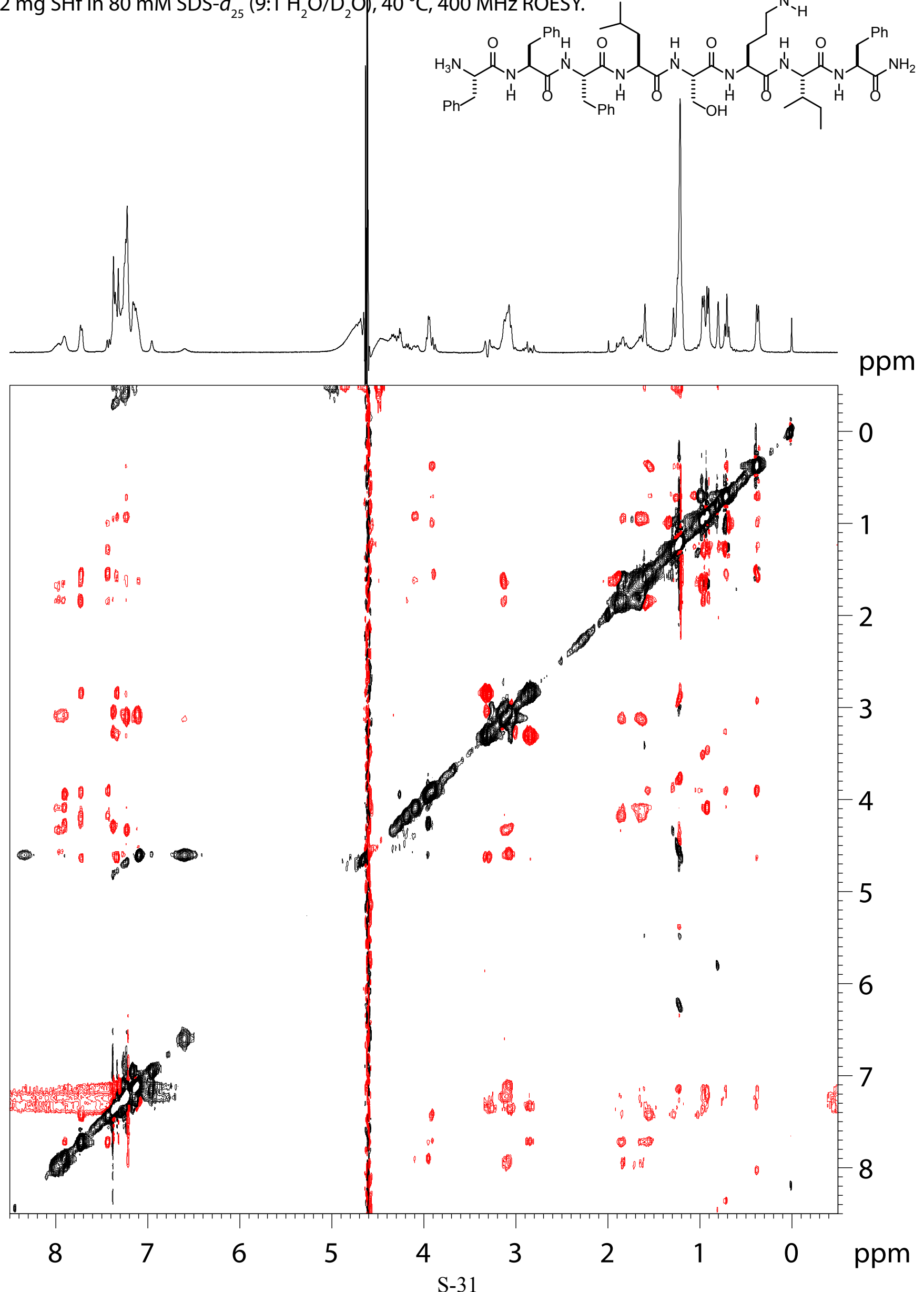


file djo_2_2773

$2 \mathrm{mg}\left[\mathrm{S}^{2}\right] \mathrm{SHf}$ in $80 \mathrm{mM}$ SDS- $d_{25}\left(9: 1 \mathrm{H}_{2} \mathrm{O} / \mathrm{D}_{2} \mathrm{O}\right), 40{ }^{\circ} \mathrm{C}, 400 \mathrm{MHz}$ TOCSY.

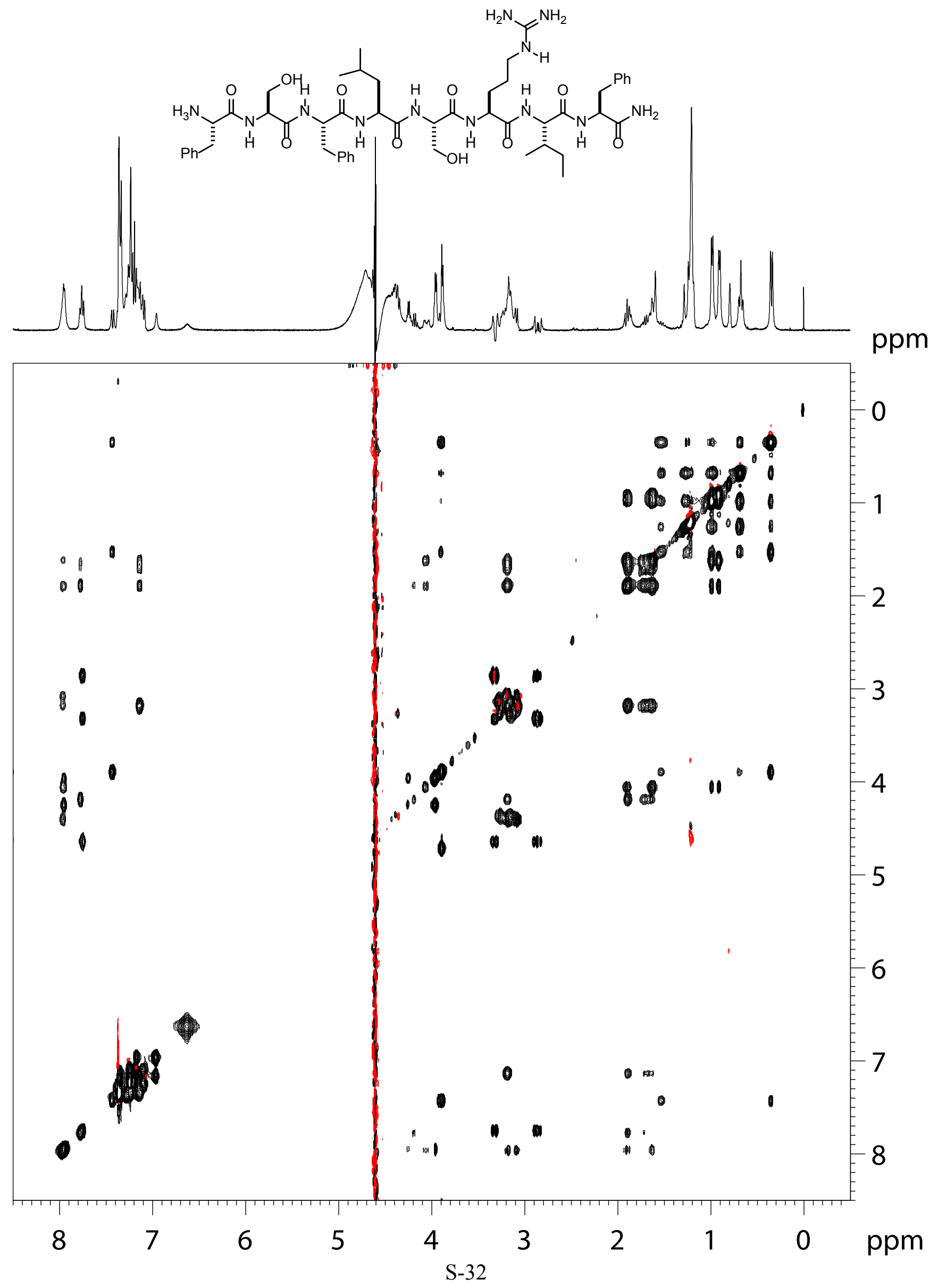


file djo_2_277 5

$2 \mathrm{mg}\left[\mathrm{S}^{2}\right] \mathrm{SHf}$ in $80 \mathrm{mM}$ SDS- $d_{25}\left(9: 1 \mathrm{H}_{2} \mathrm{O} / \mathrm{D}_{2} \mathrm{O}\right), 40^{\circ} \mathrm{C}, 400 \mathrm{MHz}$ ROESY.

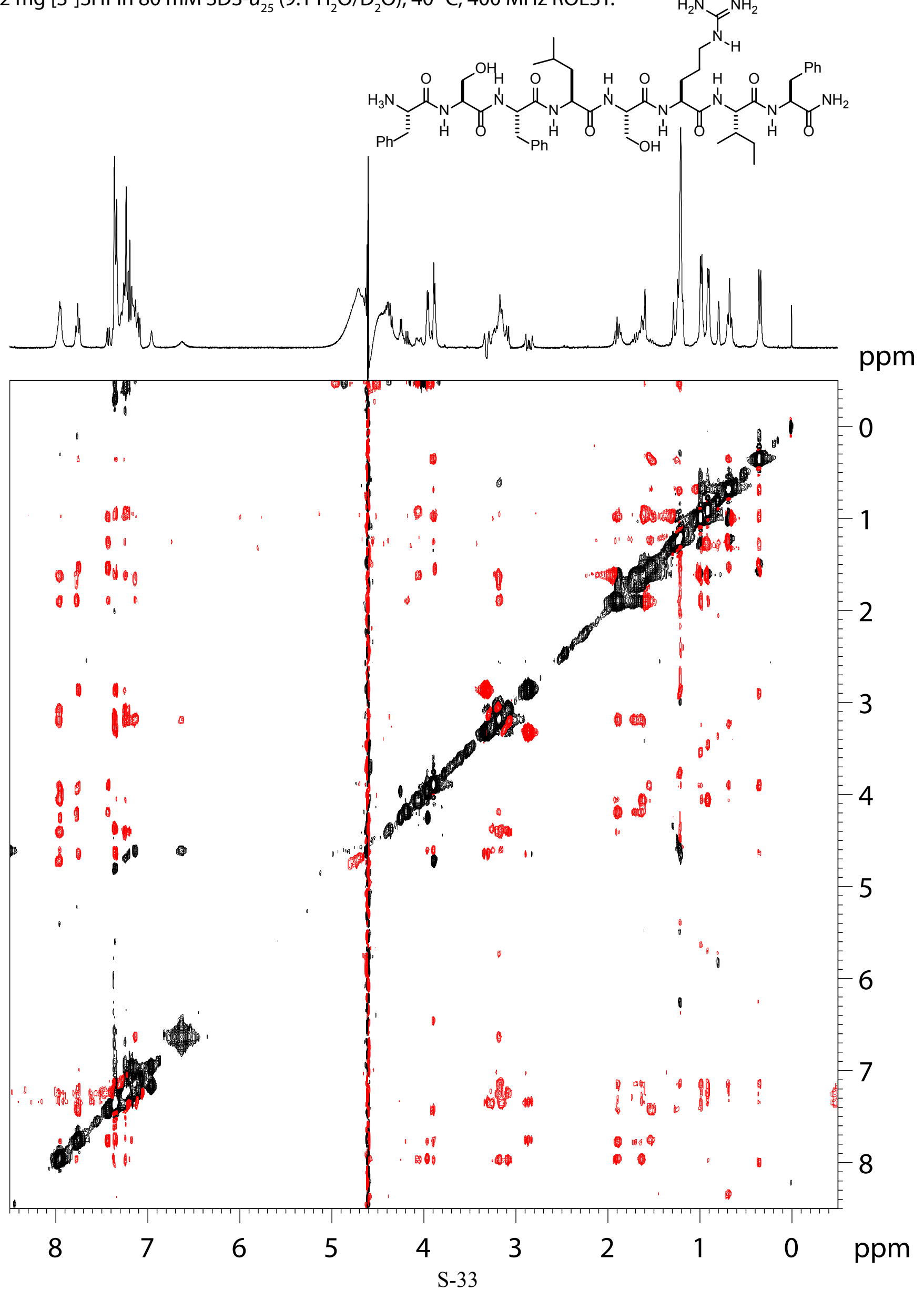


file djo_253 21

$2 \mathrm{mg}\left[\mathrm{R}^{5}\right] \mathrm{SHf}$ in $80 \mathrm{mM} \mathrm{SDS}-d_{25}\left(9: 1 \mathrm{H}_{2} \mathrm{O} / \mathrm{D}_{2} \mathrm{O}\right), 40{ }^{\circ} \mathrm{C}, 400 \mathrm{MHz}$ TOCSY.

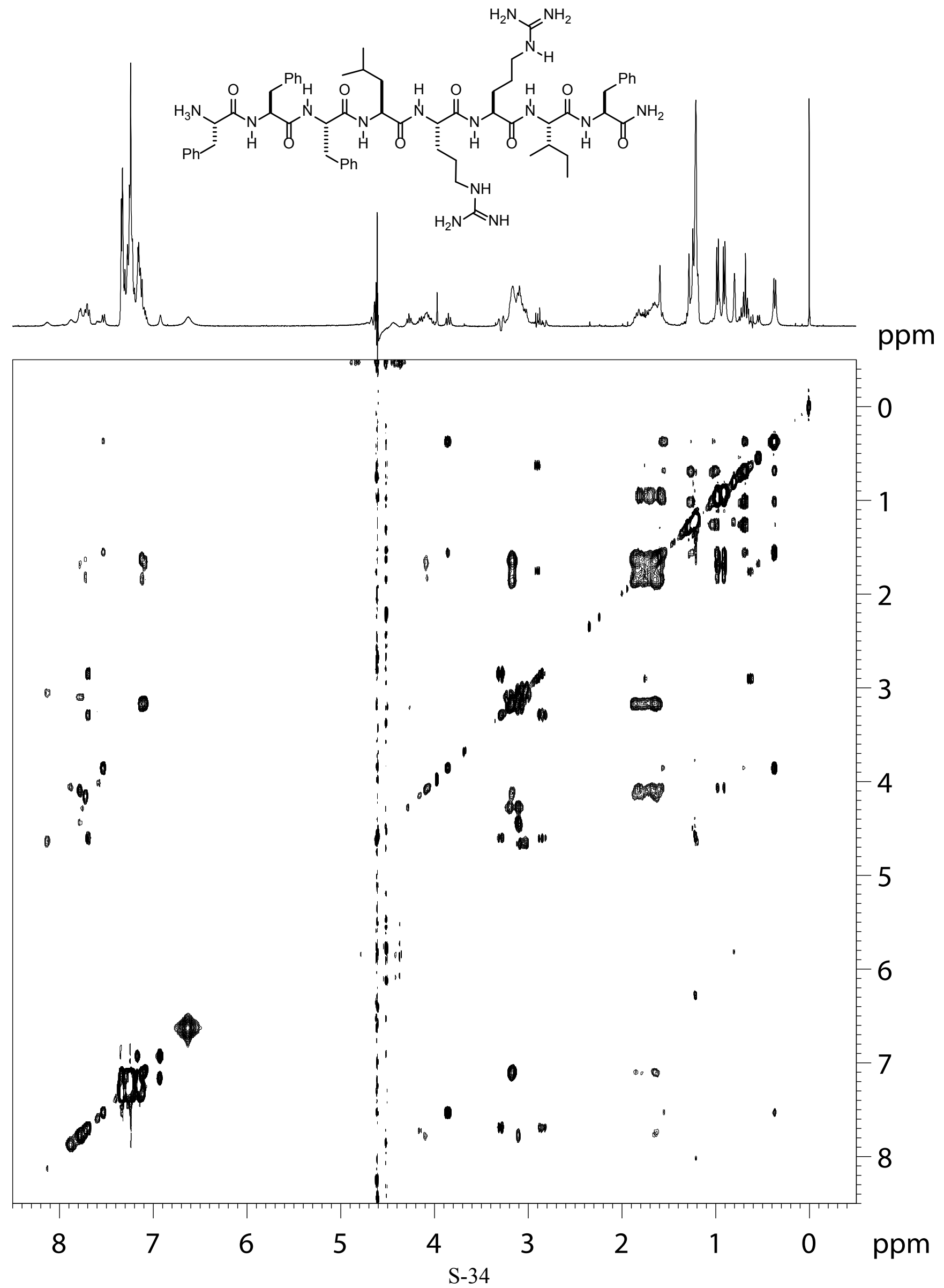


file djo_253a 20

$2 \mathrm{mg}\left[\mathrm{R}^{5}\right] \mathrm{SHf}$ in $80 \mathrm{mM}$ SDS- $d_{25}\left(9: 1 \mathrm{H}_{2} \mathrm{O} / \mathrm{D}_{2} \mathrm{O}\right), 40^{\circ} \mathrm{C}, 400 \mathrm{MHz}$ ROESY.

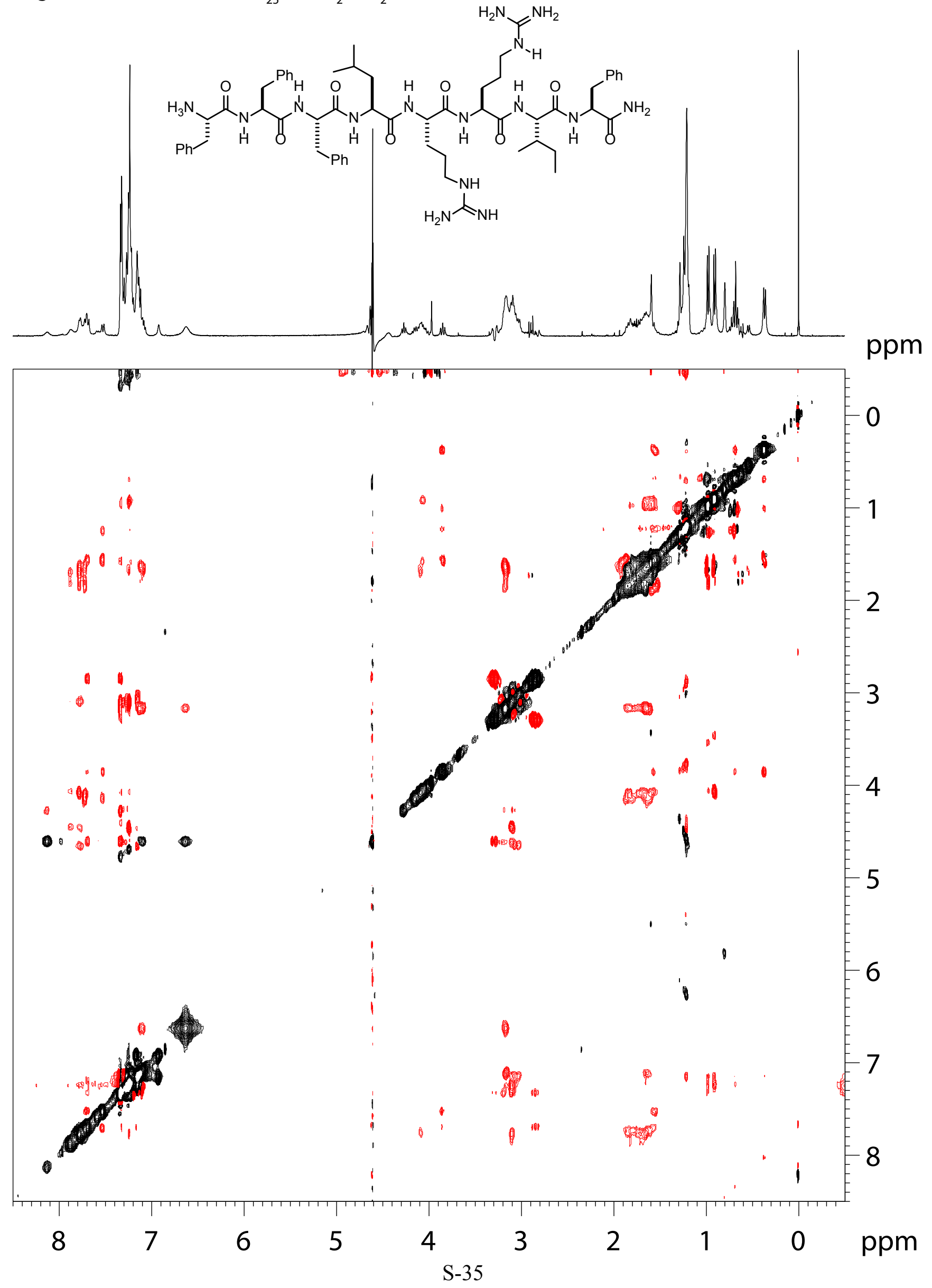


file djo_279 3

$2 \mathrm{mg}\left[\mathrm{R}^{5}\right] \mathrm{SHf}-\mathrm{CO}_{2} \mathrm{H}$ in $80 \mathrm{mM}$ SDS $-d_{25}\left(9: 1 \mathrm{H}_{2} \mathrm{O} / \mathrm{D}_{2} \mathrm{O}\right), 40^{\circ} \mathrm{C}, 400 \mathrm{MHz}$ TOCSY.

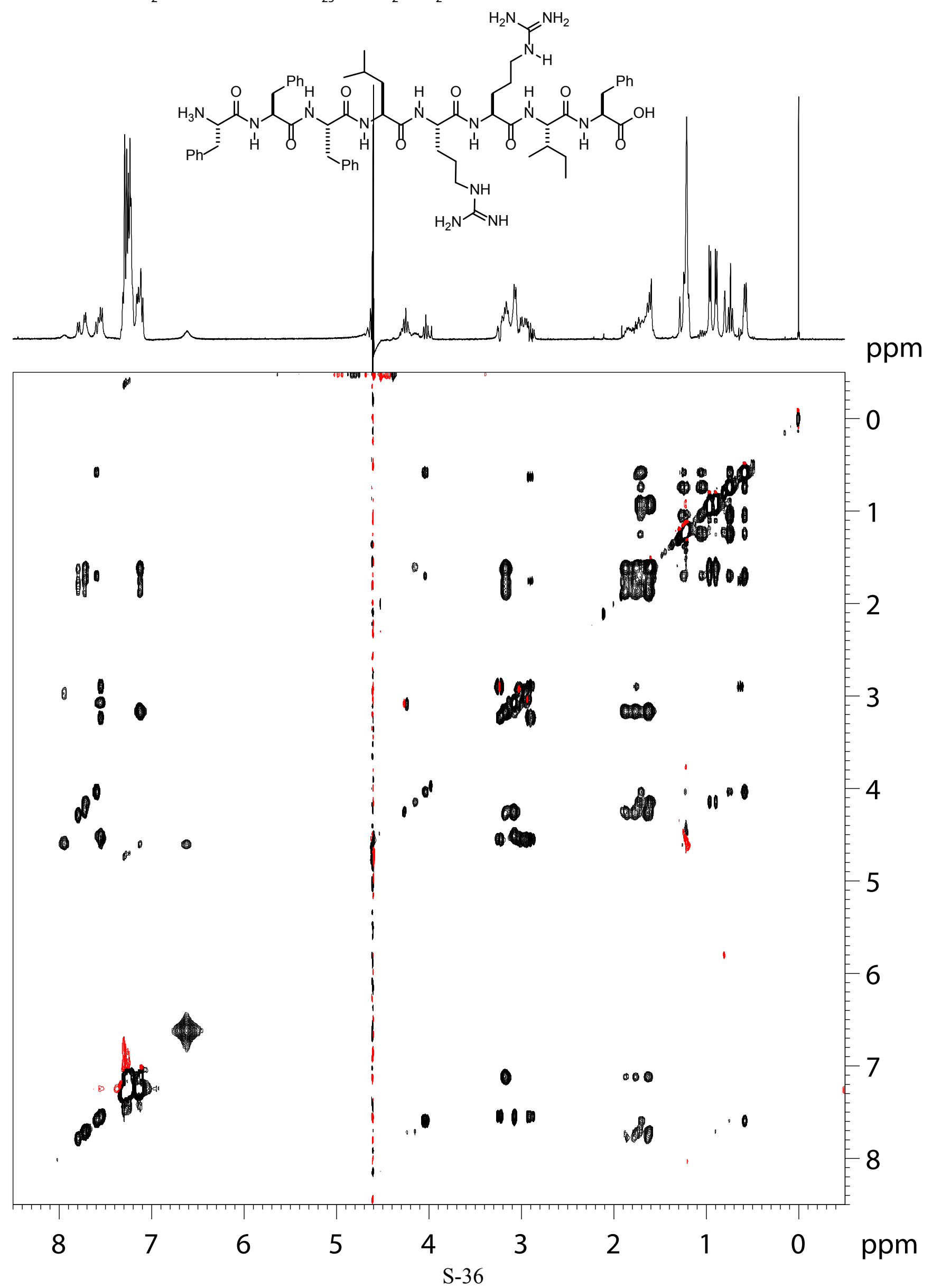


file djo_279 6

$2 \mathrm{mg}\left[\mathrm{R}^{5}\right] \mathrm{SHf}-\mathrm{CO}_{2} \mathrm{H}$ in $80 \mathrm{mM}$ SDS $-d_{25}\left(9: 1 \mathrm{H}_{2} \mathrm{O} / \mathrm{D}_{2} \mathrm{O}\right), 40{ }^{\circ} \mathrm{C}, 400 \mathrm{MHz}$ ROESY.

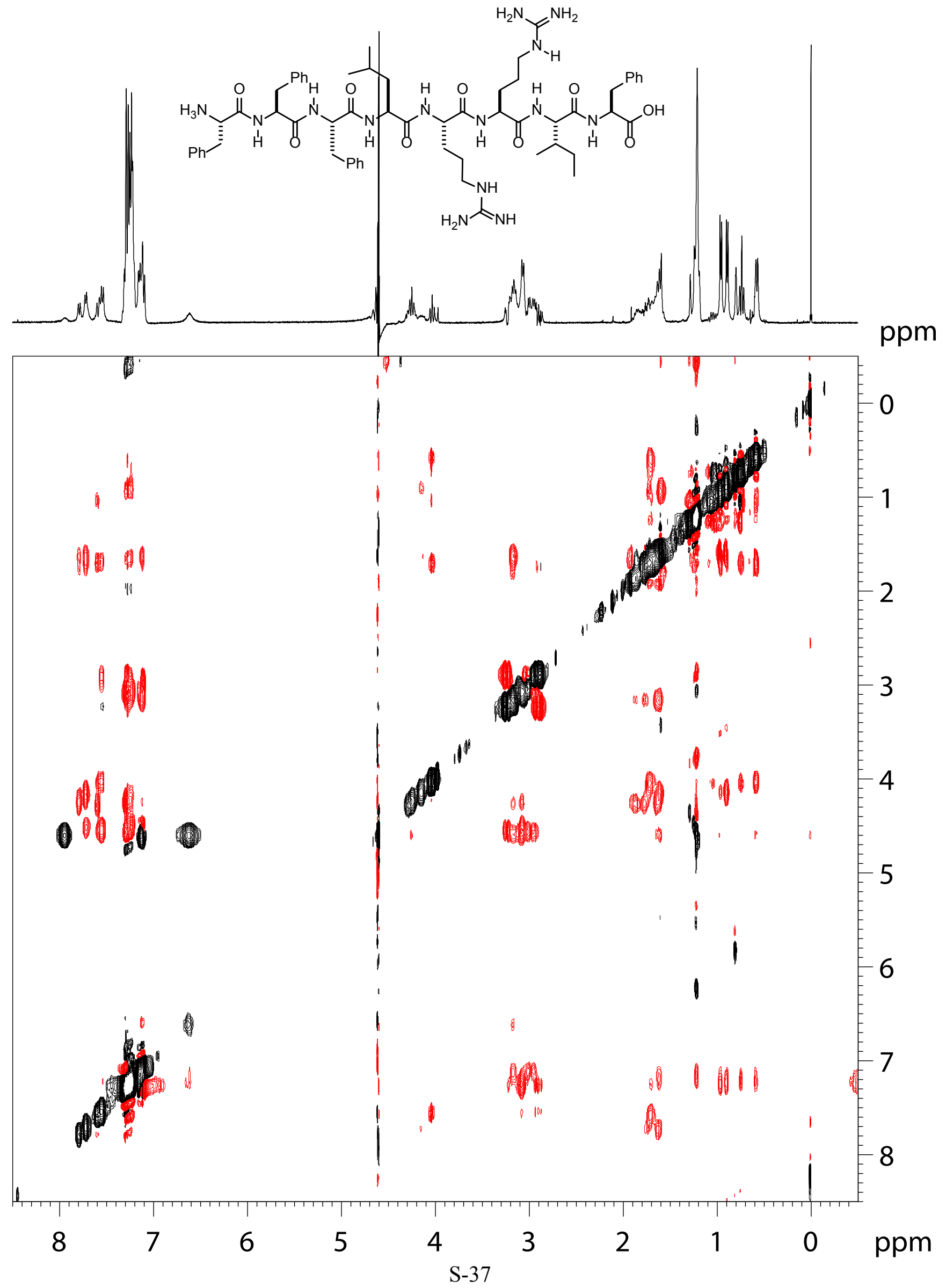


file djo_253 4

$2 \mathrm{mg}\left[\mathrm{HmS}^{5}\right] \mathrm{SHf}$ in $80 \mathrm{mM} \mathrm{SDS}^{-d_{25}}\left(9: 1 \mathrm{H}_{2} \mathrm{O} / \mathrm{D}_{2} \mathrm{O}\right), 40{ }^{\circ} \mathrm{C}, 400 \mathrm{MHz}$ TOCSY.

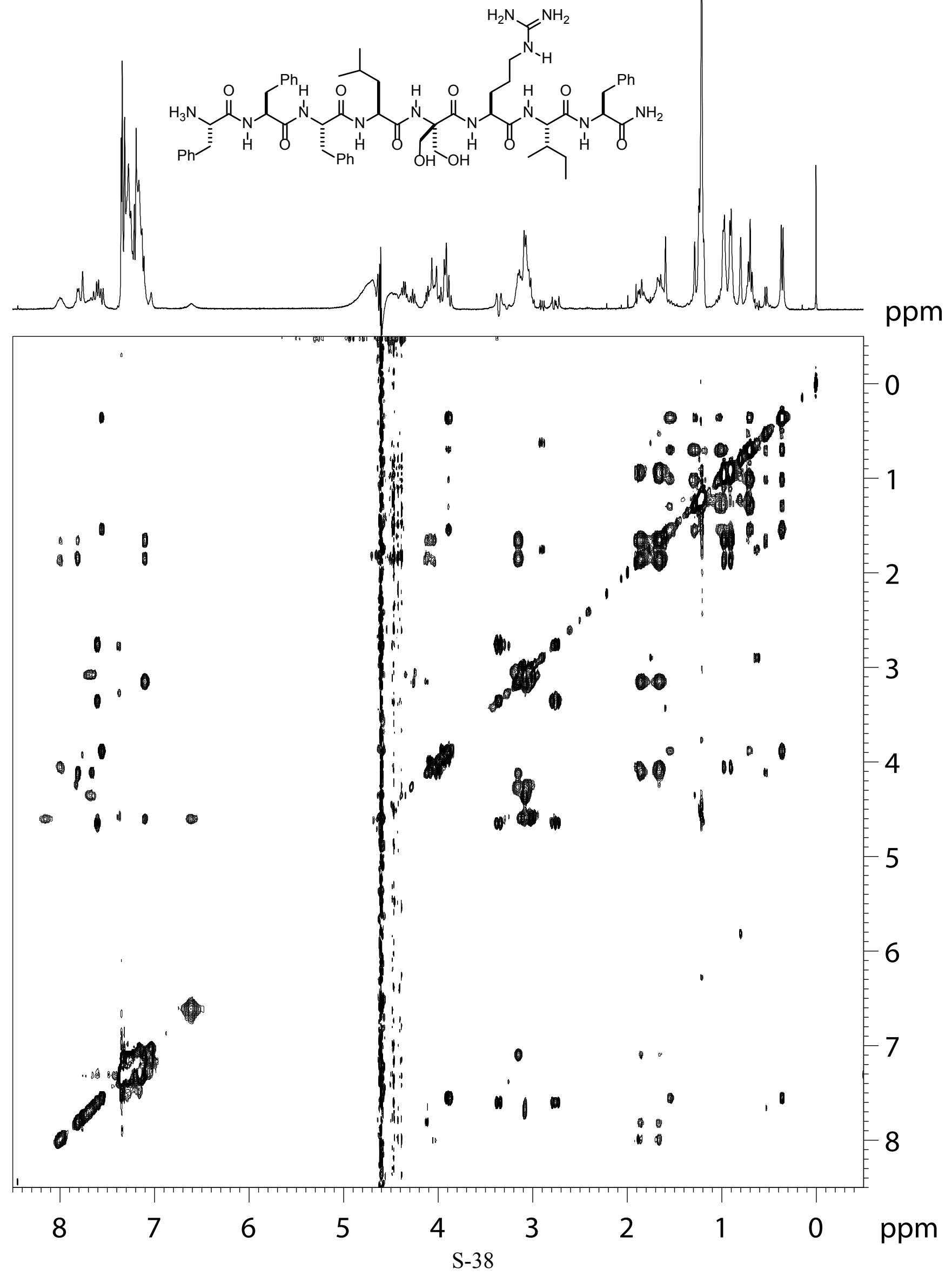


file djo_253a 4=

$2 \mathrm{mg}\left[\mathrm{HmS}^{5}\right] \mathrm{SHf}$ in $80 \mathrm{mM}$ SDS- $d_{25}\left(9: 1 \mathrm{H}_{2} \mathrm{O} / \mathrm{D}_{2} \mathrm{O}\right), 40^{\circ} \mathrm{C}, 400 \mathrm{MHz}$ ROESY.

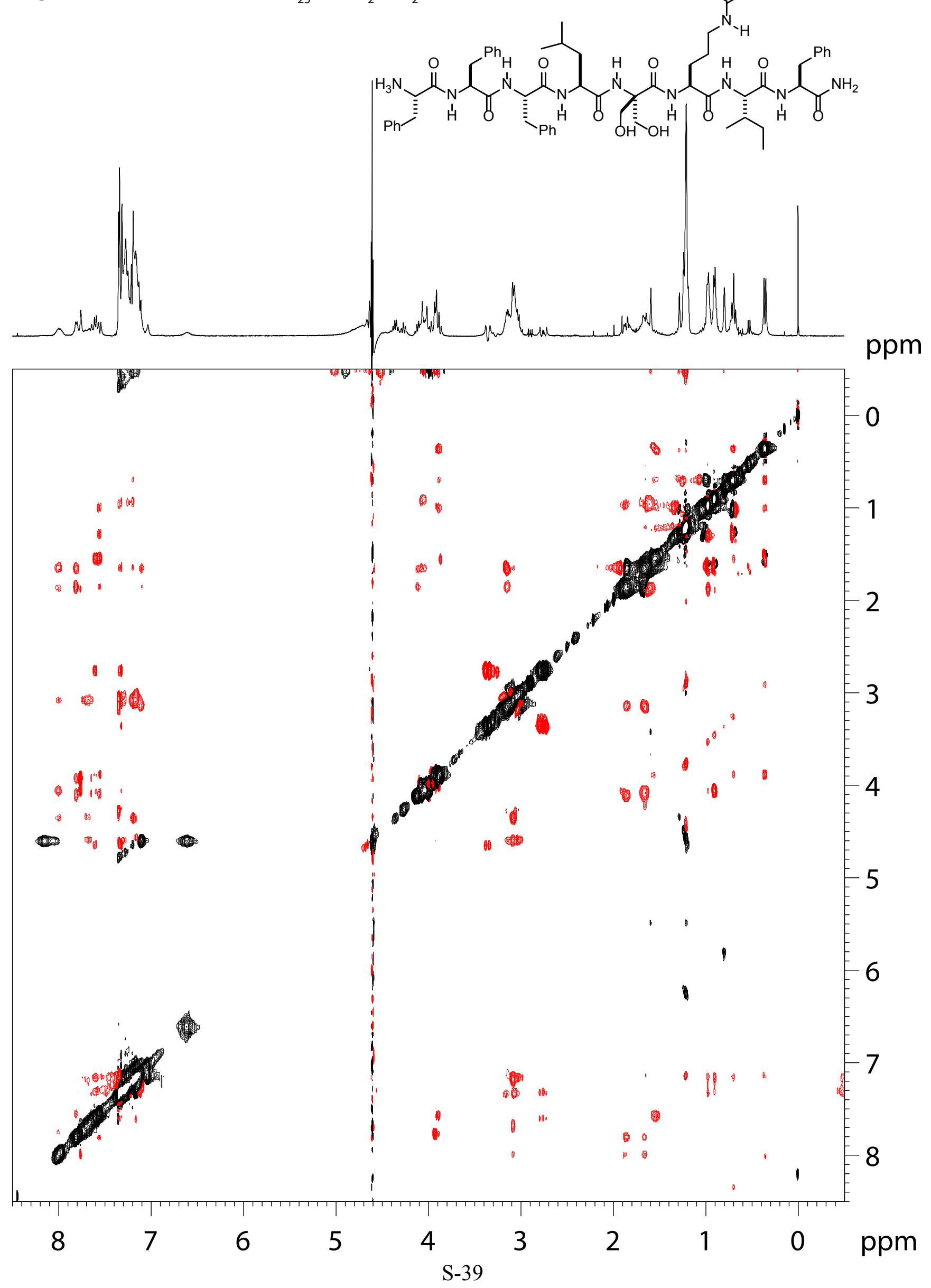


file djo_253 6

$2 \mathrm{mg}\left[\alpha \mathrm{MeF}^{3}\right] \mathrm{SHf}$ in $80 \mathrm{mM} \mathrm{SDS}-d_{25}\left(9: 1 \mathrm{H}_{2} \mathrm{O} / \mathrm{D}_{2} \mathrm{O}\right), 40{ }^{\circ} \mathrm{C}, 400 \mathrm{MHz}$ TOCSY.

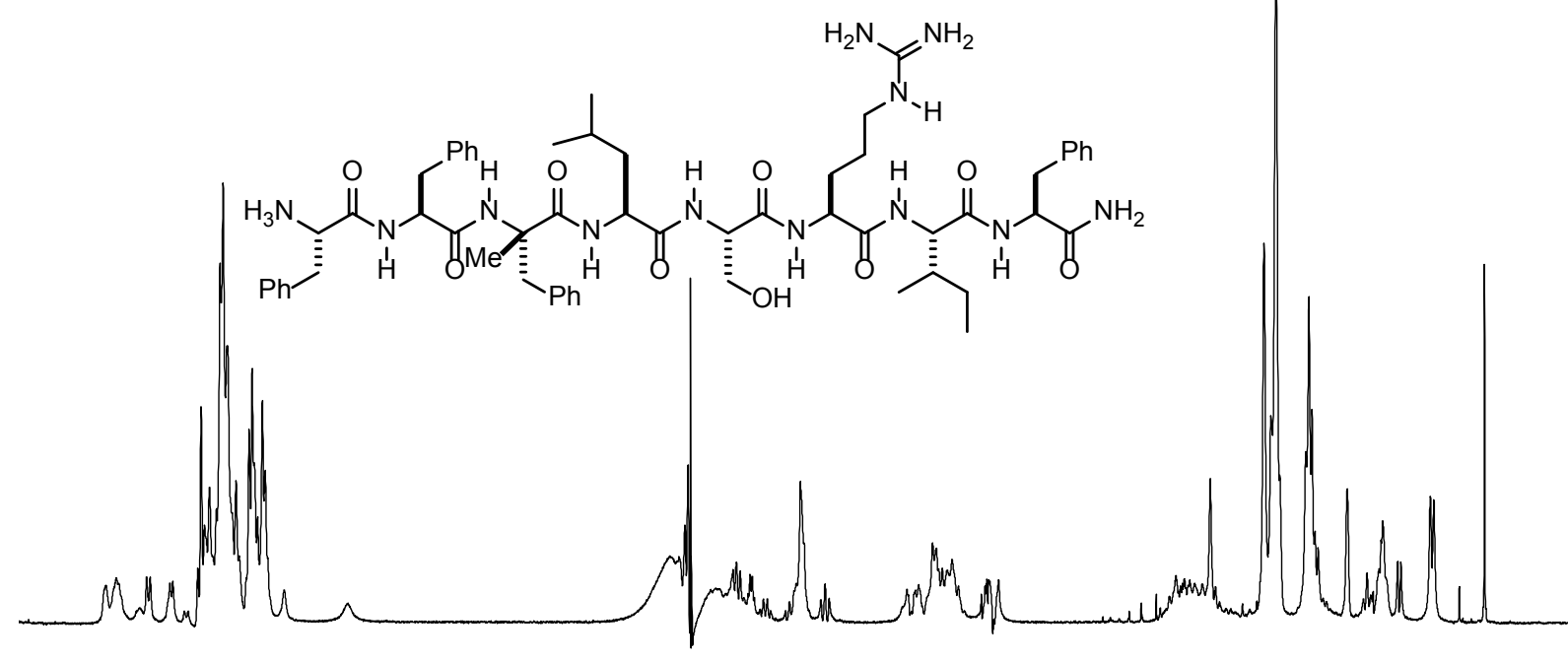

ppm

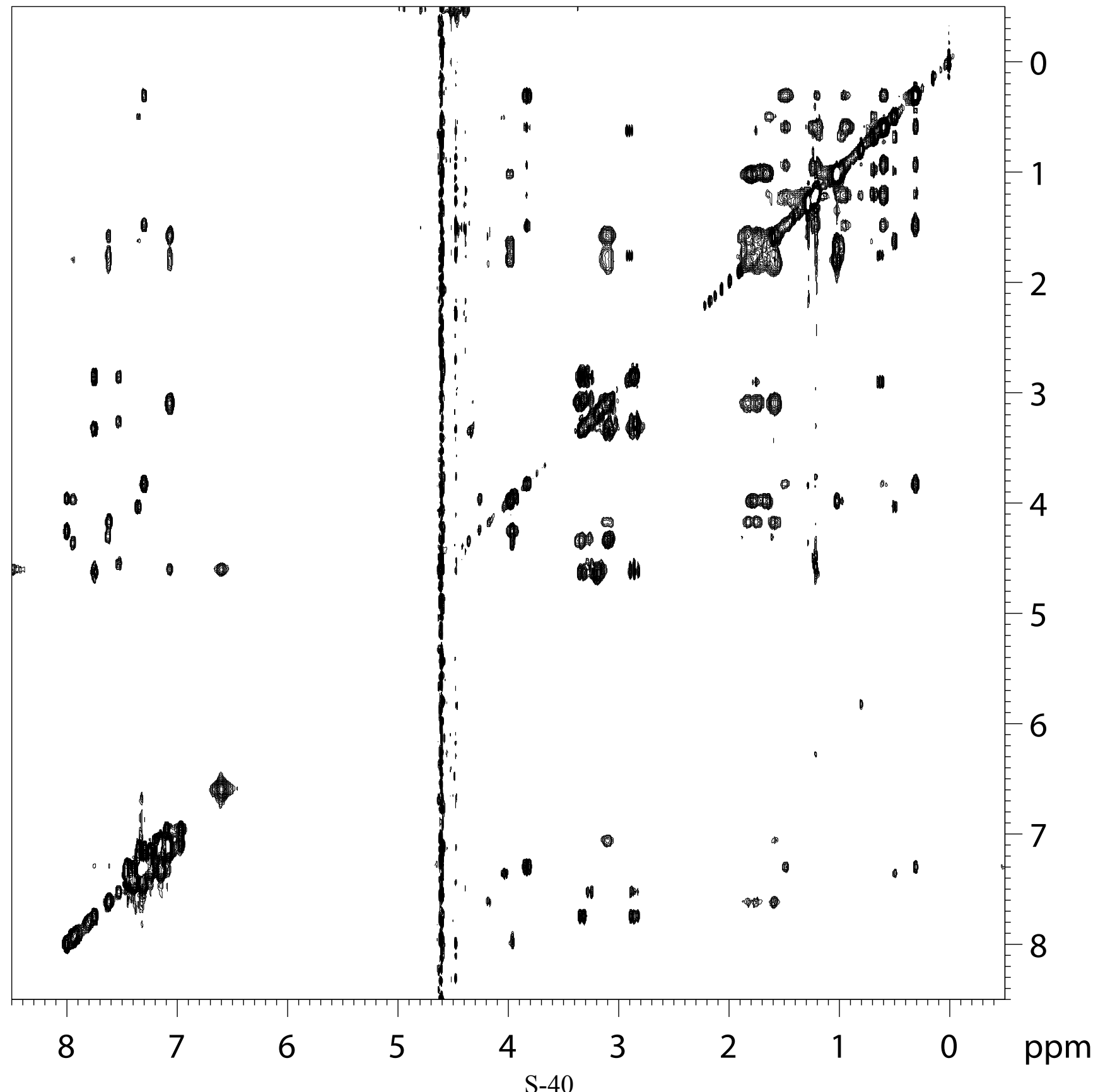


file djo_253a 6

$2 \mathrm{mg}\left[\alpha \mathrm{MeF}^{3}\right] \mathrm{SHf}$ in $80 \mathrm{mM}$ SDS- $d_{25}\left(9: 1 \mathrm{H}_{2} \mathrm{O} / \mathrm{D}_{2} \mathrm{O}\right), 40^{\circ} \mathrm{C}, 400 \mathrm{MHz}$ ROESY.

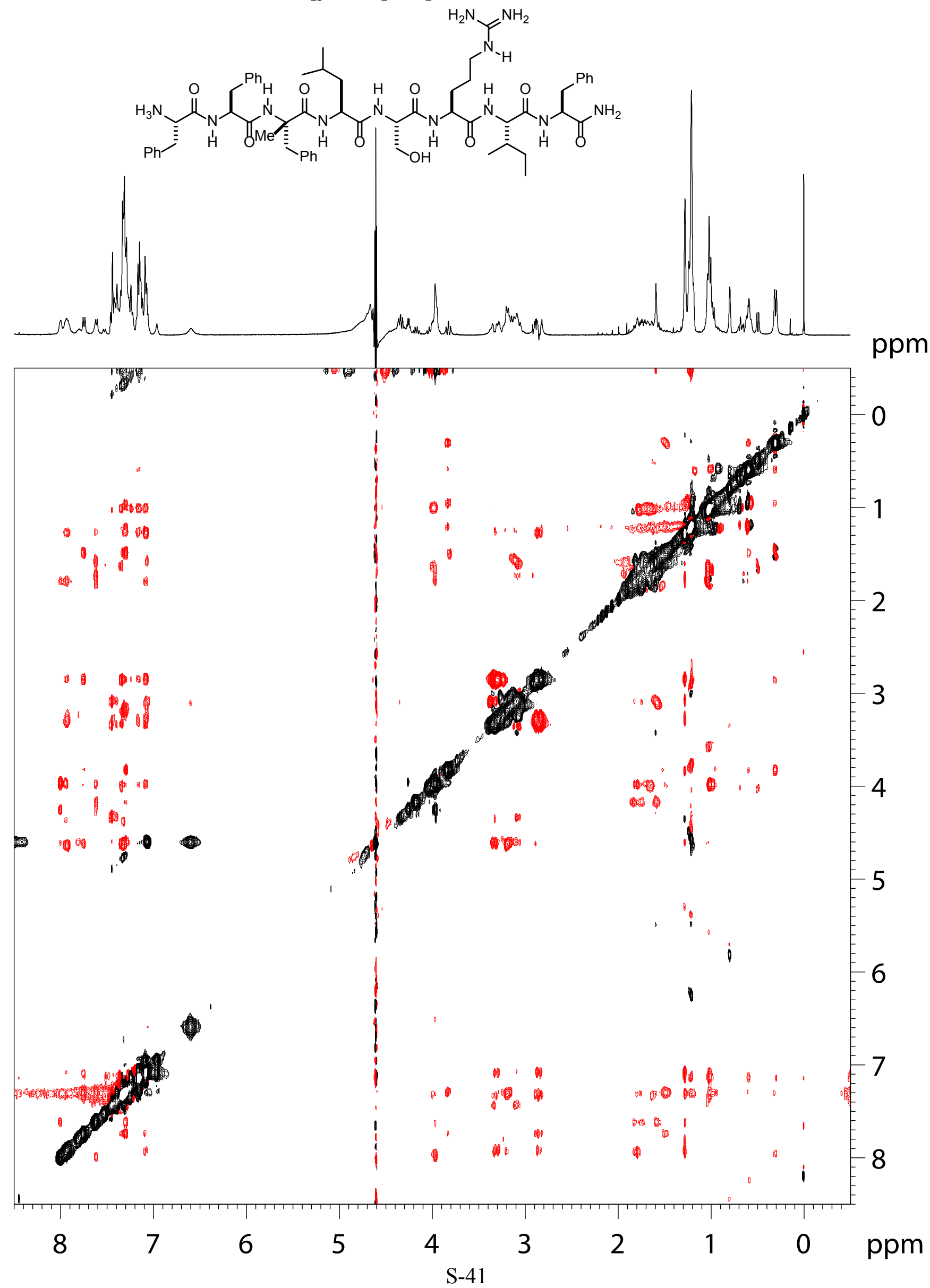


file djo_253 8

$2 \mathrm{mg}\left[\mathrm{p}^{-}{ }^{\mathrm{B}} \mathrm{BuF}{ }^{3}\right] \mathrm{SHf}$ in $80 \mathrm{mM}$ SDS- $d_{25}\left(9: 1 \mathrm{H}_{2} \mathrm{O} / \mathrm{D}_{2} \mathrm{O}\right), 40^{\circ} \mathrm{C}, 400 \mathrm{MHz}$ TOCSY.

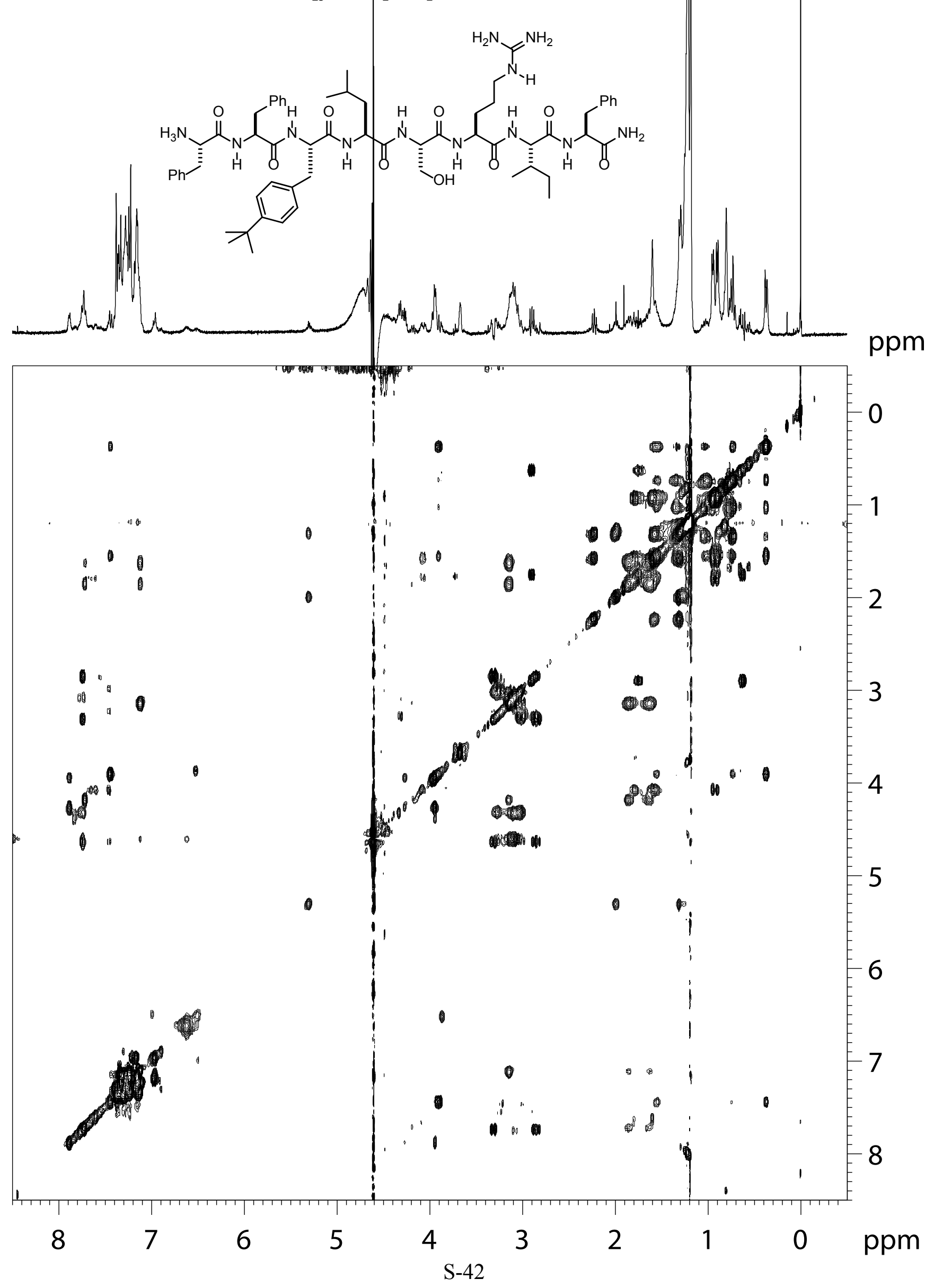


Çàç $\mid \mathrm{ORP} \sim=\mathrm{OO}=$ êçÉËó

$2 \mathrm{mg}\left[p^{-}{ }^{\mathrm{B}} \mathrm{BuF}^{3}\right] \mathrm{SHf}$ in $80 \mathrm{mM} \mathrm{SDS}-d_{25}\left(9: 1 \mathrm{H}_{2} \mathrm{O} / \mathrm{D}_{2} \mathrm{O}\right), 40{ }^{\circ} \mathrm{C}, 400 \mathrm{MHz}$ ROESY.

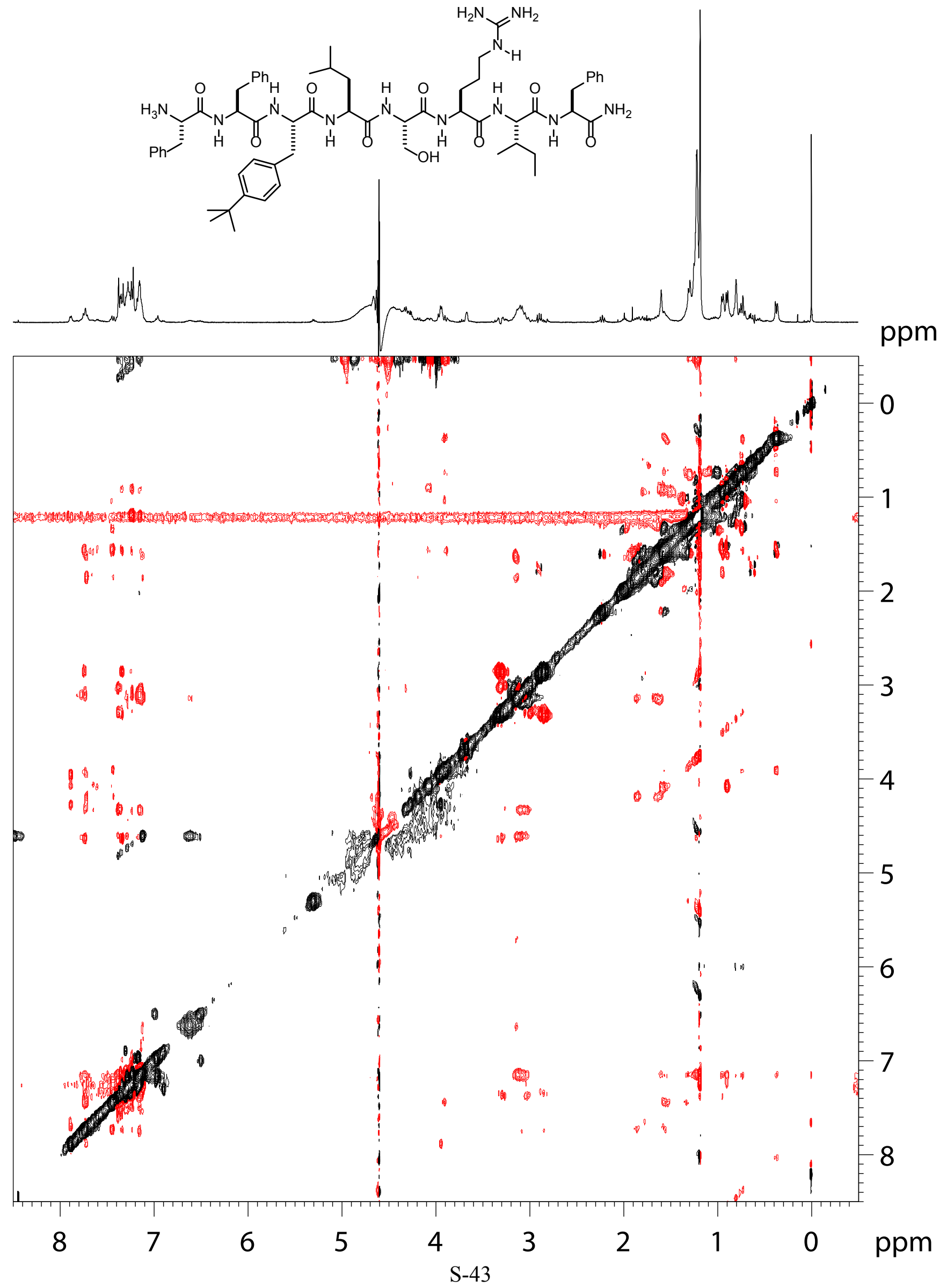


file djo_253 10

$2 \mathrm{mg}\left[p^{-}{ }^{\mathrm{B}} \mathrm{BuF}{ }^{2}\right] \mathrm{SHf}$ in $80 \mathrm{mM}$ SDS- $d_{25}\left(9: 1 \mathrm{H}_{2} \mathrm{O} / \mathrm{D}_{2} \mathrm{O}\right), 40^{\circ} \mathrm{C}, 400 \mathrm{MHz}$ TOCSY.

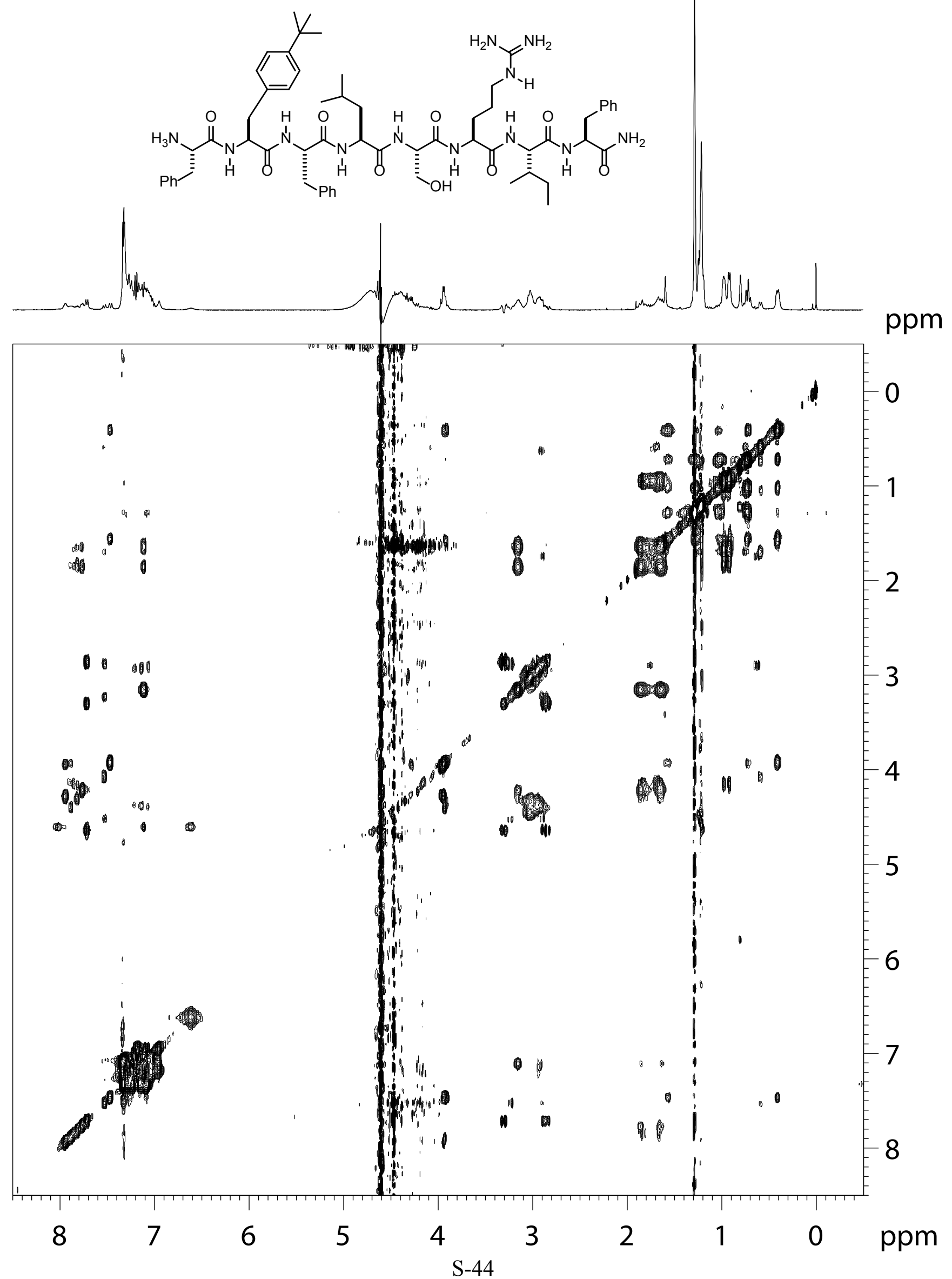


file djo_253a 10

$2 \mathrm{mg}\left[p^{-}{ }^{\mathrm{B}} \mathrm{BuF}^{2}\right] \mathrm{SHf}$ in $80 \mathrm{mM}$ SDS- $d_{25}\left(9: 1 \mathrm{H}_{2} \mathrm{O} / \mathrm{D}_{2} \mathrm{O}\right), 40^{\circ} \mathrm{C}, 400 \mathrm{MHz}$ ROESY.

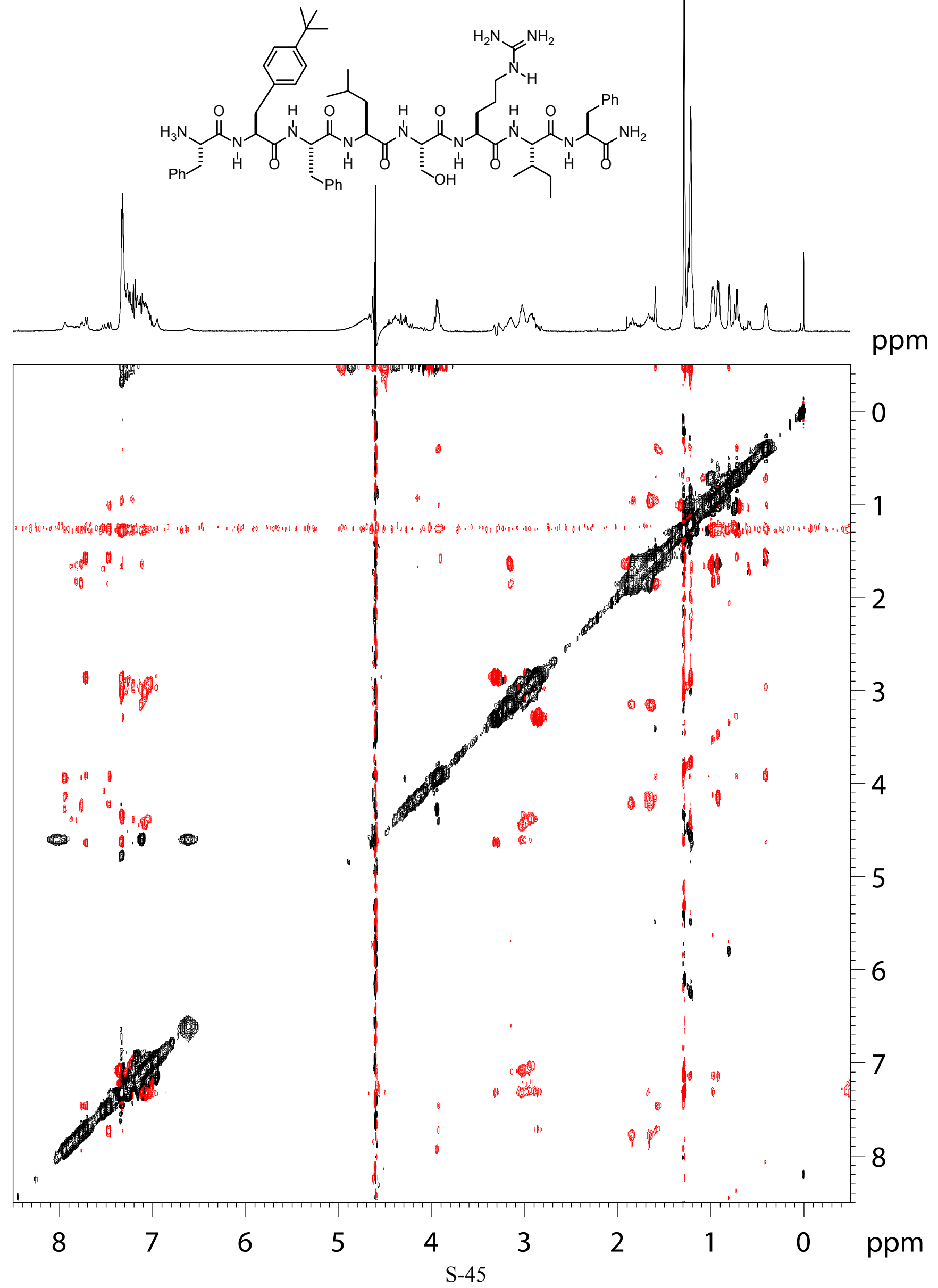


file djo_253 12

$2 \mathrm{mg}\left[p^{-}{ }^{-} \mathrm{BuF}^{\top}\right] \mathrm{SHf}$ in $80 \mathrm{mM} \mathrm{SDS}^{-} d_{25}\left(9: 1 \mathrm{H}_{2} \mathrm{O} / \mathrm{D}_{2} \mathrm{O}\right), 40^{\circ} \mathrm{C}, 400 \mathrm{MHz}$ TOCSY.

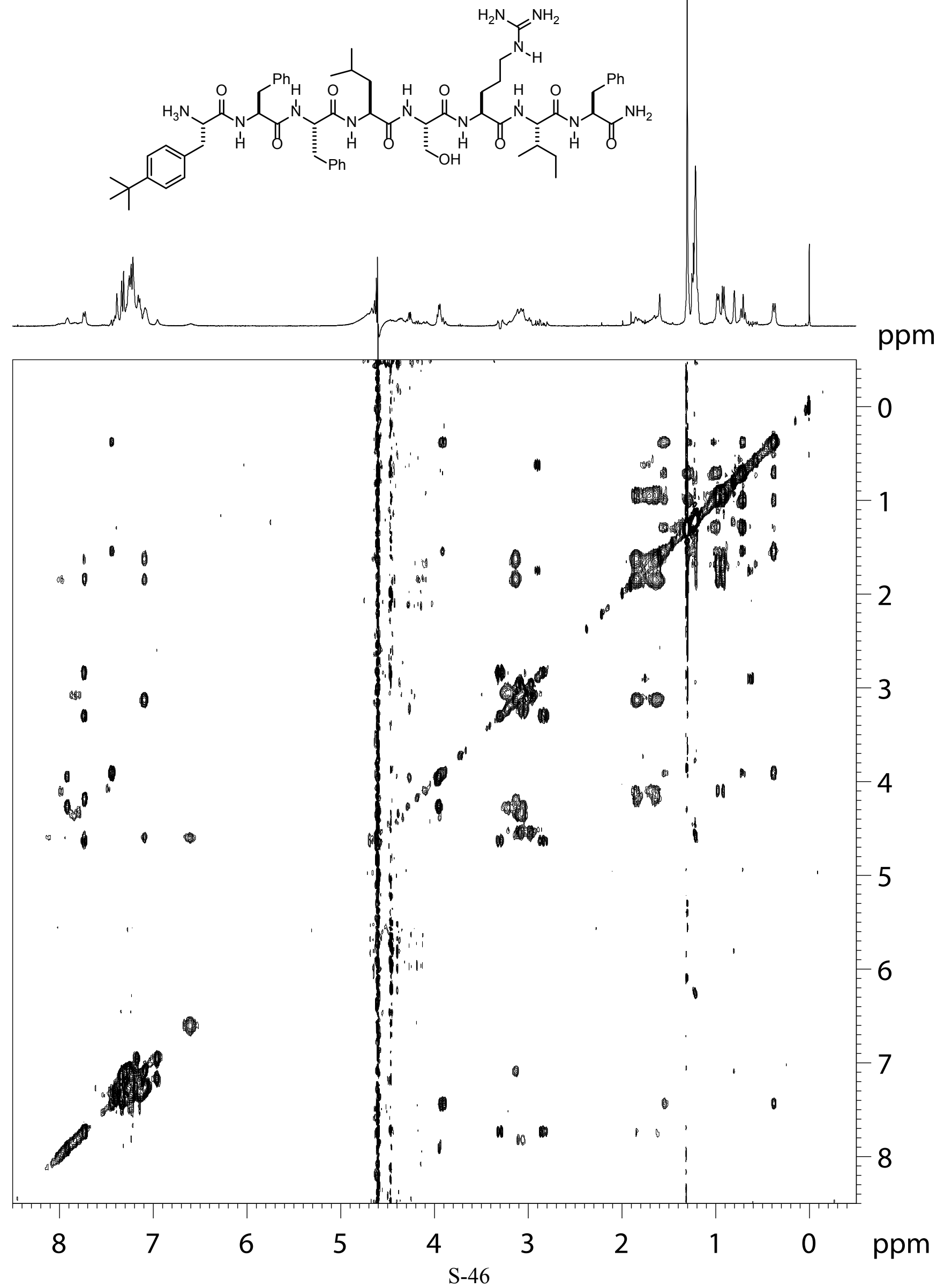


file djo_253a 12

$2 \mathrm{mg}\left[p^{-}{ }^{\mathrm{B}} \mathrm{BuF}{ }^{1}\right] \mathrm{SHf}$ in $80 \mathrm{mM}$ SDS- $d_{25}\left(9: 1 \mathrm{H}_{2} \mathrm{O} / \mathrm{D}_{2} \mathrm{O}\right), 40^{\circ} \mathrm{C}, 400 \mathrm{MHz}$ ROESY.

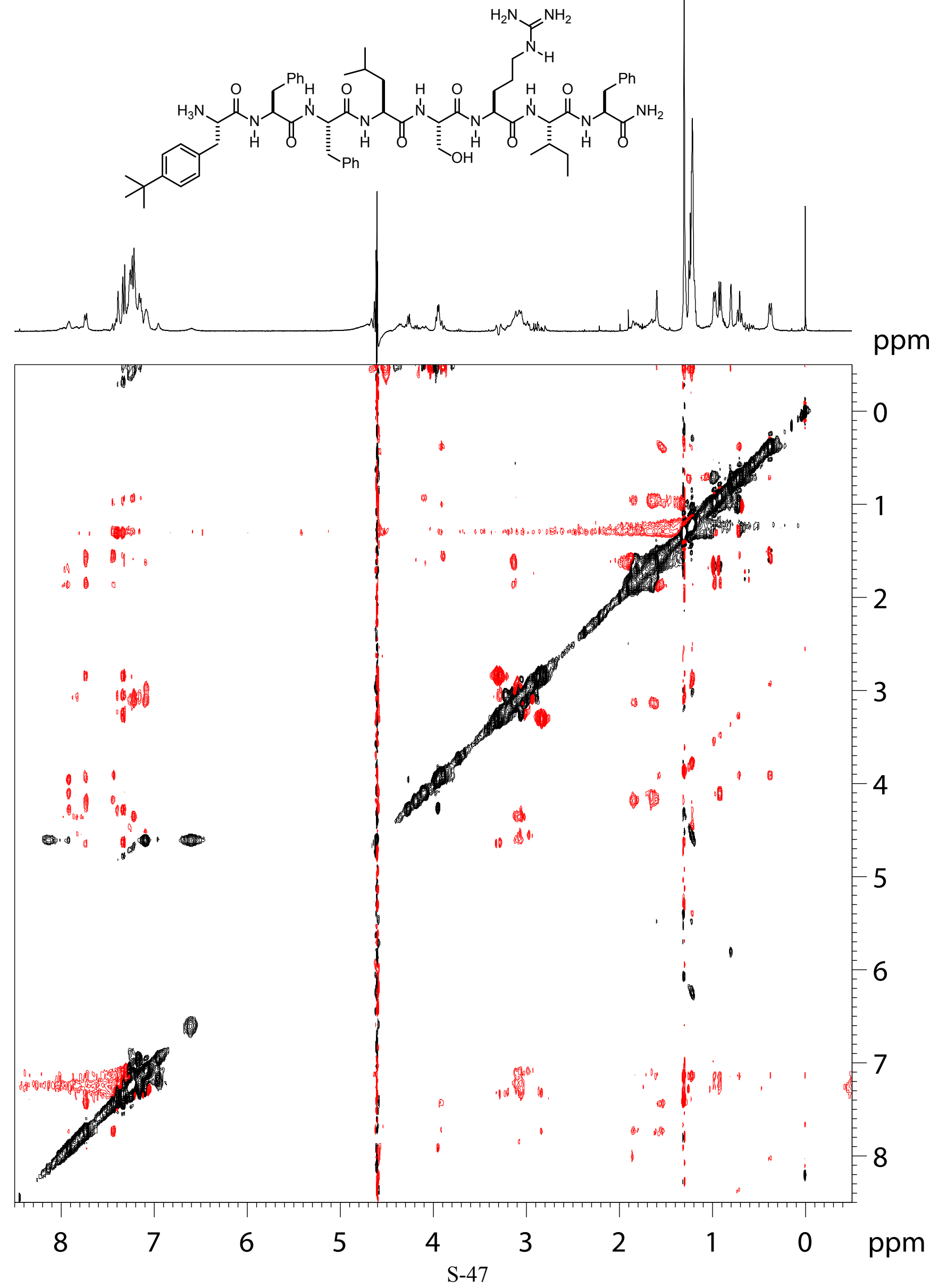


file djo_253 14

$2 \mathrm{mg}\left[p-{ }^{-} \mathrm{BuF}^{3}, \mathrm{R}^{5}\right] \mathrm{SHf}$ in $80 \mathrm{mM}$ SDS- $d_{25}\left(9: 1 \mathrm{H}_{2} \mathrm{O} / \mathrm{D}_{2} \mathrm{O}\right), 40^{\circ} \mathrm{C}, 400 \mathrm{MHz}$ TOCSY.

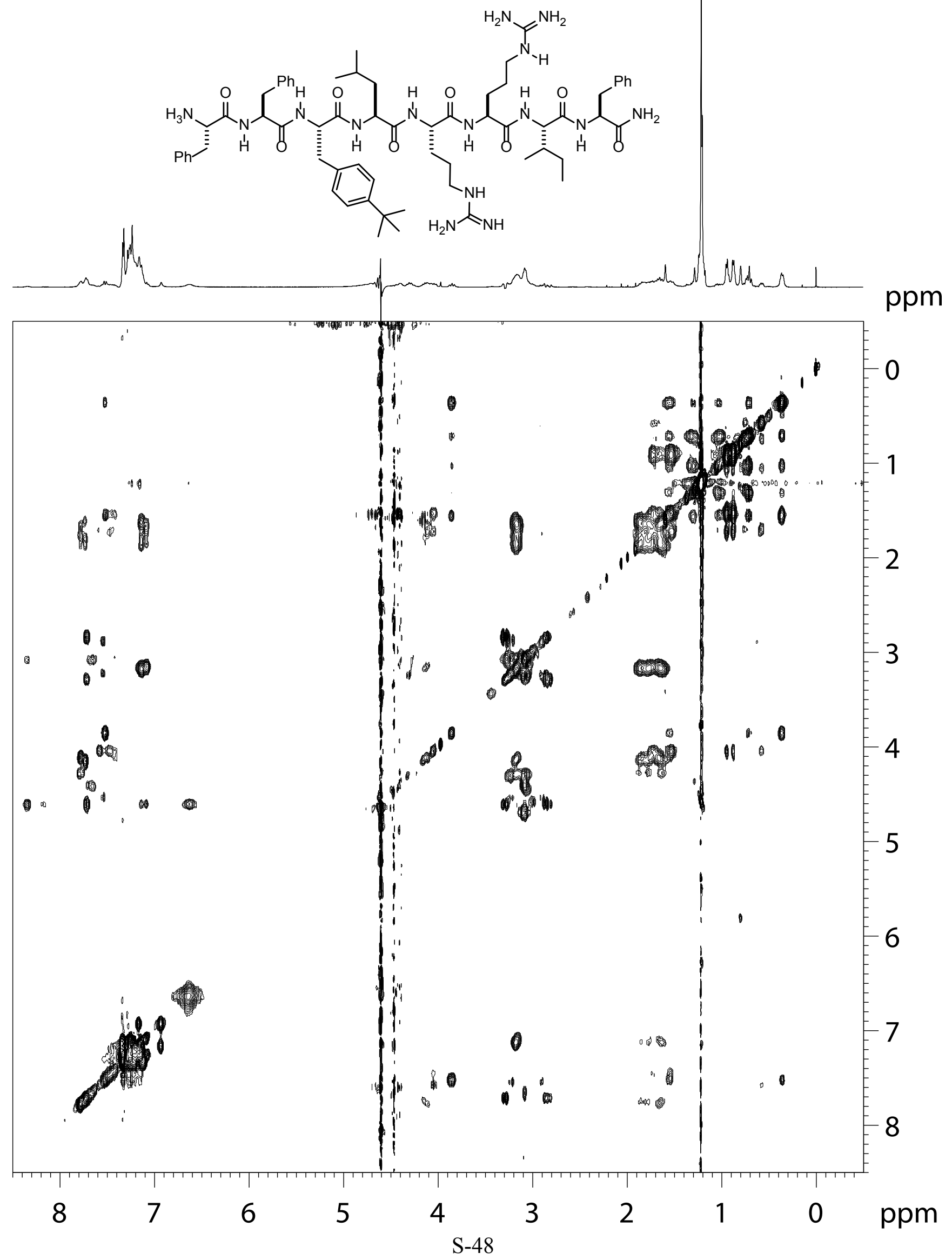


file djo_253a 14

$2 \mathrm{mg}\left[p-{ }^{-} \mathrm{BuF}^{3}, \mathrm{R}^{5}\right] \mathrm{SHf}$ in $80 \mathrm{mM}$ SDS- $d_{25}\left(9: 1 \mathrm{H}_{2} \mathrm{O} / \mathrm{D}_{2} \mathrm{O}\right), 40^{\circ} \mathrm{C}, 400 \mathrm{MHz}$ ROESY.

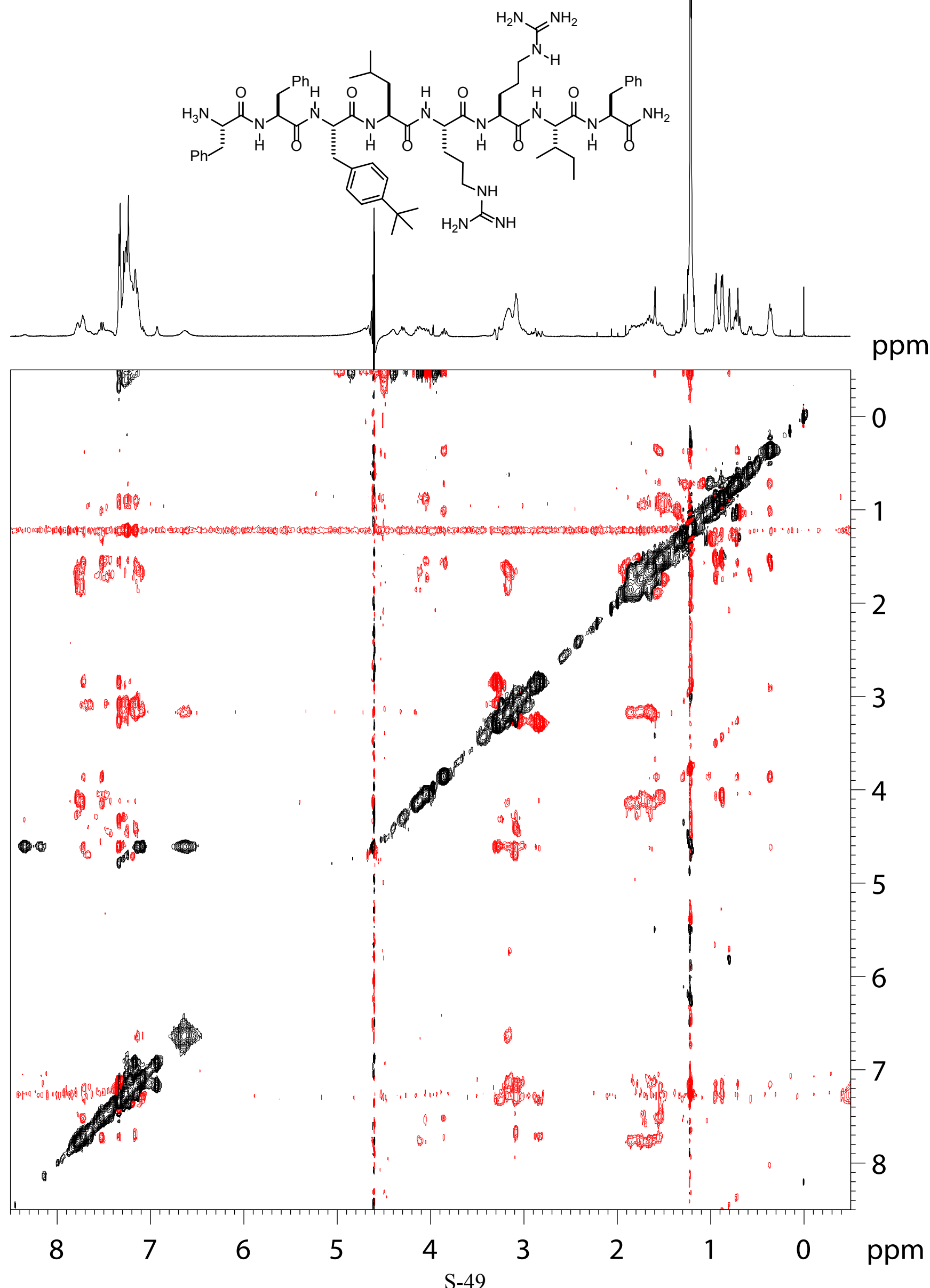


file djo_253 16

$2 \mathrm{mg}\left[p-{ }^{\mathrm{t}} \mathrm{BuF}^{2}, \mathrm{R}^{5}\right] \mathrm{SHf}$ in $80 \mathrm{mM}$ SDS- $d_{25}\left(9: 1 \mathrm{H}_{2} \mathrm{O} / \mathrm{D}_{2} \mathrm{O}\right), 40^{\circ} \mathrm{C}, 400 \mathrm{MHz}$ TOCSY.

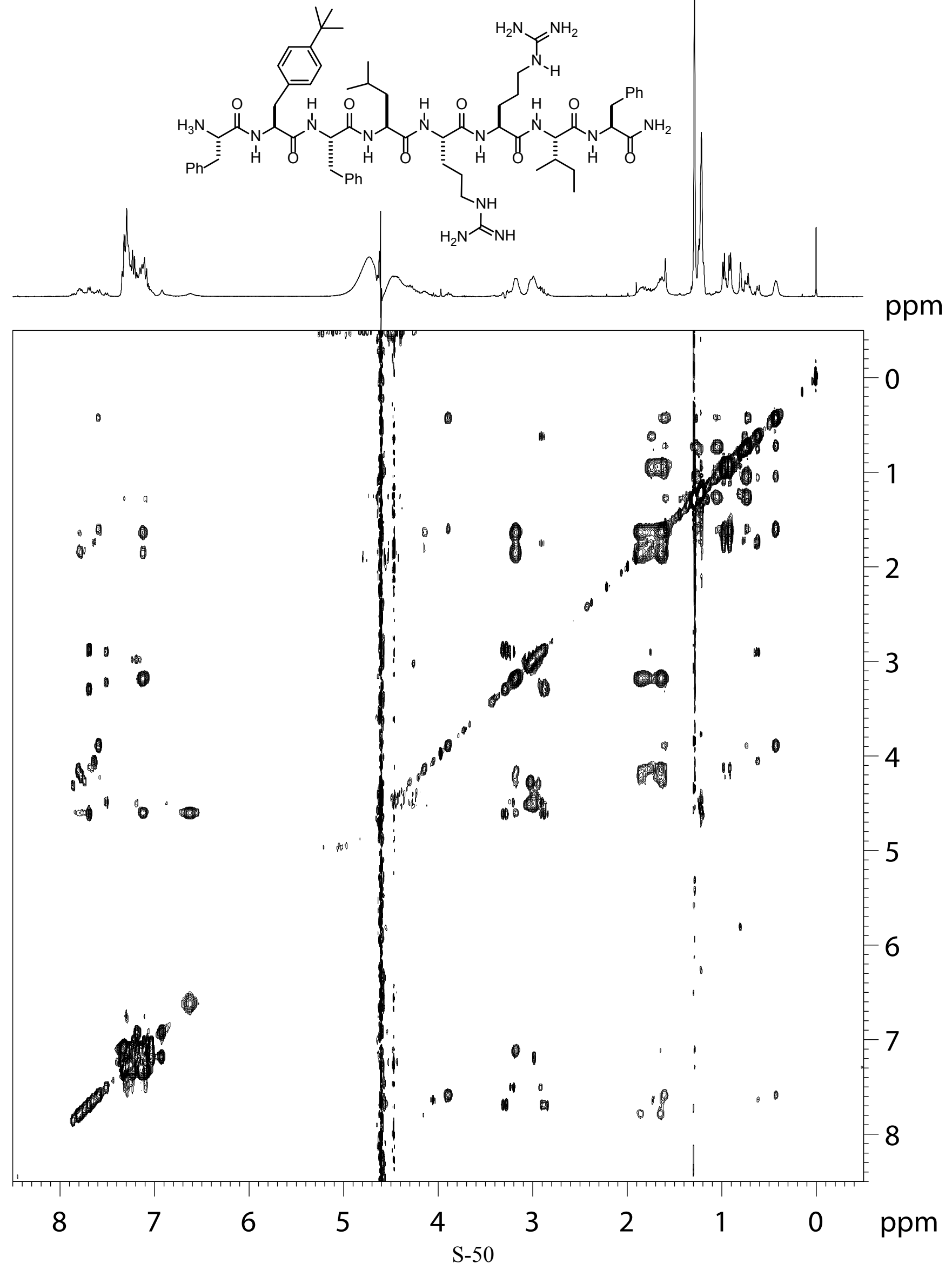


file djo_253a 16

$2 \mathrm{mg}\left[p-{ }^{-} \mathrm{BuF}^{2}, \mathrm{R}^{5}\right] \mathrm{SHf}$ in $80 \mathrm{mM}$ SDS- $d_{25}\left(9: 1 \mathrm{H}_{2} \mathrm{O} / \mathrm{D}_{2} \mathrm{O}\right), 40^{\circ} \mathrm{C}, 400 \mathrm{MHz}$ ROESY.

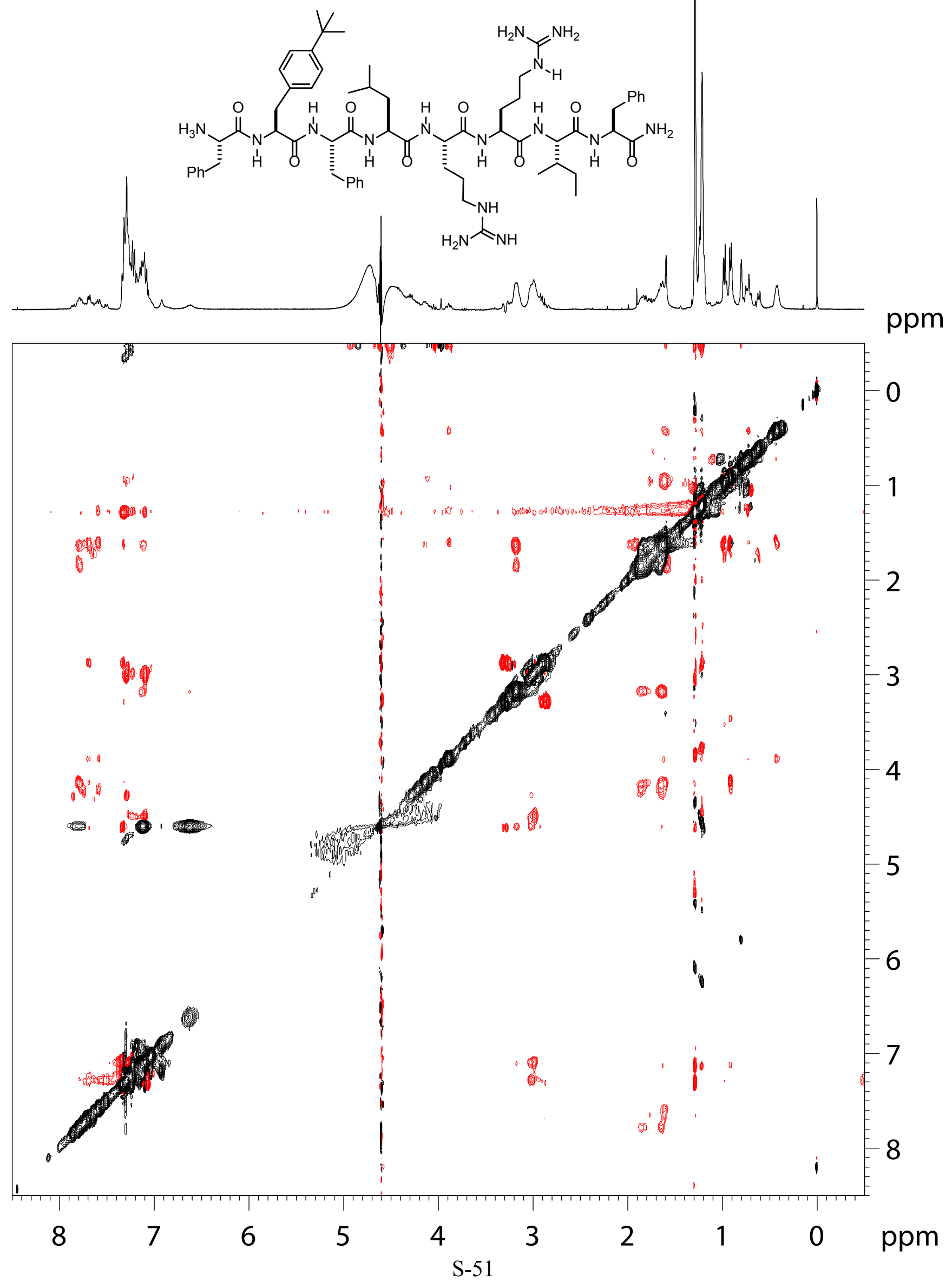


file djo_253 18

$2 \mathrm{mg}\left[p^{-}{ }^{-} \mathrm{BuF}^{1}, \mathrm{R}^{5}\right] \mathrm{SHf}$ in $80 \mathrm{mM} \mathrm{SDS}-d_{25}\left(9: 1 \mathrm{H}_{2} \mathrm{O} / \mathrm{D}_{2} \mathrm{O}\right), 40{ }^{\circ} \mathrm{C}, 400 \mathrm{MHz}$ TOCSY.

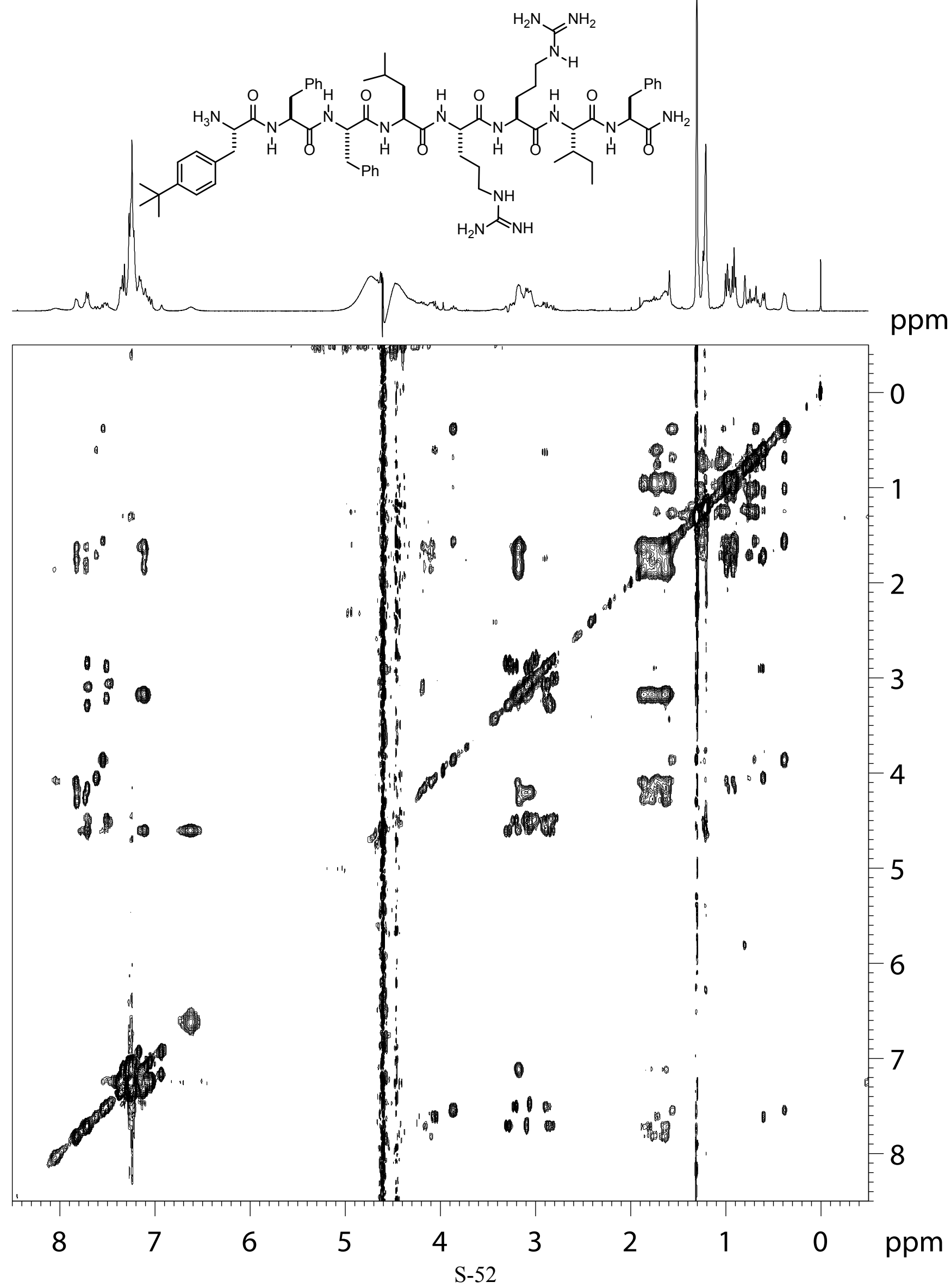


file djo_253a 18

$2 \mathrm{mg}\left[p^{-{ }^{+} \mathrm{BuF}}{ }^{1}, \mathrm{R}^{5}\right] \mathrm{SHf}$ in $80 \mathrm{mM}$ SDS- $d_{25}\left(9: 1 \mathrm{H}_{2} \mathrm{O} / \mathrm{D}_{2} \mathrm{O}\right), 40^{\circ} \mathrm{C}, 400 \mathrm{MHz}$ ROESY.

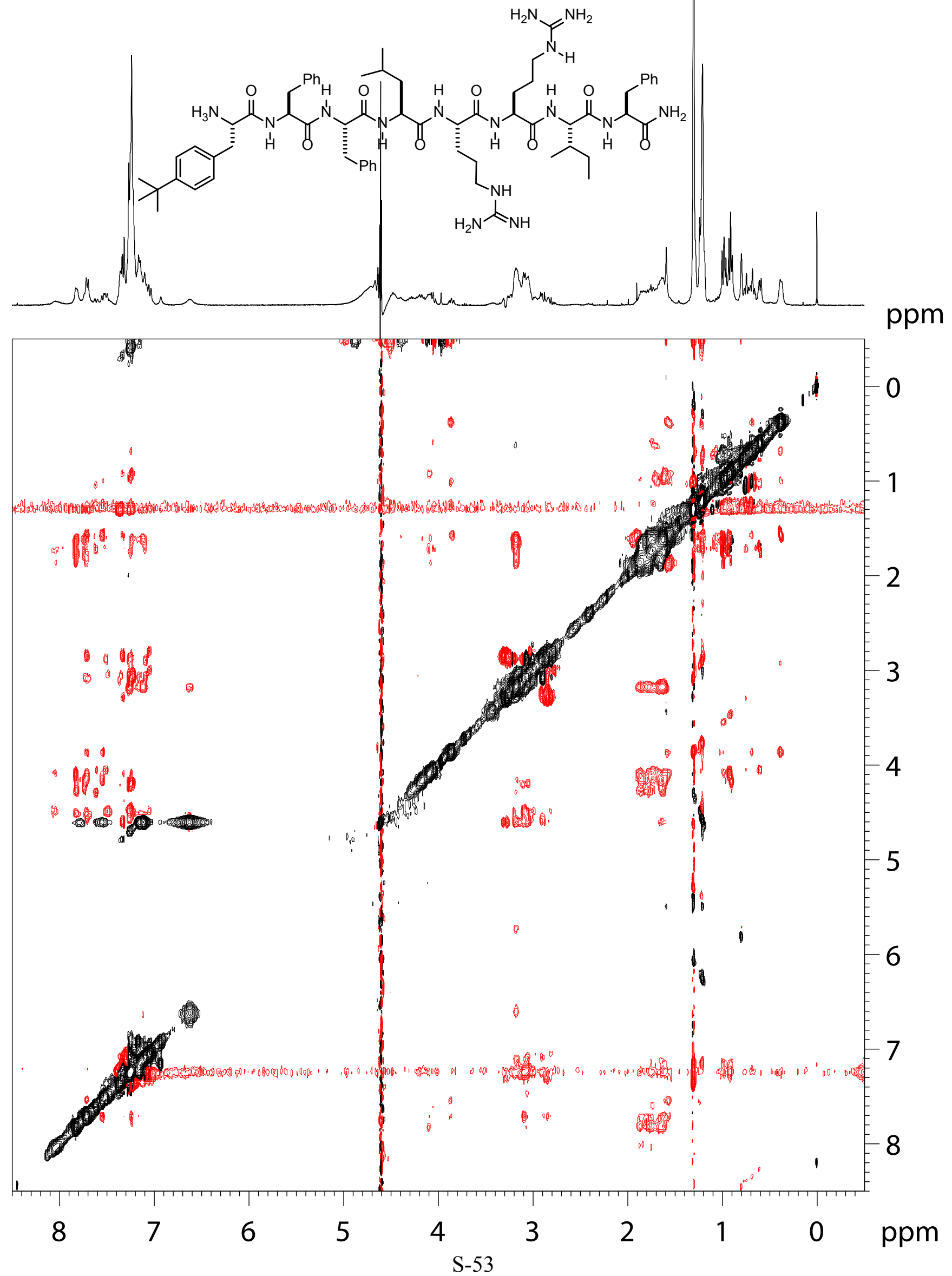

